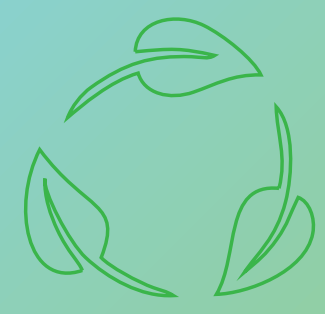

\title{
PLANO DE GESTÃO INTEGRADA DE RESÍDUOS SÓLIDOS DA UNIVERSIDADE DO ESTADO DO PARÁ (PGIRS/UEPA)
}

\section{$2021-2030$}

Relatório Técnico-científico

\author{
Volume I - PGIRS/UEPA - CAPITAL
}
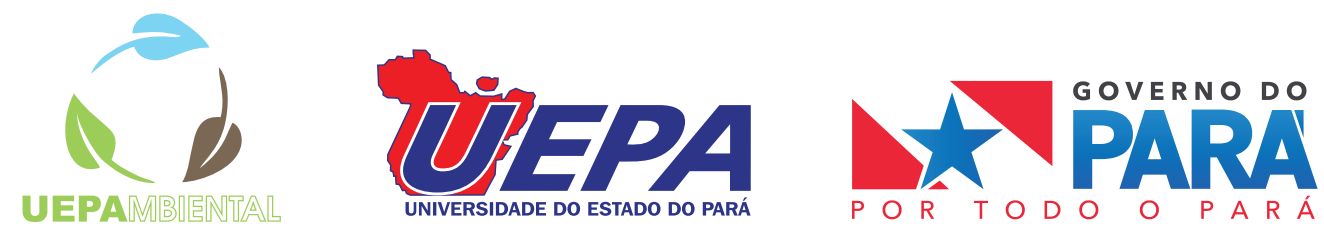



\section{PLANO DE GESTÃO INTEGRADA DE RESÍDUOS SÓLIDOS DA UNIVERSIDADE DO ESTADO DO PARÁ [PGIRS/UEPA]}

\section{$2021-2030$}

Relatório Técnico-cientîî́co

Volume I - PGIRS/UEPA - CAPITAL 
PLANO DE GESTÃO INTEGRADA DE RESÍDUOS SÓLIDOS DA UNIVERSIDADE DO ESTADO DO PARÁ (PGIRS/UEPA) $2021-2030$

Relatório Técnico-científico

Volume I - PGIRS/UEPA - CAPITAL

ORGANIZAÇÃO

Carlos José Capela Bispo

Hyago Elias Nascimento Souza 


\section{Coordenador e editor-chefe}

Nilson Bezerra Neto

\section{Conselho Editorial}

Francisca Regina Oliveira Caetano

Hebe Morganne Campos Ribeiro

Joelma Cristina Parente Monteiro Alencar

Josebel Akel Fares

José Alberto Silva de Sá

Juarez Antônio Simões Quaresma

Lia Braga Vieira

Maria das Graças da Silva

Maria do Perpétuo Socorro Cardoso da Silva

Marília Brasil Xavier

Núbia Suely Silva Santos

Renato da Costa Teixeira (Presidente)

Robson José de Souza Domingues

Pedro Franco de Sá

Tânia Regina Lobato dos Santos

Valéria Marques Ferreira Normando

Dados Internacionais de Catalogação na Publicação (CIP) Sistema de Bibliotecas da UEPA - SIBIUEPA

\section{Universidade do Estado do Pará}

Plano de gestão integrada de resíduos sólidos da Universidade do Estado do Pará (PGIRS/UEPA): 2021-2030 / Universidade do Estado do

Pará ; Organização e elaboração: Carlos José Capela Bispo e Hyago Elias Nascimento Souza. - Belém: EDUEPA, 2020.

87 f. : il., color. - (Relatório técnico-científico do PGIRS/UEPA; v.1)

Inclui bibliografias

ISBN: 978-65-88106-12-9.

Relatório técnico-científico do PGIRS/UEPA (Capital) do Programa de Gestão UEPA Ambiental.

1. Universidade do Estado do Pará. 2. Programa de Gestão UEPA Ambiental. 3. PGIRS - Relatório. 4. Gestão ambiental. 5. Meio ambiente. 6. Resíduos sólidos. 7. Educação ambiental. I. Bispo, Carlos José Capela. II. Souza, Hyago Elias Nascimento. III. Título.

CDD $363.728-22$. ed.

Ficha Catalográfica: Rosilene Rocha CRB-2/1134 
Universidade do Estado do Pará - UEPA

CNPJ: 34.860.833/000 I-44

Rua do Una, 156 - Telégrafo.

CEP: $66.050-540$

Belém - PA

www.uepa.br

PROF. DR. RUBENS CARDOSO DA SILVA

Reitor

PROF. DR. CLAY ANDERSON NUNES CHAGAS

Vice-Reitor

PROF. MSC.ANA DA CONCEIÇÃO OLIVEIRA

Pró-Reitora de Graduação

PROF. DR. RENATO DA COSTA TEIXEIRA

Pró-Reitor de Pesquisa e Pós-Graduação

PROF. MSC.ALBA LUCIA RIBEIRO RAITHY PEREIRA

Pró-Reitora de Extensão

PROF. MSC. CARLOS JOSÉ CAPELA BISPO

Pró-Reitor de Gestão e Planejamento 


\section{COMISSÃO TÉCNICA}

CARLOS JOSE CAPELA BISPO

Presidente

ALINE SOUZA SARDINHA

Membro

ANA JÚLIA SOARES BARBOSA

Membro

CAIO JOSE LIMA GOUVEA NOGUEIRA

Membro

DENISE CRISTINA TORRES COSTA

Membro

ELZELIS MULLER DA SILVA

Membro

FRANCINELY DO SOCORRO AUAD THIJM

Membro

HYAGO ELIAS NASCIMENTO SOUZA

Membro

TATIANE MONTE SANTANA

Membro

VIVIANNY LIMA GONCALVES ROSA

Membro 


\section{DISCENTES COLABORADORES}

ÁGATA MAISE DE JESUS CALDAS

ANA CLARA SILVA GARCIA

BRENO DO CARMO ALEXANDRINO

CAROLINEARAÚJO RODRIGUES

DÉBORA REIS CORDEIRO

EDUARDO AYRON GOMES SOARES

GIOVANNA BARROSO CAVALCANTE BARATA

HELOIZA SANTOS BORGES

JAIME CARVALHO GOES

JAMIL AMORIM DE OLIVEIRA JUNIOR

JOAOVICTOR SANTANA

LANA GABRIELA PARDAL

LEONARDO SILVA DO NASCIMENTO

LUANA LOPES COSTA

LUCAS MATEUS COELHO NUNES

MACELLA ANTONIA PINHEIRO

MARIA EDUARDA ASSUNÇAO OGORODNIK

MARIA EDUARDA DE ALMEIDA SILVA

RAYMUNDO DAVID PINHEIRO FERNANDES BAIA

SIDCLEY DIAS DA SILVA

TALITA SOARES ROCHA

WELLE KEWIN DE SOUSA ALLAIA

\section{REVISÃO}

ERIKA DO SOCORRO OLIVEIRA GONÇALVES

HYAGO ELIAS NASCIMENTO SOUZA

\section{DIAGRAMAÇÃO}

JOSENETE FERREIRA MENDES 


\section{PREFÁCIO}

O processo de crescimento pelo qual passa a Universidade do Estado do Pará - UEPA - quer pela sua abrangência, quer pela oferta de novos cursos e ampliação no número de vagas, associado ao uso mais intensivo de materiais e equipamentos, bem como pelo fluxo, em 3 (três) turnos diários, de uma comunidade formada por alunos, servidores públicos e empregados terceirizados, nos têm levado a refletir que o princípio da responsabilidade de Hans Jonas deve nos conduzir, cada vez mais, à construção de uma consciência ética e, consequentemente, ao uso integral e racional dos recursos disponíveis. É um contexto complexo, sabemos! Daí a necessidade de modelar ações estratégicas que qualifiquem o operacional e concorram para o cumprimento da missão institucional de (...) formar profissionais éticos, com responsabilidade social e comprometidos com o desenvolvimento sustentável da Amazônia.

O Plano de Gestão Integrada de Resíduos Sólidos da Universidade do Estado do Pará, na Capital (PGIRS/UEPA-Capital), é uma dessas ações. Por sua natureza multidimensional, além de atender aos preceitos da lei . $^{\circ} 12.305$, de 2 de agosto de 2010 , é uma ação de educação ambiental indicativa que integra a participação da nossa comunidade sociodiversa, em busca de um bem comum. Requer compreensão, vontade e enseja uma relação mais justa, de todos, com o nosso ambiente.

Ao mesmo tempo o Plano ajusta-se à Agenda 2030 para o Desenvolvimento Sustentável (ODS/ ONU), orientando práticas de produção e consumo sustentável, redução de resíduos e reuso de materiais, mitigação de impacto ambiental negativo, além de gerar igualdade de oportunidades para que qualquer membro da comunidade adquira conhecimentos e habilidades necessárias para mediar significados e adotar um estilo de vida sustentável que favoreça o desenvolvimento seguindo os princípios da sustentabilidade.

Como instituição formadora, alicerçada no ensino, pesquisa e extensão, a UEPA faz de suas ações uma fonte de conhecimento. E, mesmo que os resultados se afastem dos objetivos traçados, sempre restará uma oportunidade de discussão e debates de ideias na busca de correções e de melhorias contínuas nos processos consequentes.

Sob a extensão da sociodiversidade e da importância do PGIRS/UEPA-Capital, parabenizamos os professores, técnicos-administrativos e alunos que se uniram nessa tarefa de construí-lo, ressaltando a confiança no engajamento da nossa comunidade na execução diária das ações requeridas.

Rubens Cardoso da Silva

Reitor da UEPA 


\section{GLOSSÁRIO}

\begin{tabular}{|c|c|}
\hline A3P & Agenda Ambiental na Administração Pública \\
\hline ABNT & Associação Brasileira Normas Técnicas \\
\hline ANVISA & Agência Nacional de Vigilância Sanitária \\
\hline ASPLAN & Assessoria de Planejamento \\
\hline CAD & Coordenação Administrativa \\
\hline CCBS & Centro Ciências Biológicas e da Saúde \\
\hline CCNT & Centro de Ciências Naturais e Tecnologia \\
\hline CCPP & Centro de Ciências e Planetário do Pará \\
\hline CCSE & Centro de Ciências Sociais e Educação \\
\hline CONAMA & Conselho Nacional de Meio Ambiente \\
\hline CSE & Centro de Saúde Escola \\
\hline DARM & Diretoria de Administração de Recursos Materiais \\
\hline DIPE & Diretoria de Planejamento Estratégico \\
\hline EDUEPA & Editora da UEPA \\
\hline EPI & Equipamentos de Proteção Individual \\
\hline IBAMA & Instituto Brasileiro do Meio Ambiente e dos Recursos Naturais Renováveis \\
\hline IES & Instituições de Ensino Superior \\
\hline IN & Instrução Normativa \\
\hline MMA & Ministério do Meio Ambiente \\
\hline NBR & Norma Brasileira Regulamentadora \\
\hline NC & Nó-Crítico \\
\hline ODS & Objetivo para Desenvolvimento Sustentável \\
\hline OMS & Organização Mundial de Saúde \\
\hline PDI & Plano de Desenvolvimento Institucional \\
\hline PEGIRS & Plano de Gestão Integrada de Resíduos Sólidos do Estado do Pará \\
\hline PEV & Ponto de Entrega Voluntária \\
\hline PGIRS & Plano de Gestão Integrada de Resíduos Sólidos \\
\hline PIB & Produto Interno Bruto \\
\hline PNRS & Política Nacional de Resíduos Sólidos \\
\hline POP & Procedimento Operacional Padrão \\
\hline PROEX & Pró-Reitoria de Extensão \\
\hline PROGESP & Pró-Reitoria de Gestão e Planejamento \\
\hline PROPESP & Pró-Reitoria de Pesquisa e Pós-Graduação \\
\hline RDC & Resolução da Diretoria Colegiada \\
\hline REEE & Resíduos de Equipamentos Eletroeletrônicos \\
\hline
\end{tabular}


RS

RSS

RSU

TMGC

UCS

UEAFTO

UEPA

UFPA

UFSM

UNB

UNISC

USP

VDP
Resíduos Sólidos

Resíduos de Serviços de Saúde

Resíduos Sólidos Urbanos

Taxa Média Geométrica de Crescimento

Universidade de Caxias do Sul

Unidade de Fisioterapia e Terapia Ocupacional

Universidade do Estado do Pará

Universidade Federal do Pará

Universidade Federal de Santa Maria

Universidade de Brasília

Universidade de Santa Cruz do Sul

Universidade de São Paulo

Vetores de Descrição de Problema 


\section{LISTA DE TABELAS}

Tabela I. Descrição das Unidades da UEPA na capital, quantidade de servidores ativos e estagiários, alunos matriculados, público externo e população total (pop. total).

Tabela 2. Geração média diária de RSU, rejeitos sanitários e resíduos de podas ( $\mathrm{kg} / \mathrm{dia}) \pm$ erro padrão $(n=5)$, por Unidade.

Tabela 3. Descrição anual da quantidade de servidores, alunos e população total (Pop. total) entre os anos de 2016 a 2020.

Tabela 4. Descrição das Unidades da UEPA, quantidade de servidores, alunos e população total (Pop. total) no ano de 2019.

Tabela 5. Projeção de crescimento populacional da UEPA por Unidade até 2030.

Tabela 6. Projeção da geração de RSU (kg/dia) por Unidade da UEPA até 2030.

Tabela 7. Projeção da geração per capita de RSU por Unidade da UEPA até 2030.

Tabela 8. Expansão e ampliação de cursos de graduação (2017-2027), número de vagas e ano de implantação na UEPA Capital.

Tabela 9. Infraestrutura física das Unidades da UEPA Capital.

Tabela 10. Detalhamento das Metas.

Tabela II. Descrição da distribuição, quantidade das lixeiras e colaboradores de Limpeza por Unidade referente ao Plano de Ação dos Quadros 13 e 14. 


\section{LISTA DE QUADROS}

Quadro I. Características do gerenciamento interno de RS das Unidades da UEPA até fevereiro de 2019.

Quadro 2. Descrição dos componentes de cada Categoria de RSU e sua respectiva Classe (NBR 10.004/2004).

Quadro 3. Potencial de reciclagem para as diferentes categorias de RSU gerados na UEPA.

Quadro 4. Descrição dos tipos de REEE de cada categoria e sua respectiva vida útil (anos) adotada. Quadro 5. Procedimentos de gerenciamento de Equipamentos de consumo (cartuchos/toner de impressão) realizados nas Unidades da UEPA.

Quadro 6. Procedimentos de gerenciamento de Equipamentos de consumo (pilhas e baterias) realizados nas Unidades da UEPA.

Quadro 7.Procedimentos de gerenciamento de Equipamentos de iluminação (lâmpadas) realizados nas Unidades da UEPA.

Quadro 8. Procedimentos de gerenciamento de informática e telecomunicações realizado nas Unidades da UEPA.

Quadro 9. Gerenciamento dos RSS realizados nas Unidades de saúde da UEPA.

Quadro 10.Aplicação do modelo FPSEEA.

Quadro II. Hierarquização dos níveis, prazos e descrição.

Quadro 12. Definição das Proposições do Plano (202I-2030).

Quadro 13. Plano de Ações dos Resíduos Sólidos Urbanos - RSU.

Quadro I4. Plano de Ações dos Resíduos de Equipamentos Eletroeletrônicos (REEE).

Quadro 15. Plano de Ações dos Resíduos de Serviços de Saúde (RSS).

Quadro 16. Plano de Ações de Educação Ambiental. 


\section{LISTA DE FIGURAS}

Figura I. Principais dificuldades encontradas.

Figura 2. Localização das Unidades da Universidade do Estado do Pará nos diferentes bairros do município de Belém-PA. Fonte:Adaptado de Nunes et al. (2017).

Figura 3. Geração de RSU (kg/dia) e geração per capita (kg/pop.dia) das Unidades da UEPA na Capital. Erro padrão $(n=5)$.

Figura 4. Composição gravimétrica dos RSU da Universidade do Estado do Pará com I6I,42 kg/ dia.

Figura 5. Composição gravimétrica das Unidades Reitoria, CCSE e CCBS- Campus II da Universidade do Estado do Pará.

Figura 6. Composição gravimétrica das Unidades CCBS- Enfermagem, CCBS- Ed. Física e CCNT da Universidade do Estado do Pará.

Figura 7. Composição gravimétrica das Unidades CCPP,Almoxarifado,Arquivo/Patrimônio e EDUEPA/Confúcio da Universidade do Estado do Pará.

Figura 8. Árvore de Problemas.

Figura 9. Estágios de evolução do Plano de Gestão Integrada da UEPA. 


\section{APRESENTAÇÃO}

ste documento apresenta o relatório final do Plano de Gestão Integrada de Resíduos Sólidos da Universidade do Estado do Pará, na Capital (PGIRS/UEPA-Capital), o qual expõe em seu conteúdo a compreensão técnica e científica das informações que foram organizadas em 6 (seis) Capítulos elaborados ao longo de 2 anos (2019-2020) como ação prioritária do Programa de Gestão UEPA Ambiental.

Os produtos que compuseram as etapas de evolução do PGIRS/UEPA-Capital são o PréDiagnóstico da Gestão de Resíduos Sólidos da UEPA-Capital (Capítulo I), realizado entre os meses de janeiro a março de 2019 como etapa inicial para diagnosticar a atual gestão dos resíduos sólidos da Instituição.

O Diagnóstico de Resíduos Sólidos Urbanos (RSU) da UEPA-Capital (Capítulo 2), realizado no ano de 2019 com ênfase no gerenciamento dos RSU pela Universidade.

O Diagnóstico de Resíduos de Equipamentos Eletroeletrônicos (REEE) da UEPACapital (Capítulo 3) que concerne às categorias de bens de consumo e permanentes da UEPA.

O Diagnóstico de Resíduos de Serviços de Saúde (RSU) da UEPA-Capital (Capítulo 4) que foca no gerenciamento dos RSS nas Unidades de ensino e serviços de saúde oferecidos pela Instituição.

O Prognóstico do PGIRS/UEPA-Capital (Capitulo 5) que contempla as projeções e cenários futuros da geração de resíduos sólidos da UEPA em um horizonte de 10 anos (202I2030).

Eas Proposições do PGIRS/UEPA-Capital (Capítulo 6) que engloba as diretrizes, estratégias, objetivos, metas, projetos e ações que propiciarão as mudanças necessárias à implantação das transformações para uma gestão ambientalmente adequada dos resíduos sólidos da Universidade do Estado do Pará na Capital.

No Universo da UEPA, este Plano consiste no primeiro volume (Volume I) com ênfase nas Unidades administrativas, de ensino e de serviços da Universidade presentes na Capital (Belém/PA). Posteriormente será publicado o segundo volume deste Plano (Volume II), que irá contemplar a UEPA no âmbito da interiorização em todos os municípios em que ela se faz presente no Estado do Pará. 


\section{SUMÁRIO}

\section{CAPÍTULO I}

PRÉ-DIAGNÓSTICO DA GESTÃO DE RESÍDUOS SÓLIDOS DA UEPA.........................16

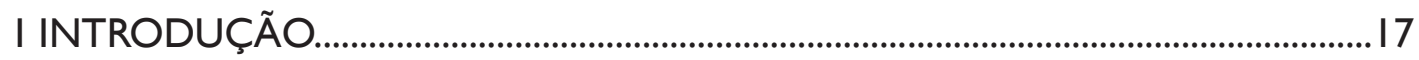

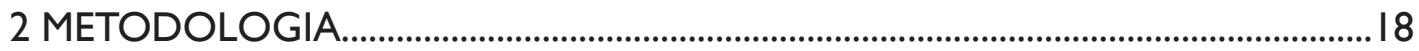

2.I Coleta de dados.........................................................................................................

2.2 Análise de dados........................................................................................................

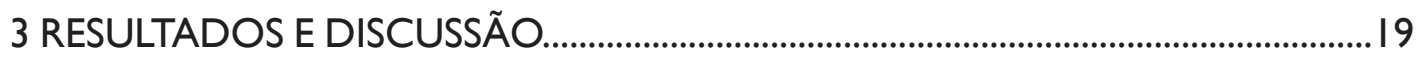

3.I Gerenciamento interno e externo de resíduos sólidos...........................................19

3.2 Identificação das principais dificuldades......................................................................2I

3.3 Iniciativas sustentáveis para gerenciamento de RS no âmbito da "UEPA Ambiental".....................................................................................................................22

4 CONSIDERAÇÕES FINAIS...................................................................................................

\section{CAPÍTULO 2}

DIAGNÓSTICO DA GESTÃO DE RESÍDUOS SÓLIDOS URBANOS DA UEPA............24

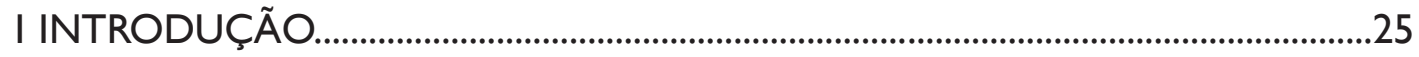

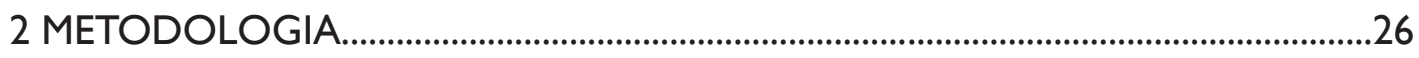

2.I Estrutura física da Universidade do Estado do Pará na Capital...............................26

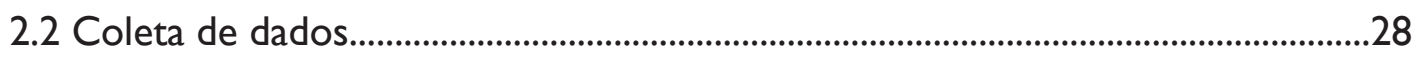

2.3 Análise de dados..............................................................................................................2

3 RESULTADOS E DISCUSSÃO_................................................................................2

3.I Geração de RSU...............................................................................................................29

3.2 Caracterização e gestão dos RSU da UEPA...............................................................

3.3 Caracterização e gestão dos RSU por Unidade.......................................................32

3.4 Potencial de reciclagem para as categorias de RSU...................................................37

4 CONSIDERAÇÕES FINAIS...........................................................................................

\section{CAPÍTULO 3}

DIAGNÓSTICO DA GESTÃO DE RESÍDUOS DE EQUIPAMENTOS ELETROELETRÔNICOS DA UEPA....................................................................................................................................................38

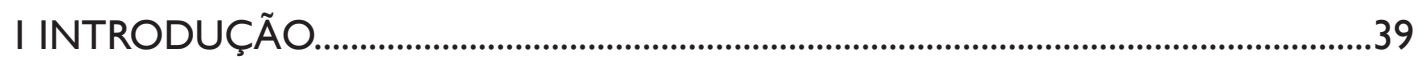

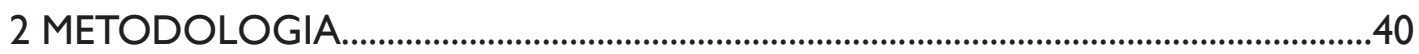

2.I Coleta e análise de dados..................................................................................................40

3 RESULTADOS E DISCUSSÃO....................................................................................4

3.I Equipamentos de consumo.......................................................................................4

3.2 Equipamentos de iluminação....................................................................................4

3.3 Equipamentos de informática e telecomunicações.....................................................4

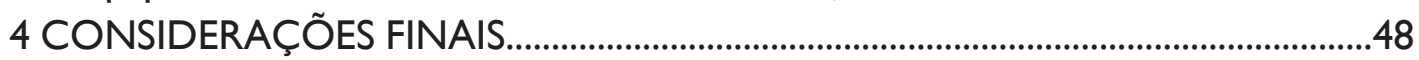




\section{CAPÍTULO 4}

DIAGNÓSTICO DA GESTÃO DE RESÍDUOS DE SERVICOS DESAÚDE DA UEPA......49

I INTRODUÇÃO.

2 METODOLOGIA

2.I Coleta e Análise de dados...........................................................................................

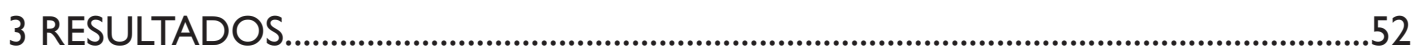

4CONSIDERAÇÕESFINAIS...................................................................................................

\section{CAPÍTULO 5}

PROGNÓSTICO DO PLANO DE GESTÃO INTEGRADA DE RESÍDUOS SÓLIDOS DA UEPA

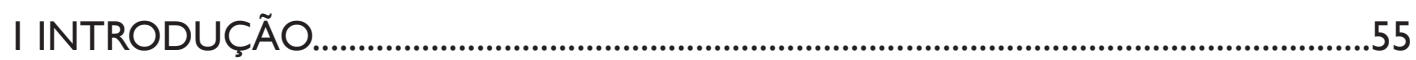

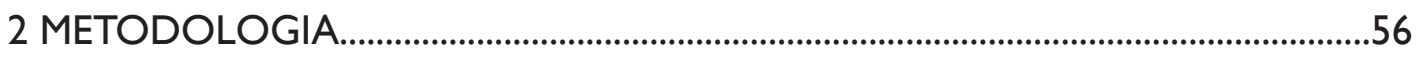

2.I Projeção do crescimento populacional..........................................................................56

2.2 Projeção do crescimento da geração dos RSU.........................................................58

3 RESULTADOS........................................................................................................5

3.I Projeção populacional por Unidade da UEPA............................................................59

3.2 Projeção da geração de RSU por Unidade da UEPA..................................................59

3.3 Projeção da geração per capita de RSU por Unidade da UEPA...............................60

3.4 As Projeções frente ao Plano de Desenvolvimento Institucional - PDI..................60

4 CONSIDERAÇÕES FINAIS.............................................................................................62

\section{CAPÍTULO 6}

PROPOSIÇÕES DO PLANO DE GESTÃO INTEGRADA DE RESÍDUOS SÓLIDOS DA UEPA.

I INTRODUÇÃO.

2 METODOLOGIA .....................................................................................................6

3 EXPLICITAÇÃO DA ÁRVORE DE PROBLEMAS........................................................67

4 EXPLICITAÇÃO DOS EIXOS, OBJETIVOS, METAS, PROJETOS E AÇÕES............69

4.I Indicadores..................................................................................................................

4.2 Detalhamento das Metas....................................................................................................70

4.3 Detalhamento dos Planos de Ações............................................................................73

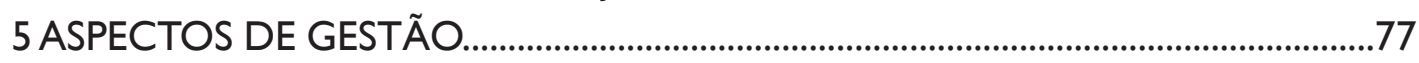

6 CONSIDERAÇÕES FINAIS...........................................................................................77 
CAPÍTULO 1

PRÉ-DIAGNÓSTICO

DA GESTÃO

DE RESÍDUOS

SÓLIDOS DA UEPA

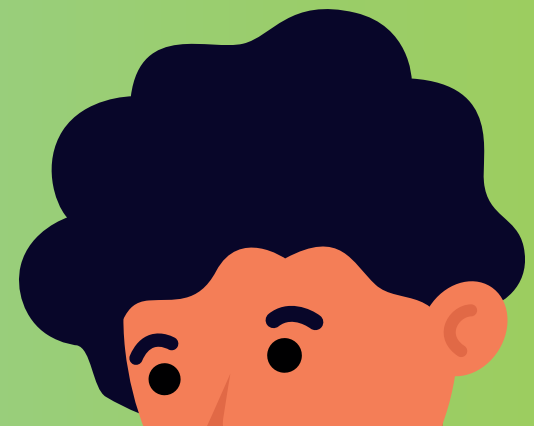

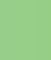




\section{INTRODUÇÃO}

A preocupação com a geração de resíduos sólidos (RS) está sendo pauta na gestão de diferentes instituições do poder público. A Política Nacional de Resíduos Sólidos (PNRS), instituída pela Lei I2.305/20I0, estabelece a responsabilidade compartilhada quanto ao gerenciamento ambientalmente adequado desde a geração, o transporte e a destinação final dos resíduos sólidos. Nesse contexto, a PNRS estabelece a elaboração e implantação do Plano de Gestão Integrada de Resíduos Sólidos (PGIRS) abrangendo todas as etapas de gerenciamento para todos os grandes geradores, incluindo órgãos públicos (MINOTTO; MAGALHÃES, 2018).

Quanto à gestão de resíduos sólidos em universidades públicas, várias instituições têm tomado iniciativas significativas voltadas ao gerenciamento adequado dos RS. A exemplo da Universidade de Caxias do Sul (UCS) que, através de uma Central de Triagem e Armazenamento de Resíduos da Cidade Universitária, vem adotando mecanismos para aperfeiçoar o sistema de segregação e coleta seletiva do RS (DE COUTO et al., 2010). Outra instituição que desenvolve importantes ações ambientais é a Universidade de São Paulo (USP) com a criação de órgão ambiental responsável, centralizador e de apoio dentro da Universidade (MOREIRA et al., 2014).

Ademais, outras instituições de ensino superior vêm se destacando em relação a iniciativas de gerenciamento de RS como a Universidade Federal de Santa Maria (UFSM), Universidade de Brasília (UNB) e Universidade de Santa Cruz do Sul (UNISC) (MARTINS; SILVEIRA, 20I0; HOFMANNGATTI et al., 20I I; KIPPER et al., 2010).

Na região amazônica, muitas universidades públicas buscam desenvolver iniciativas voltadas ao gerenciamento de RS. Nesse sentido, a Universidade do Estado do Pará (UEPA) institucionalizou o Programa de Gestão "UEPA Ambiental" em dezembro de 20I8, baseado nas diretrizes da Agenda Ambiental na Administração Pública (A3P), do Ministério do Meio Ambiente (MMA). Dentre os eixos norteadores deste Programa, destaca-se o Eixo "Gestão adequada de Resíduos Sólidos" que possui como um dos seus objetivos estratégicos a elaboração e implantação de um Plano de Gestão Integrada de Resíduos Sólidos (PGIRS) na Instituição (MMA, 20I7).

A Universidade do Estado do Pará foi criada em 18 de maio 1993 pela Lei Estadual n ${ }^{\circ}$ 5.747, a partir da fusão das faculdades estaduais de Medicina, Enfermagem, Educação Física e Educação. Assim, seu espaço físico não foi estruturado como Cidade Universitária e suas Unidades, tanto de ensino como administrativas, ficam localizadas em diferentes bairros da cidade de Belém (Capital do Estado) e em municípios do interior do Estado do Pará, caracterizando-a como uma estrutura Multicampi (DE NEZ, 20I6).

Na capital, a UEPA possui 3 Centros de Ciências, divididos em 5 Campi: Centro de Ciências Sociais e Educação - CCSE (Campus I), Centro de Ciências Biológicas e da Saúde - CCBS (Campus II), Curso de Educação Física (Campus III), Escola de Enfermagem "Magalhães Barata" (Campus IV), Centro de Ciências Naturais e Tecnologia - CCNT (Campus V). O CCBS é um centro composto por 3 Unidades de ensino em endereços distintos. Além dos Centros, outras unidades compõem a IES: Reitoria, Centro Saúde-Escola do Marco (CSE), Unidade de Fisioterapia e Terapia Ocupacional (UEAFTO) Centro de Ciências e Planetário do Pará (CCPP),Almoxarifado Central, 
Arquivo Central, Patrimônio, Instituto Confúcio e Editora da UEPA (EDUEPA), que serão mais bem detalhadas no Capítulo 2.

Como objeto de análise deste Capítulo, foram estudadas 7 (sete) Unidades: I (um) Reitoria, 2 (dois) Centro de Ciências Sociais e Educação - CCSE (Campus I), 3 (três) Centro de Ciências Biológicas e da Saúde - CCBS (Campus II), 4 (quatro) Curso de Educação Física (Campus III), 5 (cinco) Escola de Enfermagem “Magalhães Barata" (Campus IV), 6 (seis) Centro de Ciências Naturais e Tecnologia - CCNT (CampusV) e 7 (sete) Centro de Ciências e Planetário do Pará - CCPP.

Diante do exposto, o Capítulo I apresenta o Pré-Diagnóstico sobre a gestão dos resíduos sólidos no âmbito de 7 (sete) Unidades da Universidade do Estado do Pará a fim de identificar o processo de gerenciamento dos RS de cada Unidade, as principais dificuldades encontradas pelos gestores locais e a existência de iniciativas sustentáveis de gerenciamento dos RS.

\section{METODOLOGIA}

\section{I Coleta de dados}

Baseado nas diretrizes do Plano de Gestão Socioambiental - PGS nas Universidades Públicas da A3P e na Política Nacional de Resíduos Sólidos, elaborou-se um questionário qualitativo que foi aplicado aos servidores das 7 (sete) Unidades estudadas através de um sistema online, semiestruturado, abrangendo assim seus diferentes setores. Além disso, foram realizadas entrevistas semiestruturados, em modo presencial, com os Coordenadores Administrativos (CAD) de cada Unidade sobre o gerenciamento local dos RS. (MMA, 20I7; MINOTTO, MAGALHÃES, 20I8).

Os dados foram analisados em 3 eixos:

- Gerenciamento interno e externo de RS na Unidade;

- Identificação das principais dificuldades;

- Iniciativas sustentáveis de gerenciamento de RS.

\subsection{Análise de dados}

Como método de análise do gerenciamento interno e externo dos RS de todas as Unidades, foi levado em consideração, segundo Monteiro (200I):

- Os tipos de resíduos sólidos, segundo a Associação Brasileira Normas Técnicas (ABNT), gerados pelos setores administrativos;

- Realização de coleta seletiva dos RS na Unidade;

- Acondicionamento temporário dos RS;

- Transporte interno dos RS;

- Existência de resíduos de equipamentos eletroeletrônicos (REEE) oriundos de bens inservíveis da Instituição;

- Gerenciamento externo.

No gerenciamento externo dos RS foram observadas quais medidas de tratamento e/ou destinação final são realizadas após o gerenciamento interno. 
Para identificação das principais dificuldades de execução do gerenciamento dos RS foram consultadas as CAD e os coordenadores de laboratórios. Para identificação das iniciativas sustentáveis de gerenciamento dos RS foi realizado uma consulta junto a Pró-Reitoria de Pesquisa e Pós-Graduação (PROPESP), a Pró-Reitoria de Extensão (PROEX) e aos Docentes e Discentes das Unidades de ensino (COSTA, 20I4; MINOTTO; MAGALHÃES, 20I8; MMA, 20I7).

\section{RESULTADOS E DISCUSSÃO}

\section{I Gerenciamento interno e externo de resíduos sólidos}

A aplicação do questionário alcançou 70 (setenta) servidores de diferentes setores de todas as Unidades, onde Reitoria e CCNT contribuíram com o maior número de respostas com $\mathbf{3 7 , I} \%$ e $\mathbf{4 7 , I} \%$, respectivamente. Dentre os questionamentos, aproximadamente $\mathbf{7 5} \%$ dos setores utilizam copos descartáveis para beber água e $\mathbf{7 8} \%$ para beber café.

No uso do papel para atividades administrativas, $\mathbf{7 0} \%$ dos setores não reutiliza ou destina os resíduos de papel para cooperativas de catadores de materiais recicláveis, descartando-os juntamente aos demais tipos de RS.Além disso, 98,6\% dos setores não utiliza papel reciclado em suas atividades e $\mathbf{2 4 , 3} \%$ ainda não utiliza as duas faces do papel em impressões.

Ações de educação ambiental voltadas à sensibilização dos servidores da Universidade foram realizadas no ano de 2018, através do Programa de Gestão “UEPA Ambiental”, orientando ao não uso de descartáveis e ao reaproveitamento de papel. Entretanto, mesmo com as ações educativas, os resultados demonstraram que uma parcela significativa de servidores ainda não praticam atitudes sustentáveis em suas atividades. Essa mesma observação também foi constatada por Ross et al. (2017) em uma Universidade Federal no Paraná.

A educação ambiental é uma das principais ferramentas para minimizar a geração de RS em instituições públicas, reeducando e sensibilizando servidores sobre práticas sustentáveis baseadas na política dos 5 Rs (repensar, reduzir, recusar, reutilizar e reciclar) e contribuindo na diminuição dos RS destinados a aterros sanitários ou vazadouros a céu aberto (COSTA; RODRIGUES, 20I4).

No gerenciamento interno e externo de resíduos sólidos, os resultados demonstraram que a Universidade não possui Plano de Gestão Integrada de Resíduos Sólidos e que cada Unidade adota medidas independentes para gerenciar os RS gerados. Como a UEPA possui uma estrutura multicampi, cada Centro possui uma geração específica de resíduos devido as diferentes atividades

que cada uma desenvolve. O Quadro I apresenta as características dos tipos de RS gerados por cada Unidade e o gerenciamento interno até fevereiro de 2019. 
Quadro I. Características do gerenciamento interno de RS das Unidades da UEPA até fevereiro de 2019.

\begin{tabular}{|c|c|c|c|}
\hline Resíduos Sólidos & Unidades & $\begin{array}{c}\text { Classificação } \\
\text { ABNT NBR } 10.004 / 2004\end{array}$ & $\begin{array}{l}\text { Gerenciamento } \\
\text { Interno }\end{array}$ \\
\hline $\begin{array}{l}\text { Resíduos Sólidos Urba- } \\
\text { nos Reciclável }\end{array}$ & $\begin{array}{l}\text { Reitoria, CCSE, CCBS, Educação Fí- } \\
\text { sica, Enfermagem, CCNT, Planetário }\end{array}$ & Classe II B & Sem gerenciamento \\
\hline $\begin{array}{l}\text { Resíduos Sólidos Urba- } \\
\text { nos não Reciclável }\end{array}$ & $\begin{array}{l}\text { Reitoria, CCSE, CCBS, Educação Fí- } \\
\text { sica, Enfermagem, CCNT, Planetário }\end{array}$ & Classe II A II B & Sem gerenciamento \\
\hline $\begin{array}{l}\text { Resíduos Sólidos Urba- } \\
\text { nos Orgânicos }\end{array}$ & $\begin{array}{l}\text { Reitoria, CCSE, CCBS, Educação Fí- } \\
\text { sica, Enfermagem, CCNT, Planetário }\end{array}$ & Classe II A & Sem gerenciamento \\
\hline $\begin{array}{l}\text { Resíduos Perigosos de } \\
\text { Serviço de Saúde }\end{array}$ & CCBS, Enfermagem & Classe I & $\begin{array}{l}\text { Gerenciamento inter- } \\
\text { no e externo }\end{array}$ \\
\hline $\begin{array}{l}\text { Resíduos Perigosos } \\
\text { Químicos }\end{array}$ & $\begin{array}{l}\text { CCSE, CCBS, Educação Física, En- } \\
\text { fermagem, CCNT }\end{array}$ & Classe I & Sem gerenciamento \\
\hline $\begin{array}{l}\text { Resíduos Sólidos } \\
\text { Urbanos de Vegetação } \\
\text { (podas) }\end{array}$ & $\begin{array}{l}\text { Reitoria, CCSE, CCBS, Educação Fí- } \\
\text { sica, Enfermagem, CCNT, Planetário }\end{array}$ & Classe II A & Sem gerenciamento \\
\hline $\begin{array}{l}\text { Resíduos eletroele- } \\
\text { trônicos Lâmpadas } \\
\text { Fluorescentes }\end{array}$ & $\begin{array}{l}\text { Reitoria, CCSE, CCBS, Educação Fí- } \\
\text { sica, Enfermagem, CCNT, Planetário }\end{array}$ & Classe I & Sem gerenciamento \\
\hline $\begin{array}{l}\text { Resíduos eletroeletrô- } \\
\text { nicos Pilhas e Baterias }\end{array}$ & $\begin{array}{l}\text { Reitoria, CCSE, CCBS, Educação Fí- } \\
\text { sica, Enfermagem, CCNT, Planetário }\end{array}$ & Classe I & Sem gerenciamento \\
\hline $\begin{array}{l}\text { Resíduos Eletroeletrô- } \\
\text { nicos } \\
\text { Informática e telecomu- } \\
\text { nicação }\end{array}$ & $\begin{array}{l}\text { Reitoria, CCSE, CCBS, Educação Fí- } \\
\text { sica, Enfermagem, CCNT, Planetário }\end{array}$ & Classe I & Sem gerenciamento \\
\hline $\begin{array}{l}\text { Resíduos eletroele- } \\
\text { trônicos Cartuchos e } \\
\text { Toner de Impressoras }\end{array}$ & $\begin{array}{l}\text { Reitoria, CCSE, CCBS, Educação Fí- } \\
\text { sica, Enfermagem, CCNT, Planetário }\end{array}$ & Classe I & Sem gerenciamento \\
\hline
\end{tabular}

Os resíduos sólidos urbanos (RSU) são gerados por todas as Unidades da Universidade e resultam das atividades administrativas e de ensino, pesquisa e extensão. Resíduos de serviços de saúde (RSS) são gerados em Unidades específicas (CCBS e Escola de Enfermagem), havendo um gerenciamento interno que é realizado pelo CAD da Unidade em atendimento à Resolução CONAMA n 358/2005 e RDC ANVISA n 306/2004 que dispõe sobre classificação, tratamento, disposição final e regulamento técnico para o gerenciamento dos RSS.

O gerenciamento externo dos RSS é realizado por empresa especializada no serviço através do Contrato $n^{\circ} 006 / 2016$, tendo como objeto a prestação de serviços de coleta externa, tratamento (incineração) e destinação final de resíduos de serviços de saúde.A fiscalização é realizada por dois servidores designados através da Portaria Ordinária ${ }^{\circ}$ 816/2016. A empresa contratada deve emitir relatórios mensais dos serviços executados, além das guias de coletas que serão assinadas pelos fiscais responsáveis.

Os resíduos de equipamentos eletroeletrônicos (lâmpadas, pilhas, baterias, informática, telecomunicações, cartucho e toner de impressora) são gerados por todas as Unidades e nenhum deles apresenta gerenciamento interno e disposição final adequada.Alguns coordenadores administrativos acondicionam esses resíduos em salas improvisadas para não serem misturados e descartados juntos a outros tipos de resíduos. Em alguns casos, esses REEE são destinados a campanhas de 
coleta seletiva promovida por empresas ou cooperativas para coleta especifica desse tipo de RS. Contudo, essa iniciativa não ocorre com frequência na cidade de Belém.

Como descrito na Tabela I, foram identificados 10 tipos de RS que são gerados na Universidade, no entanto, apenas os resíduos de serviços de saúde possuem gerenciamento interno e externo. Esse tipo de resíduo possui baixa produção no Brasil, em torno de I a 3 \% (RODRIGUES et al., 2016), porém, seu elevado potencial de risco à saúde humana e ao meio ambiente classifica esses resíduos como perigosos (SODRÉ; LEMOS, 2017). Também foi constatado que os Campi de saúde não possuem Planos de Gerenciamento de Resíduos Serviços de Saúde - PGRSS como exigido pelo Artigo $4^{\circ}$ da Resolução CONAMA n 358/2005.

Os demais resíduos sólidos identificados no Quadro I são encaminhados à coleta pública realizada pela prefeitura municipal e destinados ao Aterro do Aurá (aterro sanitário utilizado para destinação final de RS dos municípios da região metropolitana de Belém) sem nenhum tipo de tratamento, o que ainda caracteriza uma realidade comum à maioria dos municípios brasileiros, principalmente na região Amazônica (LAVNITCKI et al., 20I8; BARROS et al., 20I7).

\subsection{Identificação das principais dificuldades}

A partir da percepção dos Coordenadores Administrativos de cada Unidade, foram destacadas as principais dificuldades para aplicação de medidas de gerenciamento adequado dos RS na Universidade (Figura I).

Figura I. Principais dificuldades encontradas.

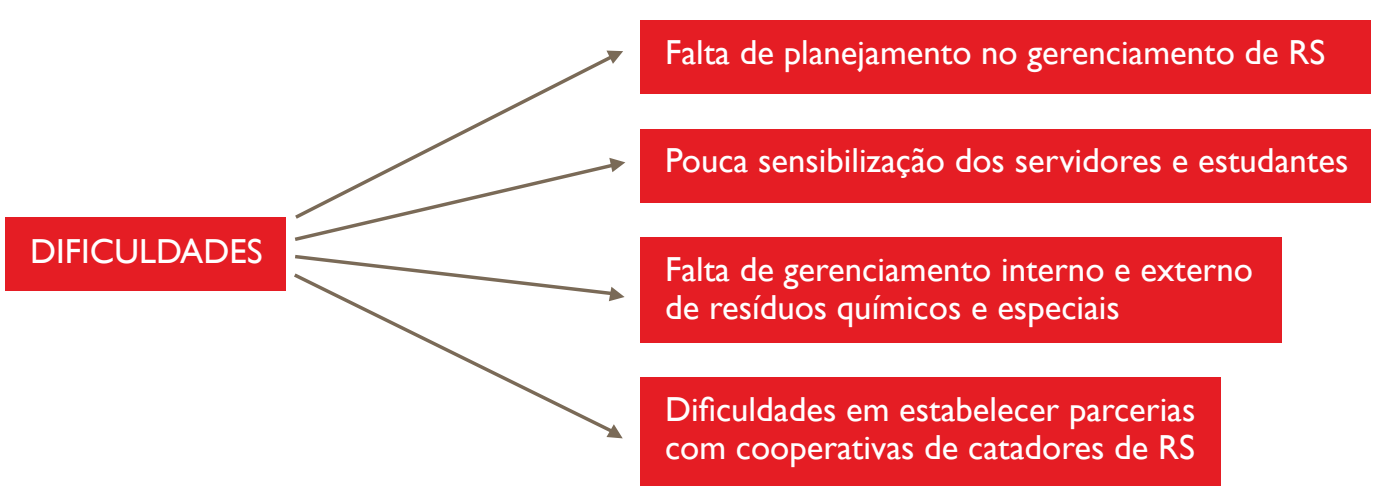

Fica evidente que a Universidade não possui planos de gerenciamento interno de seus RS e realiza apenas o gerenciamento dos RSS. Este cenário desencadeia uma carência no sistema de coleta, transporte e destinação final dos RS, tornando o gerenciamento realizado inadequado. A PNRS dispõe que todo grande gerador deve elaborar e implantar seu Plano a fim de estruturar medidas ambientalmente adequadas de gerenciamento para cada tipo de RS (MINOTTO; MAGALHÃES, 2018).

Ações de educação ambiental para servidores de Universidades públicas têm sido uma significativa ferramenta de conscientização e sensibilização sobre as questões ambientais. No entanto, a mudança de hábitos ainda é um grande desafio para que o servidor adéque suas ações a uma rotina de trabalho sustentável (ARCIOTTE; SACCARO JUNIOR, 20I2). 
Esse cenário ainda faz parte das principais dificuldades encontradas para implantação do gerenciamento de RS na Universidade do Estado do Pará. Iniciativas voltadas à sensibilização de servidores e também de estudantes devem ser contínuas e avaliadas periodicamente para identificar se as mudanças de hábitos estão de fato ocorrendo (MOREIRA et al., 20।4).

Outra dificuldade significativa é a falta de gerenciamento interno e externo de resíduos de equipamentos eletroeletrônicos. Como observado no Quadro I, os REEE e resíduos químicos são classificados como Classe I pela ABNT NBR 10.004/2004, necessitando de gerenciamento específico. Os resíduos químicos são gerados durante as atividades de ensino e pesquisas na Instituição e estão sob responsabilidade das coordenações de laboratório que devem elaborar planos de gerenciamento interno dentro dos seus procedimentos operacionais padrão (POP) de acordo com as atividades e reagentes utilizados nos laboratórios, como proposto por Ferreira et al. (2016).

Em relação aos REEE, a principal dificuldade é buscar alternativas de logística reversa e destinação final adequada. A medida adotada pelas Unidades atualmente é separar e acondicionar esses REEE em locais improvisados da Instituição para evitar que sejam descartados junto aos RSU, e buscar alternativa de logística reversa. Alguns servidores com habilidades de manutenção buscam reaproveitar peças dos REEE, considerados como bens inservíveis.

Por fim, outra dificuldade consiste em estabelecer parcerias formais com cooperativas de catadores de materiais recicláveis que atuam legalmente na Região Metropolitana de Belém. De acordo com o Decreto Federal 7.404/20 I0, os Planos devem prever a participação de associações ou de cooperativas de catadores de materiais recicláveis, desde que tais cooperativas tenham capacidade técnica e operacional de realizar o gerenciamento externo dos RS da Instituição (PINHEIRO, FRANCISCHETTO, 2016).

\subsection{Iniciativas sustentáveis para gerenciamento de RS no âmbito da "UEPA Ambiental”"}

Desde 2015 a Universidade do Estado do Pará tem proposto uma nova política de gestão baseada nos princípios da sustentabilidade. Nesse contexto, a criação do projeto "UEPA Ambiental: novos hábitos fazem a diferença" em 20I5, objetivou a discussão e o planejamento de ações para uma gestão socioambiental na Universidade. Em resultado, nos anos de 2016 e 2017, ações piloto foram aplicadas principalmente à diminuição do consumo de energia elétrica e água potável, visando o uso racional destes, além da aquisição de equipamentos tecnológicos mais econômicos para a Instituição.

A criação de uma Comissão técnica constituída por servidores de diferentes setores da Universidade foi medida chave para a elaboração de um Programa baseado nas orientações da Agenda Ambiental na Administração Pública (A3P). Em 2018 foi institucionalizado o Programa de Gestão "UEPA Ambiental" com o slogan "Sua atitude faz a diferença. Novos hábitos, nova UEPA”. E desde então, ações norteadas em 4 (quatro) Eixos têm sido colocadas em prática.

No eixo "Gestão adequada de Resíduos Sólidos” algumas iniciativas realizadas pelo Programa UEPA Ambiental devem ser ressaltadas: o levantamento de informações como pré-diagnóstico para conhecimento da realidade atual da gestão de RS pela Universidade foi uma ação inicial. Essa ação 
visa o conhecimento das diferentes formas de gerenciamento de RS que cada Campi desenvolve, uma vez que a Instituição ainda não possui PGRS, resultando como produto desta ação este documento.

Uma ação realizada pela Pró-Reitoria de Gestão e Planejamento (PROGESP) da UEPA foi a diminuição gradativa na compra e fornecimento de copos descartáveis para a IES.A ação visa à redução com objetivo de eliminar o uso de descartáveis pelos servidores em médio prazo (3 anos).

Outra ação está atrelada à conscientização de servidores e estudantes quanto à separação de RS com a instalação de lixeiras de coleta seletiva em todos as Unidades da Universidade.Ademais, a capacitação de servidores também é prioridade, nesse sentido foi realizada uma pesquisa consultando-os sobre temáticas para cursos de capacitação, 37,2\% dos servidores solicitaram o tema "Ferramentas 5R - reduzir, repensar, reaproveitar, reciclar e recusar", demonstrando o interesse dos mesmos em obter conhecimentos no Eixo de Gestão adequada de RS.

Diversas Universidades públicas já divulgaram suas iniciativas sustentáveis em relação à gestão de resíduos sólidos (DE COUTO et al., 20I0; MOREIRA et al., 20I4; MARTINS, SILVEIRA, 20I0; HOFMANNGATTI et al., 20I I; KIPPER et al., 20I0; MINOTTO, MAGALHÃES, 20I8; RODRIGUES et al., 20I6), porém, na região amazônica, as ações de Universidades e outras Instituições públicas ainda são inexpressivas quando comparadas a outras regiões do Brasil (MMA, 20I7).

Outras iniciativas a serem destacadas ocorrem nos projetos de extensão universitária realizados por docentes e estudantes. De acordo com a Pró-Reitoria de Extensão da UEPA (PROEX), no ano 2009 foi criado o Programa "UEPA nas Comunidades" que promove a conexão e interação entre a Universidade e a comunidade, realizando atividades na temática ambiental, saúde e educação.

Outro Programa que também desenvolve diversas atividades em educação ambiental é o "Netrilhas". Como projeto deste programa, destaca-se o "Curumim Ambiental na Folia" que visa trabalhar a educação ambiental com crianças e adolescentes e realizar oficinas para confecção de trajes e fantasias de carnaval a partir do reaproveitamento de resíduos sólidos.

A exemplo de iniciativas que ocorrem na Universidade fora da capital, podem-se citar os projetos: Compostagem de resíduos sólidos orgânicos como ferramenta didática para aprendizagem e desenvolvimento social;Aproveitamento de resíduos de maracujá em empreendimentos informais de feiras livres e Educação ambiental e criação de objetos com reaproveitamento de resíduos sólidos.

\section{CONSIDERAÇÕES FINAIS}

A Universidade do Estado do Pará não possui nenhum plano de gerenciamento de seus resíduos sólidos e apenas os resíduos de serviços de saúde apresentam um gerenciamento interno e externo. É perceptível a preocupação dos servidores sobre o gerenciamento adequado dos RS, no entanto, uma expressiva parcela não adota hábitos sustentáveis que venham contribuir nesse gerenciamento.

Diante do cenário apresentando neste Pré-Diagnóstico foi necessário realizar diagnósticos quali-quantitativos de gestão dos diferentes tipos de resíduos (RSU, REEE e RSS), considerando as especificidades de todas as Unidades, que são apresentados nos Capítulos a seguir. 
CAPÍTULO 2

DIAGNÓSTICO

DA GESTÃO DE

RESİDUOS SÓLIDOS

URBANOS DA UEPA
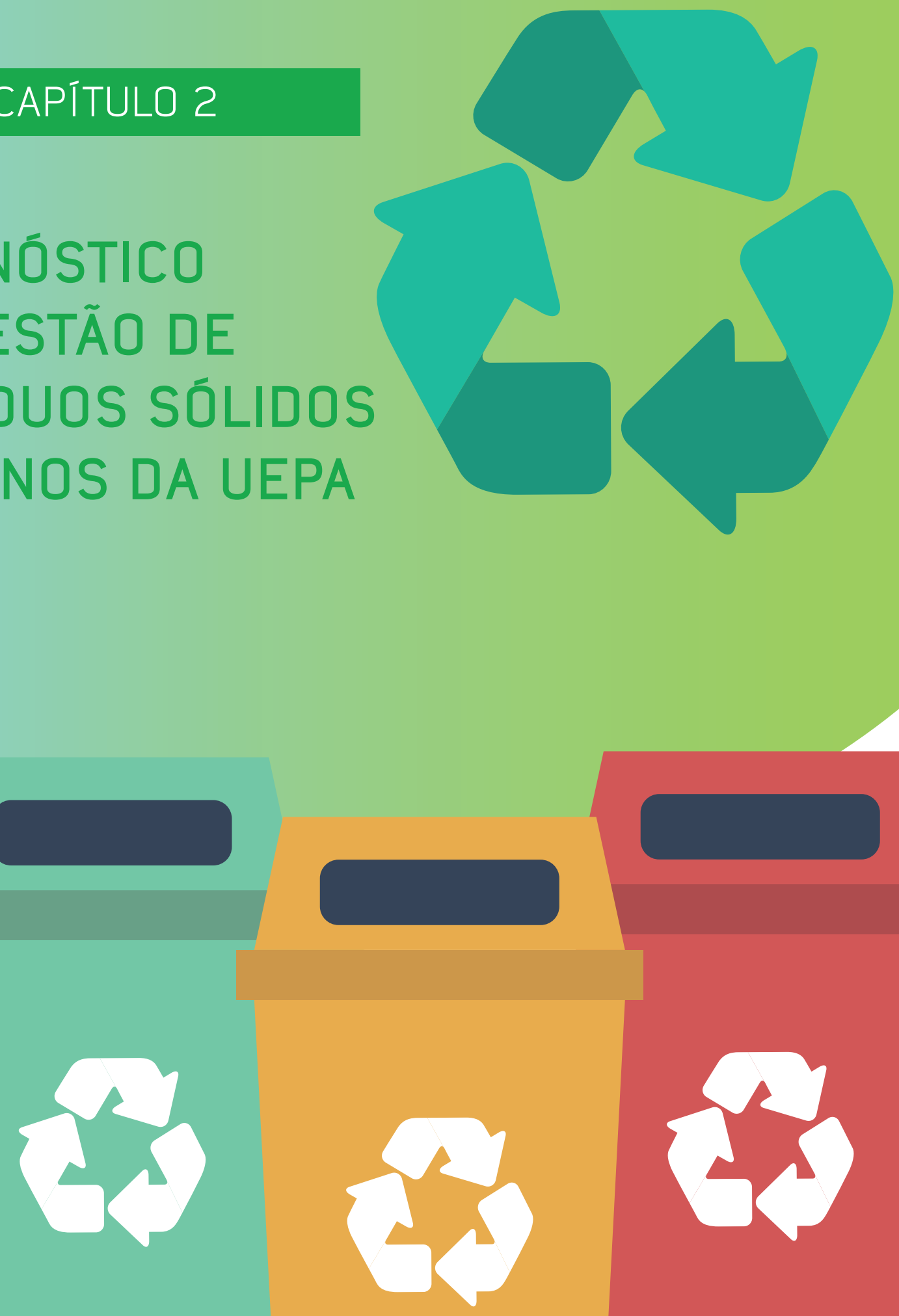


\section{INTRODUÇÃO}

As Instituições de Ensino Superior (IES) podem ser consideradas como pequenos núcleos urbanos ou "minicidades", com grande cobertura territorial e diversas atividades em ensino, pesquisa e extensão. Além de oferecerem serviços de restaurantes, lanchonetes, alojamentos, conveniências e lazer (ADENIRAN et al., 2017). Diante disso, a IES necessita de uma infraestrutura adequada com abastecimento de água e energia, saneamento ambiental, logística, engenharia e administração para que todas as atividades possam ser oferecidas com qualidade (TAUCHEN, BRANDLI, 2006).

Como consequência dessa estrutura e operação, há geração de resíduos sólidos urbanos (RSU) que são produzidos diariamente pelas IES. Devido à magnitude e o elevado montante populacional das universidades, seu potencial de geração de RSU é bastante significativo, podendo ser consideradas como grandes geradoras de resíduos (BONNET et al., 2002; JACOBI, BESEN, 201 I).

A preocupação com a gestão de RSU vem sendo discutida nas diferentes esferas do poder público. A Política Nacional de Resíduos Sólidos (PNRS), instituída pela Lei 12.305/2010 estabelece a responsabilidade compartilhada quanto ao gerenciamento ambientalmente adequado desde a geração, o transporte e a destinação final dos RSU.

Nas Universidades públicas, a gestão adequada dos RSU já é uma realidade e diversas IES pelo Brasil têm tomado iniciativas voltadas ao gerenciamento ambientalmente adequado dos resíduos sólidos como apresentadas no Capitulo I.

Ademais, IES internacionais adotam práticas de gerenciamento adequado dos RSU muito antes das instituições brasileiras. Nos EUA, mais de $80 \%$ das IES já apresentavam programas institucionalizados de gestão de resíduos sólidos no início do século XXI (ALLEN, 1999). No continente africano, IES localizadas na Tanzânia realizam, desde o inicio do século XXI, estudos para caracterizar a geração de RSU, observando um potencial de 70\% para aproveitamento e reciclagem desses resíduos (MBULIGWE, 2002).

Universidades no México também são um exemplo de iniciativas. O Instituto Tecnológico e de Estudos Superiores de Monterrey desde 1992 possui programas de gerenciamento adequado de RSU, com projetos de reciclagem para alumínio e papel (MONTERREY, 2007). Outras instituições mexicanas, como a Universidade de Guadalajara e o Research Center of Advanced Studies-Mérida (CINVESTAV) possuem programas de gerenciamento de resíduos, onde esta última, desde 2003, já reduziu mais de $65 \%$ do total de RSU gerados e enviados aos aterros sanitários (MALDONADO, 2006).

No Brasil, a necessidade desse gerenciamento adequado dos RSU baseia-se em um arcabouço legal discutido desde a criação da Lei n. 6.938, de 31 de agosto de 198 I que dispõe sobre a Política Nacional do Meio Ambiente até a Lei n. 12.305/2010, que Institui a Política Nacional de Resíduos Sólidos (MARCHI, 20I5). Para as instituições públicas, o Ministério do Meio Ambiente dispõem ainda de uma Agenda Ambiental para a Administração Pública (A3P) que norteia as instituições a aplicarem a gestão ambiental em suas atividades com objetivo de atender, dentre outras legislações, a PNRS e minimizar os impactos ambientais negativos causados por estas autarquias (MMA, 2019). 
A PNRS estabelece a elaboração e implantação do Plano de Gestão Integrada de Resíduos Sólidos (PGIRS) que abrange todas as etapas de gerenciamento com geração, acondicionamento, coleta seletiva, tratamento e disposição final dos rejeitos, para todos os grandes geradores, incluindo órgãos públicos (ADENIRAN et al., 20I7). Nesse sentido, as instituições devem adotar propostas de gerenciamento dos RSU a partir de um diagnóstico que demonstre, de forma quali-quantitativa, a geração desses resíduos. E, tem como objetivo geral, retratar a situação atual da gestão de resíduos sólidos (SILVA et al., 2018).

O diagnóstico compõe a primeira etapa para elaboração de PGIRS e as principais informações que ele apresenta são as características e quantificação dos RSU que são gerados (DEVEJA et al., 2008). Em áreas urbanas, a média de produção mundial é de I,3 bilhão de toneladas de RSU por ano, ou I,2 kg por dia para cada habitante (RODRIGUES et al., 20l6). No Brasil a produção média é de I,23 kg/hab.dia ${ }^{-1}$, e esses dados divulgados, a partir de um diagnóstico, demonstram a necessidade de tomadas de decisão voltadas à gestão sustentável dos RSU (BARROS, SILVEIRA, 2019).

Perante o exposto, esse capítulo tem como objetivo principal diagnosticar a geração e o gerenciamento dos resíduos sólidos urbanos da Universidade do Estado do Pará na capital.

\section{METODOLOGIA}

\section{I Estrutura física da Universidade do Estado do Pará na Capital}

Como descrito no Capitulo I, a Universidade do Estado do Pará possui 3 Centros de Ciências, divididos em 5 campi: Centro de Ciências Sociais e Educação - CCSE (Campus I), Centro de Ciências Biológicas e da Saúde - CCBS (Campus II), Curso de Educação Física (Campus III), Escola de Enfermagem “Magalhães Barata” (Campus IV), Centro de Ciências Naturais e Tecnologia - CCNT (CampusV). O CCBS é um centro composto por 3 Campi em endereços distintos.

Além disso, outras Unidades compõem a IES na Capital: Reitoria, Centro Saúde-Escola do Marco (CSE), Unidade de Fisioterapia e Terapia Ocupacional (UEAFTO) Centro de Ciências e Planetário do Pará (CCPP), Almoxarifado Central, Arquivo Central, Patrimônio, Instituto Confúcio e Editora da UEPA (EDUEPA). Todas essas Unidades possuem endereços distintos como demonstrado na Figura 2. 
Figura 2. Localização das Unidades da Universidade do Estado do Pará nos diferentes bairros do município de Belém-PA. Fonte:Adaptado de Nunes et al. (2017).

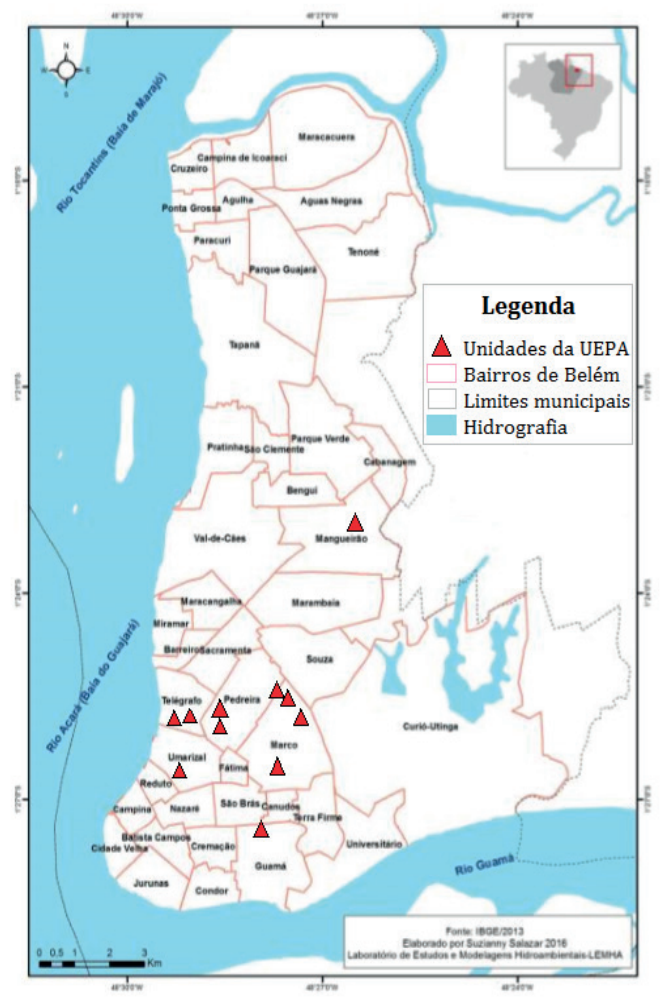

No total, I 4 Unidades da UEPA foram alvos do método de gravimetria de RSU: Reitoria, CCSE, CCBS - Campus II, CCBS - Escola de Enfermagem, CCBS - Educação Física, CSE, UEAFTO, CCNT, CCPP, Almoxarifado Central, Arquivo Central, Patrimônio, Instituto Confúcio e EDUEPA.

Por questões administrativas, a gravimetria dos RSU foi realizada em conjunto nas seguintes Unidades: CSE e UEAFTO;Arquivo Central e Patrimônio; Confúcio e EDUEPA, pois estas Unidades possuem o mesmo gerenciamento interno (Tabela I).

Tabela I. Descrição das Unidades da UEPA, quantidade de servidores ativos e estagiários, alunos matriculados, publico externo e população total (pop. total).

\begin{tabular}{|l|c|r|r|r|}
\hline Unidades & $\begin{array}{c}\text { Servidores/ } \\
\text { estagiários }\end{array}$ & Alunos & $\begin{array}{r}\text { Público } \\
\text { externo }\end{array}$ & Pop. total \\
\hline \multicolumn{1}{|c|}{ Reitoria } & 340 & 0 & 50 & 390 \\
\hline CCSE & 160 & 3.173 & 200 & 3.533 \\
\hline CCBS- Campus II & 154 & 1.055 & 0 & 1.209 \\
\hline CCBS- Enfermagem & 50 & 440 & 0 & 490 \\
\hline CCBS- Ed. Física & 135 & 654 & 500 & 1.289 \\
\hline CSE/UEAFTO & 120 & 0 & 519 & 639 \\
\hline CCNT & 73 & 773 & 0 & 846 \\
\hline CCPP & 47 & 0 & 120 & 167 \\
\hline Almoxarifado & 09 & 0 & 04 & 13 \\
\hline Arquivo/Patrimônio & 10 & 425 & 0 & 10 \\
\hline EDUEPA/Confúcio & 17 & 6.520 & 1.403 & 9.038 \\
\hline Total & 1.115 & & & \\
\hline
\end{tabular}




\subsection{Coleta de dados}

A metodologia utilizada foi aplicada em 2 etapas. A primeira etapa consistiu em uma análise qualitativa sobre a gestão atual de RSU de todas as Unidades da UEPA na Capital. Foi elaborado um questionário qualitativo baseado nas diretrizes do Plano de Gestão Socioambiental nas Universidades Públicas da A3P e na Política Nacional de Resíduos Sólidos (MMA, 2019).

O questionário foi aplicado aos servidores através de um sistema online, abrangendo todas as unidades da IES. Os dados obtidos a partir dos formulários foram analisados com ênfase ao gerenciamento interno e externo dos RSU nas Unidades (MINOTTO et al., 20I8). Esse método permitiu identificar as formas de gerenciamento dos RSU adotadas em cada Unidade.

A segunda etapa enfatizou a coleta de dados quantitativos da geração de RSU. Essa metodologia seguiu as diretrizes da NBR 10.007/2004 e NBR 10.004/2004 da Associação Brasileira de Normas Técnicas (ABNT) e baseou-se nos métodos de orientação técnica da American Society for Testing and Materials (ASTM) D523I-92 (2016).

Para aplicar o método de gravimetria, foi utilizada a técnica de quarteamento para redução da massa de resíduos sólidos urbanos. A técnica de pesagem foi realizada com balança, do tipo plataforma, com capacidade para $300 \mathrm{~kg}$. A gravimetria foi feita durante 5 dias úteis em cada Unidade da IES (kg/dia).

\subsection{Análise de dados}

A geração per capita de RSU foi calculada entre a razão da quantidade média diária produzida em cada Unidade (kg/dia) e a população total (Pop. total) da Unidade (SILVA et al., 20I8; KER et al., 2017).

A população total foi definida através da equação:

$$
\text { Pop.total }=\text { Quant.serv }+ \text { Quant.alun }+ \text { Quant.est }+ \text { Pub.ex }
$$

Onde:

Quant.serv $=$ Quantidade de servidores ativos na Unidade;

Quant . alun $=$ Quantidade de alunos matriculados;

Quant. est $=$ Quantidade de estagiários contratados;

Pub.ex = Estimativa do público externo que frequenta a Unidade diariamente, em busca de serviços oferecidos a comunidade.

Os dados utilizados para o cálculo da população total foram disponibilizados pela Coordenação Administrativa (CAD) de cada Unidade da IES.

A caracterização das amostras seguiu a classificação em categoriais principais baseada no sistema de agrupamento do College and University Recycling Council adaptado de Adeniran et al. (2017) (Quadro 2). Para estimativa da composição gravimétrica foi utilizado o cálculo da porcentagem de peso para cada categoria descrito por DeVega et al. (2008). Os rejeitos gerados em banheiros 
e resíduos de podas gerados pelas atividades de podagem e jardinagem também foram quantificados. Não foi possível realizar a classificação dos RSU na Unidade CSE/UEAFTO.

Quadro 2. Descrição dos componentes de cada Categoria de RSU e sua respectiva Classe (NBR 10.004/2004).

\begin{tabular}{|l|l|c|}
\hline \multicolumn{1}{|c|}{ Categoria } & \multicolumn{1}{|c|}{ Descrição } & Classe (NBR 10.004/2004) \\
\hline Papel & $\begin{array}{l}\text { Folhas de caderno, papel A4, livros, revistas, embalagens de } \\
\text { Papel e papelão. }\end{array}$ & II-B \\
\hline Plástico & $\begin{array}{l}\text { Garrafas PETI, HDPE2, embalagens plásticas, embalagem de } \\
\text { polietileno. }\end{array}$ & II-B \\
\hline Metal & $\begin{array}{l}\text { Latas, latas de alumínio, ferro e não alumínio, embalagens } \\
\text { laminadas BOPP3. }\end{array}$ & II-B \\
\hline Vidro & Todos os materiais de vidro. & II-B \\
\hline Embalagens Tetra Pak & Todas as embalagens de Treta Pak. & II-B \\
\hline Isopor & Todos os materiais de isopor. & II-B \\
\hline Resíduos orgânicos & Sobras de alimentos, cascas de frutas, pó de café. \\
\hline Resíduos de podas & Folhas, galhos, grama, flores, areia, pedra. & II-A \\
\hline Rejeitos & Papel higiênico, papel toalha, frauda descartável. & II-A \\
\hline Outros & $\begin{array}{l}\text { Materiais de couro, borracha, caneta, tecido, cabelo, materiais } \\
\text { diversos. }\end{array}$ & II-B \\
\hline
\end{tabular}

Fonte: Elaborado pelos autores baseado em NBR 10.004/2004 e Adeniran et al. (2017). 'PET: Poli tereftalato de Etila; ${ }^{2}$ HDPE: Polietileno de Alta Densidade; ${ }^{3}$ BOPP: Polipropileno Biorientado.

\section{RESULTADOS E DISCUSSÃO}

\section{I Geração de RSU}

A Universidade do Estado do Pará apresentou um total de geração de RSU de 16 1,42 kg/dia. Ker et al. (2017) ao estudarem uma IES em Vitória no estado do Espirito Santo, com população total de aproximadamente 7.000 pessoas, observaram uma geração média diária de RSU de 225 , I $\mathrm{kg} / \mathrm{dia}$, bem acima dos valores de RSU observados na UEPA, com uma população total de 9.038 .

$\mathrm{Na}$ Universidade de São Paulo (USP), Araújo \& Viana (20I2) observaram aproximadamente 108,4 kg/dia de RSU na Escola de Artes, Ciências e Humanidades (EACH) com população total de 5.490 pessoas. $O$ valor de RSU encontrado na $E A C H$ tem forte similaridade com os valores da UEPA. A quantidade de RSU gerados pelas IES varia de acordo com sua infraestrutura e forma de gerenciamento dos resíduos sólidos, portanto, essa diferença de geração pode ser explicada também pela dimensão física e estrutural de cada IES (TAUCHEN, BRANDLI, 2006, JACOBI, BESEN, 20I I).

Em grandes cidades universitárias a geração de RSU pode alcançar quantidades em toneladas por dia como observado no Campus da Unilag Akoka da Universidade de Lagos na Nigéria, que produz uma média de 32,2 toneladas de resíduos diariamente (ADENIRAN et al., 2017). O Campus Mexicali I da Universidade Autônoma da Baja Califórnia (UABC) no México, também apre- 
senta altos valores de geração de RSU com I tonelada por dia (DEVEGA et al., 2008, BONNET et al., 2002).

A Tabela 2 apresenta a geração média diária de RSU (kg/dia). As Unidades com maiores gerações de RSU foram o CCBS - Ed. Física, seguido pelo CCBS - Campus II e pelo CSE/UEAFTO

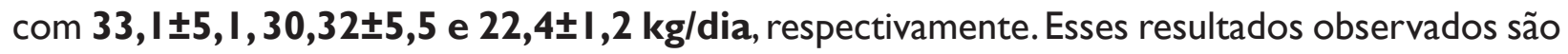
consequência do significativo número de alunos, servidores e público externo (Tabela I), pois tais Unidades oferecem serviços públicos de saúde e assistência social para a comunidade.

Silva et al. (2018) constataram uma geração média diária de 60,86 kg/dia de RSU com população total de 1.235 pessoas no Centro de Ciências e Tecnologia Agroalimentar da Universidade Federal de Campina Grande, Pombal, Paraíba. Ao comparar esse total com o valor de RSU da Unidade do CCBS - Campus II, com pop. total de I.209 pessoas, o Centro de Ciências e Tecnologia Agroalimentar da UFCG apresenta o dobro da geração de RSU por dia.

Os rejeitos somaram um valor total de $39,53 \mathrm{~kg} / \mathrm{dia}$ na UEPA, onde a Unidade com maior geração foi o CCSE com I5, $10 \pm 3,0$ kg/dia (Tabela 2). A grande geração de rejeitos na IES é explicada pelo uso de papel toalha por toda a população que frequenta as Unidades. Por se tratar de um rejeito, esse tipo de material não é reciclável e deve ser disposto em aterros sanitários da região (ADENIRAN et al., 20I7; KER et al., 2017).

Resíduos de podas não apresentam uma frequência de geração diária nas Unidades, geralmente sua produção esta relacionada à dimensão dos jardins e áreas verdes dentro da IES e na frequência das manutenções desses espaços. O CCBS- Campus II apresentou um valor bastante significativo $\mathbf{5 5 , 0 \pm 3 0 , I ~} \mathbf{k g} /$ dia, pois estava ocorrendo manutenção das áreas verdes durante a gravimetria nesta Unidade.

Tabela 2. Geração média diária de RSU, rejeitos sanitários e resíduos de podas ( $\mathrm{kg} / \mathrm{dia}) \pm$ erro padrão $(n=5)$, por Unidade.

\begin{tabular}{|c|c|c|c|}
\hline Unidades & RSU (kg/dia) & Rejeitos (kg/dia) & $\begin{array}{l}\text { Resíduos de podas } \\
\text { (kg/dia) }\end{array}$ \\
\hline Reitoria & $20,76 \pm 2, I$ & $6,74 \pm 0,7$ & 0 \\
\hline CCSE & $20,25 \pm 3,6$ & $15,10 \pm 3,0$ & 0 \\
\hline CCBS- Campus II & $30,32 \pm 5,5$ & $9,32 \pm 1,8$ & $55,0 \pm 30,1$ \\
\hline CCBS- Enfermagem & $11,40 \pm 1,5$ & $5,53 \pm 0,3$ & $0,83 \pm 0,7$ \\
\hline CCBS- Ed. Física & $33,10 \pm 5,1$ & $6,48 \pm I, 4$ & $\mathrm{II}, 28 \pm 5,3$ \\
\hline CSE/UEAFTO & $22,40 \pm 1,2$ & $2,30 \pm 0, I$ & 0 \\
\hline CCNT & $18,16 \pm 4,6$ & $6,42 \pm 1,5$ & $1 \mathrm{I}, 08 \pm 6,5$ \\
\hline CCPP & $1,88 \pm 0,2$ & $0,88 \pm 0,07$ & 0 \\
\hline Almoxarifado & $\mathrm{I}, 70 \pm 0,5$ & $0,15 \pm 0,05$ & 0 \\
\hline Arquivo/Patrimônio & $1,15 \pm 0,4$ & $0,10 \pm 0,00$ & 0 \\
\hline EDUEPA/Confúcio & $0,30 \pm 0,2$ & $0,50 \pm 0, I$ & $1,0 \pm 1,0$ \\
\hline Total & 161,42 & 39,52 & 79,199 \\
\hline
\end{tabular}


A geração per capita total de RSU da UEPA foi de 0,018 $\mathbf{~ k g / p o p . d i a . ~ E s s e ~ v a l o r ~ p o d e ~ s e r ~}$ considerado baixo quando comparados a outras IES. Finkler et al. (2014) e Silva et al. (2018) encontraram valores aproximados de geração per capita de RSU com 0,054 e 0,049 kg/pop.dia na Universidade de Caxias do Sul e Universidade Federal de Campina Grande, respectivamente. Valores de geração per capita de RSU apresentados por Alves et al. (20l3) com 0,016 kg/pop.dia no Instituto Federal de Educação, Ciência e Tecnologia de Mato Grosso, campus Cuiabá-Bela Vista, foram similares aos valores da UEPA.

A Figura 3 demonstra a geração de RSU e a geração per capita levando em consideração a população total de cada Unidade da IES. A geração per capita ficou entre 0,00I e 0,13 kg/pop. dia entre as Unidades da EDUEPA/Confúcio e Almoxarifado. Essa variabilidade deve-se à elevada quantidade de pessoas que frequentam o EDUEPA/Confúcio diariamente em relação à quantidade de RSU produzidos.A baixa geração de RSU do Almoxarifado e Arquivo/Patrimônio elevou a taxa de geração per capita destacando essas Unidades na Figura 3.

Figura 3. Geração de RSU (kg/dia) e geração per capita (kg/pop.dia) das Unidades da UEPA na Capital. Erro padrão $(n=5)$.

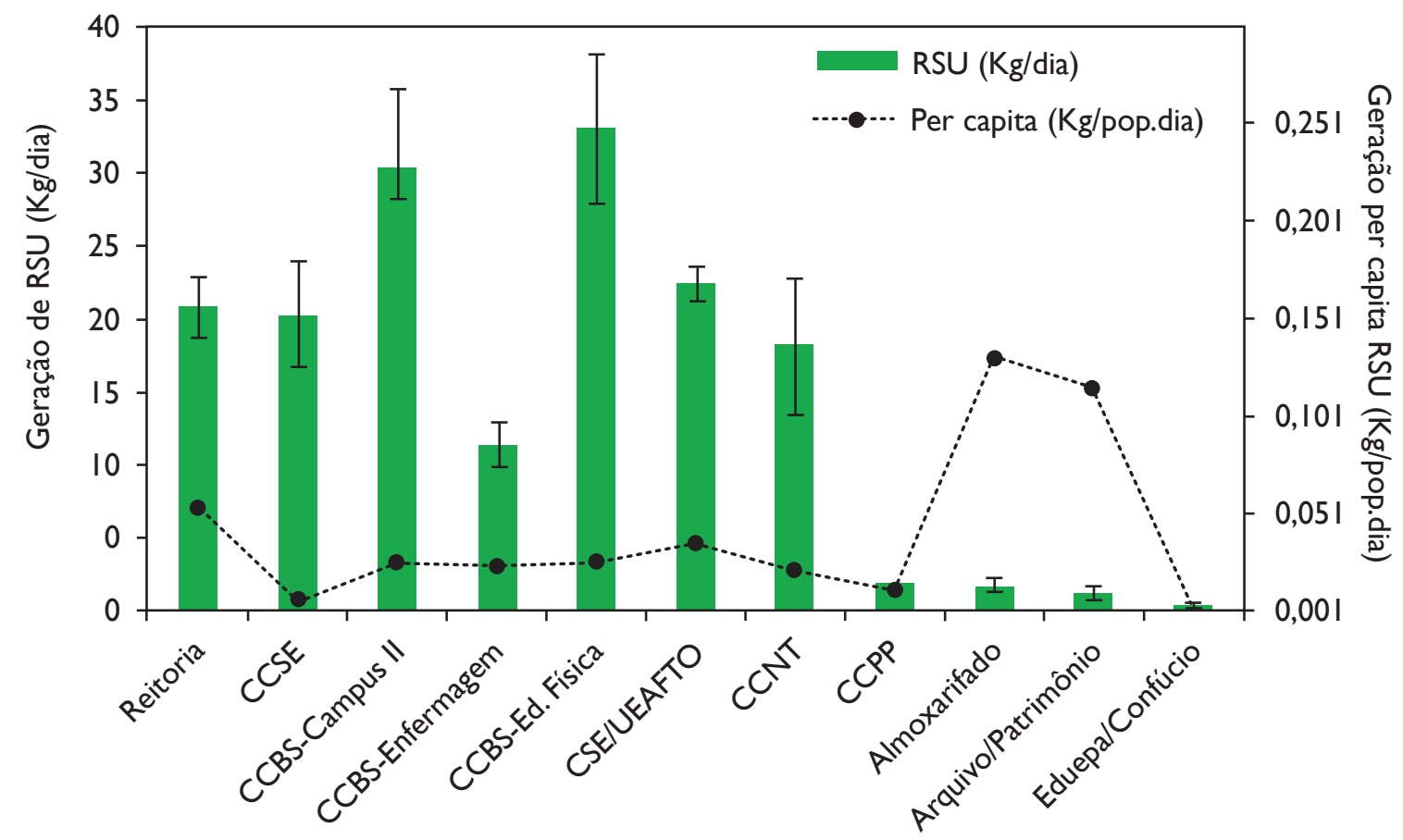

Enquanto a maioria das Unidades apresentou uma geração per capita de RSU coerente, a Reitoria destacou-se com um valor de $\mathbf{0 , 0 5 3} \mathbf{~ k g / p o p . d i a . ~ E s t e ~ d a d o ~ d e m o n s t r a ~ q u e ~ a ~ R e i t o r i a ~ e s t a ́ ~ g e r a n d o ~}$ uma quantidade superior ao observado nas demais Unidades em relação à sua população total.

\subsection{Caracterização e gestão dos RSU da UEPA}

A Figura 4 apresenta a composição gravimétrica dos RSU da UEPA. A maior geração foi observada na categoria resíduos orgânicos com $49 \%$, seguido de papel e plástico com $20 \%$ e $17 \%$, respectivamente. 
Figura 4. Composição gravimétrica dos RSU da Universidade do Estado do Pará com I6I,42kg/dia.

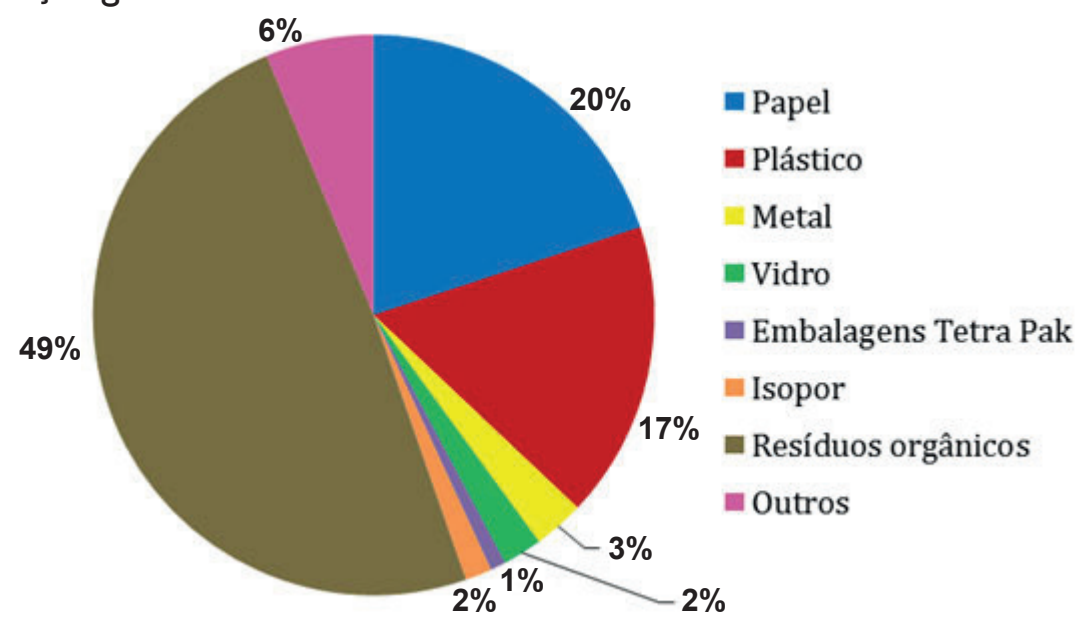

O Plano de Gestão Integrada de Resíduos Sólidos Urbanos do Estado do Pará (2014) demonstra em seu diagnóstico que aproximadamente $50 \%$ dos RSU gerados no Estado do Pará são resíduos orgânicos. Na região metropolitana do Estado, considerando as cidades de Belém, Ananindeua e Marituba, 52,2\% dos RSU coletados também são resíduos orgânicos (IMBIRIBA et al., 2020). Essas observações demonstram como as características de geração dos RSU da UEPA são similares às características do Estado e da região metropolitana.

No entanto, outras IES tiveram números diferentes, a exemplo do Campus da Unilag Akoka da Universidade de Lagos, na Nigéria, que apresentou apenas I5\% de geração na categoria resíduos orgânicos. Adeniran et al. (2017) explica que esse valor é resultado do desperdício de alimento no Campus, representando $10 \%$ do total de RSU gerados. Estima-se que até $1 / 3$ dos alimentos produzidos no mundo são desperdiçados, e as IES fazem parte deste cenário devendo, portanto, adotar medidas na gestão dos RSU junto aos servidores e estudantes para evitar o desperdício de alimentos dentro da Instituição (PERUCHIN et al., 2013).

A geração de papel também foi muito significativa na UEPA (20\%) devido ao uso intensivo de papel nas atividades e processos administrativos, bem como seu uso nas atividades de ensino e pesquisa. O Campus Mexicali I da Universidade Autônoma da Baja California (UABC), no México, apresentou em sua composição gravimétrica de RSU um total de 43,6\% na categoria papel. De Vega et al. (2008) comenta que essa elevada geração de papel ocorre principalmente em unidades administrativas e de ensino dentro do Campus. Contudo, 33\% dos resíduos gerados nestes locais são recicláveis e cabe a gestão da IES adotar um gerenciamento adequado para que estes resíduos sejam encaminhados às cooperativas de catadores de materiais recicláveis ou diretamente à indústria de reciclagem.

\subsection{Caracterização e gestão dos RSU por Unidade}

A Figura 5 apresenta a composição gravimétrica dos RSU das Unidades Reitoria, CCSE e CCBS- Campus II da UEPA. 
Figura 5. Composição gravimétrica das Unidades Reitoria, CCSE e CCBS- Campus II da Universidade do Estado do Pará.
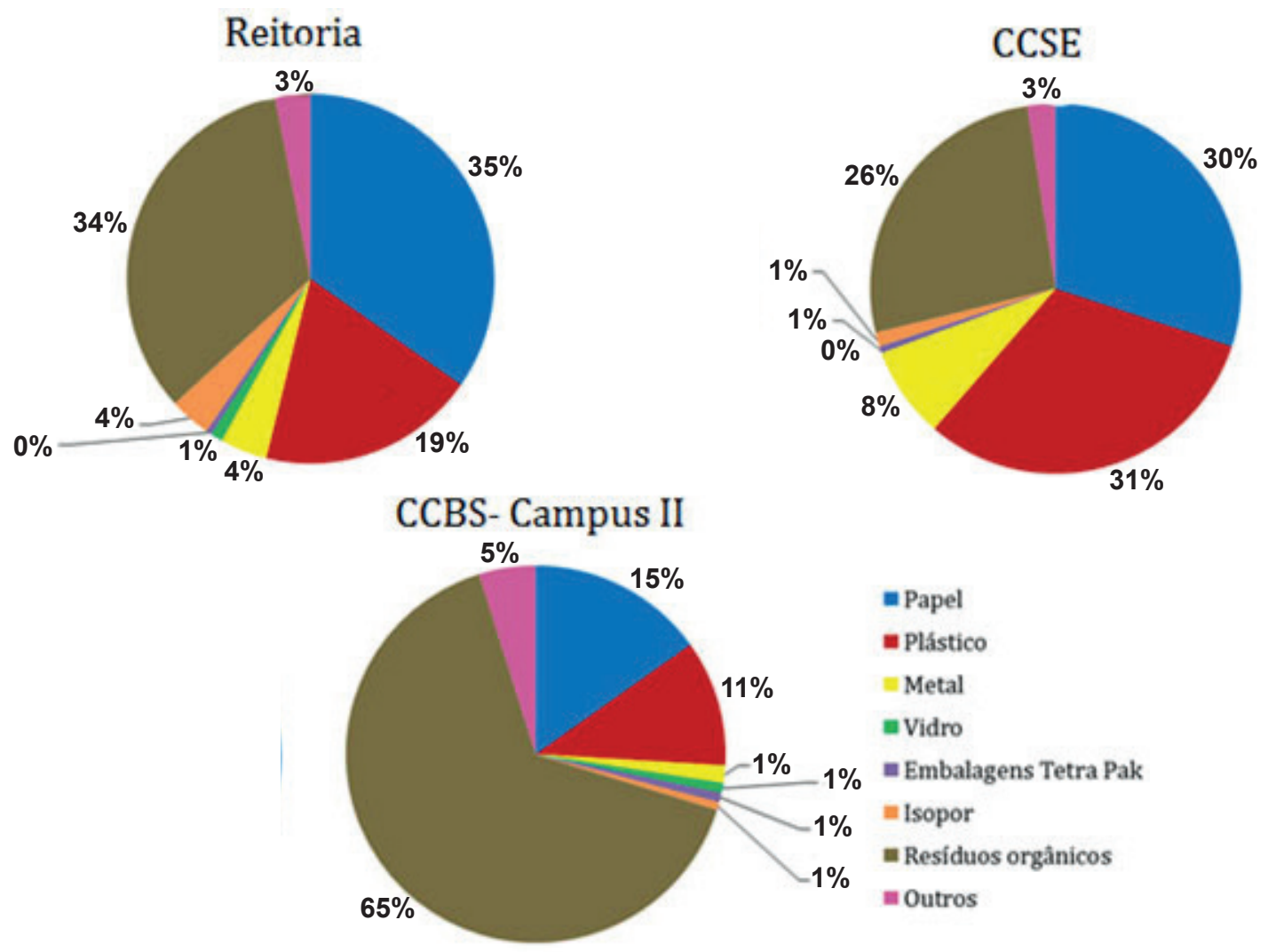

Na Reitoria foram observados maiores gerações de papel (35\%), resíduos orgânicos (34\%) e plástico (19\%) em uma geração de RSU de $20,76 \mathrm{~kg} / \mathrm{dia}$. O elevado uso de papel nos processos administrativos da IES justifica o elevado valor nesta categoria. A Unidade apresenta uma Copa onde servidores e estagiários realizam suas refeições gerando descarte de resíduos orgânicos diariamente.

Alves et al. (2013) observaram um valor de $39 \%$ na geração de papel do setor administrativo do Instituto Federal de Educação, Ciência e Tecnologia de Mato Grosso, campus Cuiabá-Bela Vista. Silva et al. (2018) descreveram $21 \%$ de geração nesta mesma categoria no prédio administrativo do Centro de Ciências e Tecnologia Agroalimentar da UFCG na Paraíba. Esses valores demonstram que as IES ainda não estão aplicando ações de redução e reaproveitamento do papel em suas atividades administrativas. Todavia, esta categoria é reciclável e deve ser encaminhada às cooperativas de catadores locais para um gerenciamento adequado (PINHEIRO et al., 2019).

O CCSE registrou um valor baixo na geração de resíduos orgânicos (26\%) devido esta Unidade possuir um Restaurante Universitário (RU) que atende a demanda de alunos, servidores, estagiários e público externo. O gerenciamento dos RSU produzidos dentro do RU é de responsabilidade da empresa que administra este espaço, assim estes resíduos sólidos não foram contabilizados na gravimetria da Unidade. O plástico foi a categoria com maior valor no CCSE (3 I\%), isso é explicado pela geração de garrafas PET, copos descartáveis e outras embalagens vendidas em pequenas lanchonetes que funcionam dentro da Unidade.A geração de RSU recicláveis deve ser levada em consideração pelo CAD desta Unidade na aplicação da coleta seletiva dos resíduos, devido ao valor econômico do plástico pela indústria de reciclagem (KER et al., 20I7). 
O CCBS - Campus II apresentou uma geração de resíduos orgânicos elevada (65\%). Esse valor significativo é explicado pela existência de um restaurante interno que atende uma elevada demanda de servidores, estagiários, alunos e público externo que realizam suas refeições neste espaço. Como não se trata de um RU, os RSU gerados neste restaurante são gerenciados pela Unidade juntamente com os demais RSU. Peruchin et al. (2013) encontraram até $82,14 \%$ de resíduos orgânicos em um restaurante escola de uma IES no sul do Brasil. De Veja et al. (2008) observaram 54, I\% de resíduos orgânicos em áreas residenciais de estudantes dentro do Campus Mexicali I da Universidade Autônoma da Baja California (UABC) no México.

Essas observações demonstram como os resíduos orgânicos são gerados em grande volume nas IES e sugerem que sejam adotadas, urgentemente, medidas para um gerenciamento ambientalmente adequado dos RSU pelas Universidades. A UEPA apresentou 49\% de resíduos orgânicos em sua geração total, onde o CCBS- Campus II foi a Unidade com maior contribuição nesse percentual, indicando que esta Unidade deve adotar medidas de gerenciamento junto ao restaurante que fornece refeições à população.

A Figura 6 apresenta a composição gravimétrica dos RSU das Unidades CCBS - Enfermagem, CCBS - Ed. Física e CCNT.As três Unidades apresentaram elevadas gerações de resíduos orgâni$\cos 45 \%, 42 \%$ e $54 \%$, respectivamente.

Figura 6. Composição gravimétrica das Unidades CCBS- Enfermagem, CCBS- Ed. Física e CCNT da Universidade do Estado do Pará.

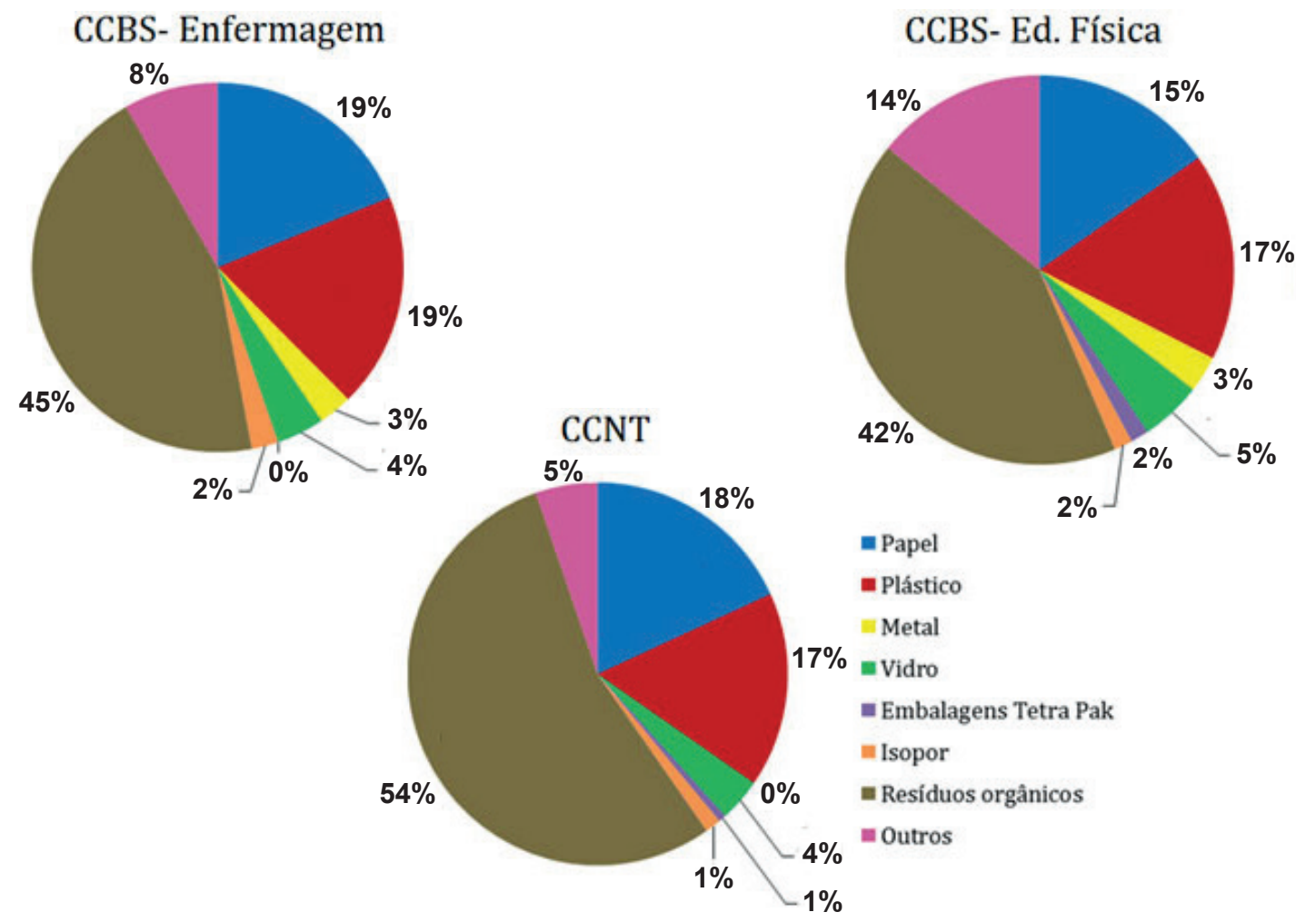

Maiores gerações de papel e plástico foram observados no CCBS - Enfermagem (19\%) devido ao uso significativo de copos descartáveis utilizados nesta Unidade pela comunidade acadêmica. Reduzir o uso de descartáveis ainda é um desafio na gestão dos RSU pelas IES. Ações de educação ambiental para conscientização e sensibilização da comunidade acadêmica devem ser aplicadas de 
forma contínua nas Universidades para reduzir o consumo de materiais descartáveis (PINHEIRO et al., 20I9;TAUCHEN, BRANDLI, 2006).

Dentre todas as Unidades da IES, o CCBS - Ed. Física apresentou o maior valor para a categoria Outros (14\%). Esse resultado foi observado devido ao descarte de resíduos de couro, borracha e tecido provenientes das áreas esportivas da Unidade que passam por manutenções periódicas e geram esse tipo de RSU.Além disso, um valor de $5 \%$ para a categoria vidro foi observado nesta Unidade, devida à identificação de garrafas vazias nas amostras de RSU classificadas.

No CCBS - Ed. Física são realizados, frequentemente, jogos e torneios esportivos, recebendo um público externo elevado durante essas atividades. Esse fluxo promove picos de geração de RSU que devem ser levado em consideração na gestão dos resíduos desta Unidade (JACOBI, BESEN, 20I I). Apesar do CCBS - Ed. Física possuir apenas um curso de graduação, sua geração de RSU foi elevada (Tabela 2). Marques et al. (2017) ressaltam que a coleta seletiva de resíduos sólidos urbanos deve ser aplicada em áreas esportivas a fim de promover um gerenciamento adequando dos RSU, bem como um impacto social ao público externo que frequenta a IES, como foi observado no Centro Esportivo Universitário do Campus da Pampulha da Universidade Federal de Minas Gerais.

O CCNT apresentou significativa geração de resíduos orgânicos. Essa Unidade possui um restaurante que atende toda a comunidade acadêmica. Os resíduos orgânicos gerados neste restaurante não possuem um gerenciamento próprio e são coletados juntamente aos RSU da Unidade. $O$ papel e plástico também apresentaram valores expressivos 18\% e 17\%, respectivamente, semelhante ao CCBS - Enfermagem e CCBS - Ed. Física.

O CCNT é um Centro que possui cursos de graduação voltados à tecnologia e meio ambiente, porém não foi observada nenhuma iniciativa de gestão específica para gerir adequadamente os RSU desta Unidade.

Ademais, o desperdício de alimentos é o principal fator influenciador na geração de RSU do CCNT. O mesmo cenário também foi observado por Adeniran et al. (2017) no Campus da Unilag Akoka da Universidade de Lagos, na Nigéria, e por Marques et al. (2017), que destacam a coleta seletiva para resíduos orgânicos como gerenciamento indispensável na gestão dos RSU em Instituições de Ensino Superior.

A Figura 7 apresenta a composição gravimétrica dos RSU das Unidades CCPP, Almoxarifado, Arquivo/Patrimônio e EDUEPA/Confúcio. O CCPP foi a Unidade que apresentou maior geração para a categoria resíduos orgânicos (43\%). Nas Unidades Almoxarifado, Arquivo/Patrimônio e EDUEPA/Confúcio foram observadas significativas gerações de papel 46\%, $59 \%$ e $67 \%$, respectivamente. Estas Unidades são diretamente ligadas a Reitoria e utilizam papel em suas atividades e processos administrativos. 
Figura 7. Composição gravimétrica das Unidades CCPP, Almoxarifado, Arquivo/Patrimônio e EDUEPA/Confúcio da Universidade do Estado do Pará.

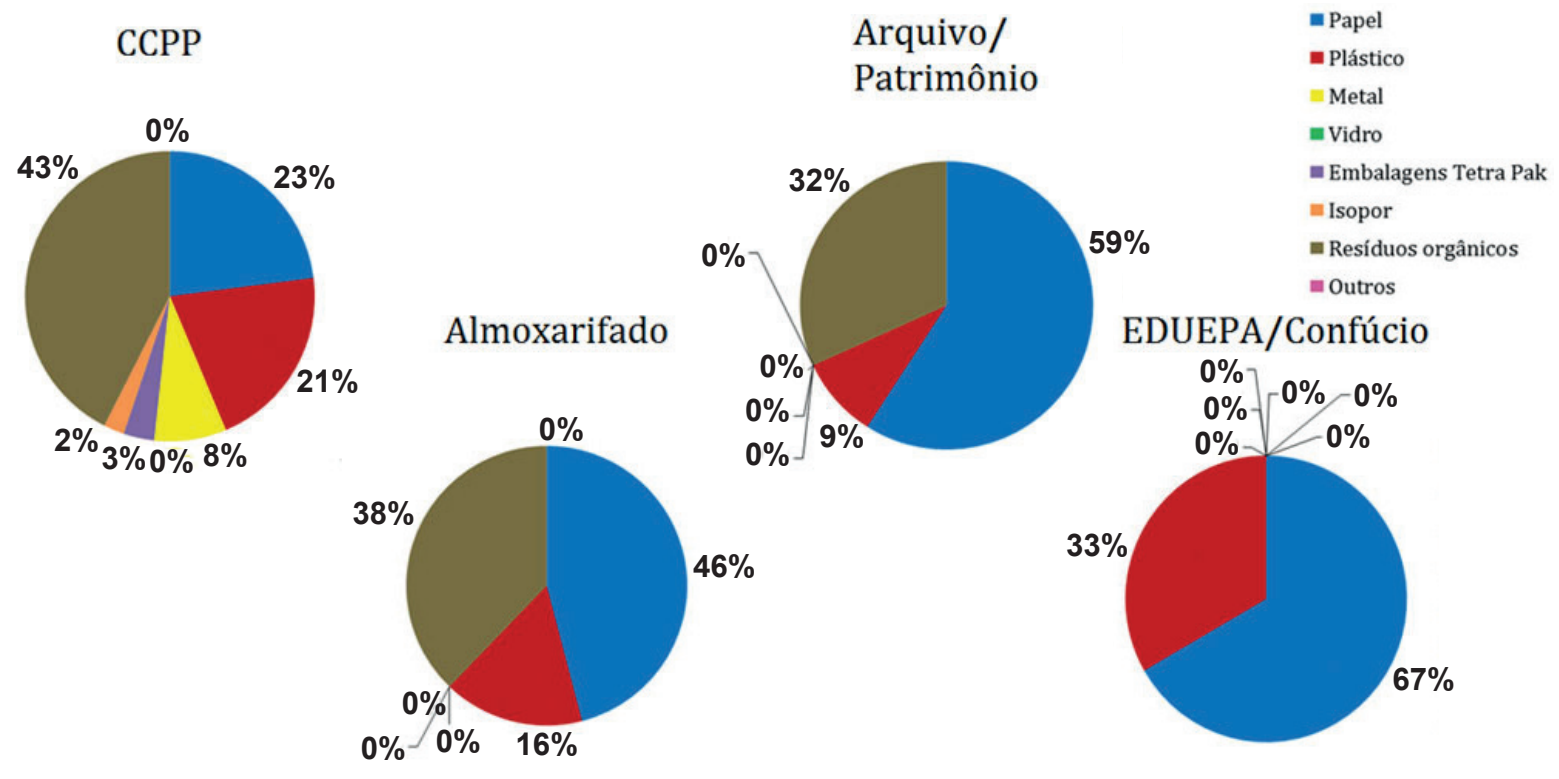

O Almoxarifado e o Arquivo/Patrimônio possuem um fluxo contínuo de recebimento e despacho de bens patrimoniais da UEPA e este fluxo gera uma expressiva quantia de embalagens de material plástico e papel. Essas embalagens geralmente apresentam um volume elevado, necessitando de um acondicionamento dimensionado para esses tipos de resíduos sólidos. Araújo e Viana (20I2) observaram 56,85\% de geração de papel em áreas administrativas da Escola de Artes, Ciências e Humanidades (EACH) da USP. Silva et al. (2018) observaram I7\% para papel e plástico na composição gravimétrica da subprefeitura e patrimônio do Centro de Ciências e Tecnologia Agroalimentar da UFCG.

A EDUEPA/Confúcio foi a Unidade que apresentou melhores resultados em geração de RSU (Tabela 2), geração per capita (Figura 3) e composição gravimétrica, sendo observada apenas a geração de papel e plástico (Figura 7). Nesta Unidade, além da Editora da UEPA, é realizado um curso de idioma em língua chinesa e ações do Instituto Confúcio, fruto de um convênio entre a UEPA e a Shandong Normal University, da China. Apesar do fluxo de alunos ser elevado devida às atividades do Instituto, a geração de RSU nesta Unidade é baixa.

O CCPP apresentou um valor expressivo para metal (8\%) devido ao consumo de bebidas em latas de alumínio por estudantes da educação básica que visitam a Unidade diariamente. Além disso, plástico, papel e resíduos orgânicos também são gerados por consequência dessas visitas. $O$ CCPP é uma importante Unidade da UEPA que oferece atividades em ciência e tecnologia para o público externo. No ano de 2018 foram realizadas 8.749 sessões escolares e 4.535 sessões públicas na Unidade, o que demonstra a necessidade de uma gestão de RSU adequada por conta dessa demanda externa. 


\subsection{Potencial de reciclagem para as categorias de RSU}

O Quadro 3 apresenta o potencial de reciclagem para as diferentes categorias de RSU gerados na UEPA. As categorias papel, plástico, metal e embalagens Tetra Pak apresentam potencial de reciclagem na Região Metropolitana de Belém - PA.

Quadro 3. Potencial de reciclagem para as diferentes categorias de RSU gerados na UEPA.

\begin{tabular}{|c|c|c|c|}
\hline \multirow[b]{2}{*}{ Categoria } & \multicolumn{3}{|c|}{ Classificação do Potencial de Reciclagem } \\
\hline & I & 2 & 3 \\
\hline Papel & $\Delta$ & & \\
\hline Plástico & $\Delta$ & & \\
\hline Metal & $\Delta$ & & \\
\hline Vidro & & $\Delta$ & \\
\hline Embalagens Tetra Pak & $\Delta$ & & \\
\hline Isopor & & & $\Delta$ \\
\hline Resíduos orgânicos & & $\boldsymbol{\Delta}$ & \\
\hline Resíduos de podas & & $\boldsymbol{\Delta}$ & \\
\hline Rejeitos & & & $\Delta$ \\
\hline Outros & & & $\Delta$ \\
\hline
\end{tabular}

*I:Resíduos recicláveis com mercado de reciclagem na região; 2:Resíduos recicláveis sem mercado de reciclagem na região; 3:Resíduos não recicláveis. Fonte:Adapatado de De Vega et al. (2008) e Adeniran et al. (2017).

Visto que esses RSU apresentaram geração significativa em todas as Unidades da UEPA, medidas de doação desses resíduos sólidos para cooperativas ou associações de catadores de materiais recicláveis devem ser adotadas na gestão dos RSU da Universidade como previsto na Lei n. I2.305/20I0.

Contudo, as categorias recicláveis sem mercado podem ser utilizadas em ações de reaproveitamento para atividades de ensino, pesquisa e extensão dentro e fora da IES (TAUCHEN, BRANDLI, 2006). Resíduos orgânicos e resíduos de podas podem ser utilizados em projetos de compostagem para geração de adubos orgânicos (PERUCHIN et al., 2013). Rejeitos e outros resíduos devem ser encaminhados ao aterro sanitário da região através da coleta pública municipal (DEVEGA et al., 2008).

\section{CONSIDERAÇÕES FINAIS}

O Diagnóstico da gestão de RSU demonstrou que todas as Unidades da Universidade do Estado do Pará apresentaram significativa geração diária de RSU nas diferentes categorias e uma geração per capita elevada na maioria das Unidades. Considerando outras IES no Brasil e no mundo, a UEPA não apresenta uma geração diária de RSU tão expressivo, entretanto, sua contribuição de RSU a ser disposto no aterro sanitário da região, contribui significativamente para gerar impactos socioambientais negativos na região.

Todas as Unidades da UEPA apresentam geração de RSU recicláveis com cooperativas e associações de catadores de materiais recicláveis presentes na região que os recebem. Resíduos orgânicos apresentam metade da geração de RSU da UEPA e seu gerenciamento adequado deve ser considerado dentro da gestão de RS da Universidade. 


\section{CAPÍTULO 3}

DIAGNÓSTICO DA GESTÃO DE RESIIDUOS DE EQUIPAMENTOS ELETROELETRÔNICOS DA UEPA

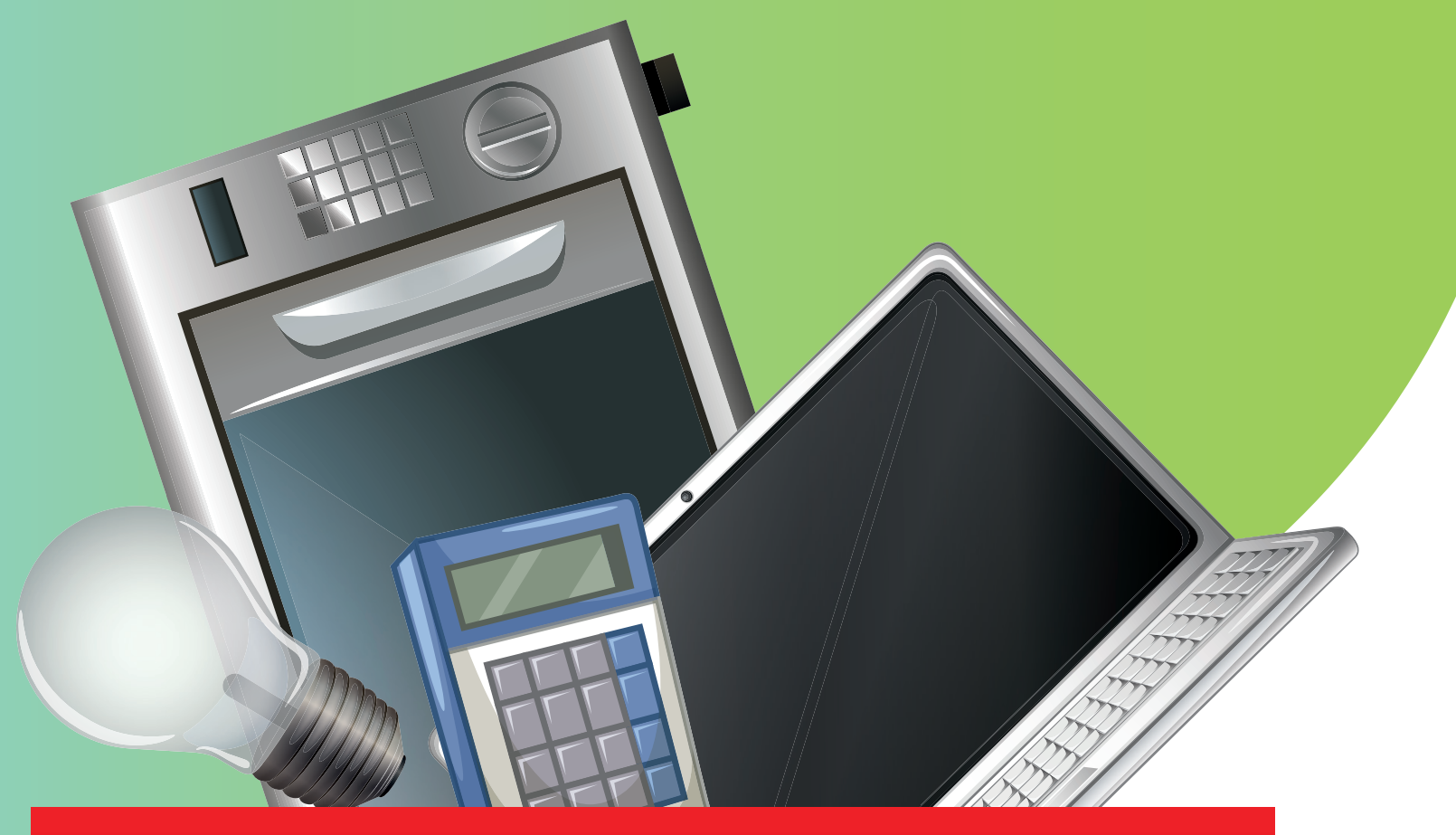




\section{INTRODUÇÃO}

A geração de resíduos de equipamentos eletroeletrônicos (REEE) é considerada como a categoria de resíduos sólidos que mais cresce no mundo, com uma taxa de 3 a $5 \%$ ao ano (ILANKOON et al., 20 I8). O relatório The Global E-waste Monitor - 20I7, publicado pela United Nations University (UNU), International Telecommunication Union (ITU) e International Solid Waste Association (ISWA), aponta que no ano de 2016 foram gerados 44,7 milhões de toneladas de REEE em todo o mundo e faz uma projeção de geração de 52,2 milhões de toneladas para 202 I (BALDÉ et al., 2017).

Os REEE também conhecidos por resíduos eletrônicos, lixo eletrônico ou lixo tecnológico, correspondem a equipamentos elétricos e eletrônicos que, após o fim da vida útil para o consumidor, tornam-se inservíveis (WATANABE et al., 2019). A Diretiva 19/20I2/EU da União Europeia (Directive 2012/19/EU-WEEE) classifica os REEE em 10 diferentes categorias. Dentre elas pode-se destacar os grandes e pequenos eletrodomésticos, como condicionadores de ar e televisores; equipamentos de informática e comunicação como telefones, computadores e impressoras; equipamentos de iluminação como lâmpadas fluorescentes ou Light Emitting Diode (LED); e equipamentos de consumo como pilhas, baterias e toner de impressão (GOLLAKOTA et al., 2020).

No Brasil, a Política Nacional de Resíduos Sólidos dispõe sobre a gestão integrada e gerenciamento dos REEE (BRASIL, 20I0). Demajorovic et al. (2016) ressaltam o caráter inovador PNRS, fazendo destaque para:

- Responsabilidade Compartilhada pelo Ciclo de Vida dos produtos;

- Logística Reversa;

- Acordos Setoriais;

- Promoção do conceito de "ecoeficiência”.

A PNRS direciona os processos de produção, incentivando a menor geração de resíduos, e que os mesmos sejam passíveis de tratamento, reciclagem, reutilização e recuperação.

A Associação Brasileira de Normas Técnicas (ABNT) classifica os REEE como resíduos perigosos em sua Norma Brasileira Regulamentadora (ABNT/NBR 10.004/2004). Os REEE são definidos como Classe I, ou seja, são resíduos que, em função de suas características intrínsecas de inflamabilidade, corrosividade, reatividade, toxicidade ou patogenicidade, apresentam riscos à saúde pública, ou ainda provocam impactos negativos ao meio ambiente quando gerenciados de forma inadequada.

Essas características dependem da composição dos REEE, que é variada e depende do tipo de produto que foi gerado, podendo ser definida por substância químicas, hidrocarbonetos e majoritariamente por metais. Entre as substâncias mais presentes e de maior impacto à saúde humana e ao meio ambiente, estão os metais pesados que podem representar até $\mathbf{7 0 \%}$ da composição total dos REEE. Substâncias como chumbo $(\mathrm{Pb})$ e mercúrio $(\mathrm{Hg})$, geralmente encontrados em lâmpadas e baterias, podendo gerar significativos problemas de saúde pública como danos ao 
cérebro, sistema nervoso, rins e sistema reprodutor (PORTO et al., 2020; OLIVEIRA et al., 20I7; KIDDEE et al., 20I3).

Nesse sentido, o gerenciamento adequado dos REEE é de extrema importância, não apenas pela sua periculosidade, mas também pelo seu significativo potencial para a reciclagem e valor econômico (ILANKOON et al., 2018). Compreender as diferentes formas de gerenciamento dos REEE é essencial para uma gestão integrada e eficiente desses resíduos em contextos urbanos. No entanto, o diagnóstico do fluxo de REEE é complexo devido à sua geração difusa e dependência do comportamento do consumidor (RODRIGUES et al., 2020;ABBONDANZA et al., 2019).

Em Instituições de Ensino Superior, a geração de REEE é significativamente elevada (WATANABE et al., 2019). Panizzon et al. (2017) evidenciaram diversas dificuldades no que tange à gestão de REEE em IES. Uma delas é a grande diversidade de equipamentos utilizados nesse tipo de instituição, visto que estão envolvidos laboratórios de ensino e pesquisa, além de atividades administrativas, e até mesmo áreas da saúde como hospitais, laboratórios de análise, farmácias, escolas e ambulatórios.

Com isso, a PNRS em seu Art. $33^{\circ}$ estabelece que os REEE e seus componentes deverão, após sua fruição, retornar à origem através de mecanismos de Logística Reversa (LR), de maneira independente dos serviços públicos de limpeza urbana e disposição de resíduos (DEMAJOROVIC et al., 2016). A LR é definida como um instrumento de desenvolvimento econômico e social caracterizado por um conjunto de ações, procedimentos e meios destinados a viabilizar a coleta e a restituição dos resíduos sólidos ao setor empresarial, para reaproveitamento, em seu ciclo ou em outros ciclos produtivos, ou outra destinação final ambientalmente adequada (BRASIL, 20I0).

O desafio em aplicar a logística reversa está no gerenciamento dos REEE, onde em muitas IES é inexistente (GOLLAKOTA et al., 2020; SILVA et al., 2019). Neste contexto, investigar os procedimentos que são realizados por gestores das instituições é necessário para diagnosticar a gestão que está sendo adotada (PORTO et al., 2020;ABBONDANZA et al, 2019).

A segregação dos REEE na fonte geradora, sua caracterização (quali-quantitativa) e identificação de origem, são etapas cruciais para o sucesso de uma gestão integrada (GOMES et al., 20।7). Diante disso, este Capítulo apresenta o diagnóstico da gestão de REEE da UEPA na Capital.

\section{METODOLOGIA}

\section{I Coleta e análise de dados}

Os procedimentos metodológicos foram aplicados nas seguintes Unidades da UEPA: CCSE, CCBS - Campus II, CCBS - Ed. Física, CCBS - Enfermagem, CCNT e CCPP, seguindo a mesma estrutura física da Universidade descrita no Capítulo 2.

A metodologia foi desenvolvida em 2 (duas) etapas. A primeira etapa consistiu no método de Estudo da Arte sobre REEE como descrito em Watanabe et al. (2019) levando em consideração a literatura nacional e internacional. 
A partir disso, foram definidas e analisadas 5 categorias de REEE baseadas na classificação da Directive 2012/19/EU-WEEE (Quadro 4).

Quadro 4. Descrição dos tipos de REEE de cada categoria e sua respectiva vida útil (anos) adotada.

\begin{tabular}{|c|c|c|}
\hline Categoria & Tipo de REEE & $\begin{array}{l}\text { Vida útil } \\
\text { (anos) }\end{array}$ \\
\hline Grandes eletrodomésticos & $\begin{array}{l}\text { Aparelhos de ar condicionado; Geladeiras; Congeladores; } \\
\text { Micro-ondas. }\end{array}$ & $\mathrm{II}, 0$ \\
\hline Pequenos eletrodomésticos & $\begin{array}{l}\text { Aparelhos de limpeza; Máquinas de café; Equipamentos para } \\
\text { medir, indicar ou registrar o tempo. }\end{array}$ & 7,0 \\
\hline $\begin{array}{l}\text { Equipamentos de informática e } \\
\text { telecomunicações }\end{array}$ & $\begin{array}{c}\text { Computadores pessoais (CPU, mouse, tela e teclado); Note- } \\
\text { book; Impressoras; Calculadoras; Telefones; Celulares; Equipa- } \\
\text { mentos de transmissão de som, imagens ou outras informações } \\
\text { por telecomunicações. }\end{array}$ & 5,0 \\
\hline Equipamentos de consumo & Toner e cartuchos para impressão, pilhas, baterias. & 0,6 \\
\hline Equipamentos de iluminação & Lâmpadas fluorescentes retas e compactas, lâmpadas LED. & 8,6 \\
\hline
\end{tabular}

Fonte:Adaptado de Gollakota et al. (2020); Panizzon et al. (2017).

A segunda etapa possui um caráter exploratório de campo de acordo com Prodanov e Freitas (20I3). Foi utilizado como método a coleta de dados realizada através de visitas técnicas em todas as Unidades da UEPA.A visita foi conduzida pela Coordenação Administrativa (CAD) para demonstração das formas de gerenciamento dos REEE que são adotadas nas Unidades.

Um formulário técnico semiestruturado foi elaborado com base em Castro at al. (2017), Faria (20I5), Ventura (20I8), Monteiro (20I7) e Monteiro (200I) e aplicado junto aos CAD propondo identificar a atual forma de gerenciamento dos REEE em cada Unidade da UEPA (LEOPOLDINO et al., 2019).

O formulário buscou interpretar o gerenciamento interno e externo adotado pelas Unidades levando em consideração:

- O acondicionamento;

- Identificação;

- Armazenamento;

- Coleta e transporte externo;

- Logística reversa;

- Destinação final tendo como base a Lei n. 12.305/2010.

Ainda foram investigadas as principais dificuldades que os coordenadores das Unidades possuem referente ao gerenciamento adequado dos REEE (GOMES et al., 20I7). 


\section{RESULTADOS E DISCUSSÃO}

A Universidade do Estado do Pará não possui logística reversa para os REEE gerados em suas Unidades e cada uma delas possui formas distintas de gerenciamento para cada tipo de resíduos. Constatou-se que os REEE gerados com maior frequência são:

- Equipamentos de consumo;

- Equipamentos de iluminação e;

-Equipamentos de informática e telecomunicações.

Agamuthu et al. (20I5) ressaltam que IES geram diferentes tipos de equipamentos eletroeletrônicos, isso inclui uma geração a curto período de toner para impressão, lâmpadas, pilhas, baterias usados principalmente em atividades administrativas, iluminação dos espaços e em equipamentos de laboratório.

\section{I Equipamentos de consumo}

Dentro os tipos de resíduos mais gerados por esta categoria, destacam-se os cartuchos e toner de impressão.A aquisição de cartuchos pelas Unidades da UEPA ocorre através de solicitação e cabe ao Almoxarifado Central da UEPA distribuir, mensalmente ou trimestralmente, esses equipamentos de consumo para todas as Unidades. A quantidade do material distribuído varia de 2 (dois) a 5 (cinco) cartuchos para cada modelo de impressora existente na Unidade. $O$ descarte dos cartuchos ocorre devido ao final da vida útil, ou seja, quando a tinta ou toner chega ao fim e não é possível carregá-los para reutilização.

A quantidade de resíduos de cartuchos descartados varia de 4 (quatro) a até 20 (vinte) equipamentos por Unidade da UEPA. No CCNT e CCBS - Ed. Física a geração desses resíduos é mensal. Contudo, nas Unidades CCBS - Campus II, CCBS - Enfermagem e CCPP a geração ocorre aproximadamente entre 3 (três) a 4 (quatro) meses. Nas Unidades CCSE e Reitoria não é registrada a frequência de geração deste resíduo (Quadro 5).

Quadro 5. Procedimentos de gerenciamento de Equipamentos de consumo (cartuchos/toner de impressão) realizados nas Unidades da UEPA.

\begin{tabular}{|c|c|c|c|c|c|c|}
\hline $\begin{array}{c}\text { Unidades } \\
\text { da UEPA }\end{array}$ & $\begin{array}{c}\text { Acondiciona- } \\
\text { mento }\end{array}$ & $\begin{array}{c}\text { Identifica- } \\
\text { ção }\end{array}$ & $\begin{array}{c}\text { Armazena- } \\
\text { mento }\end{array}$ & $\begin{array}{c}\text { Coleta e trans- } \\
\text { porte externos }\end{array}$ & $\begin{array}{c}\text { Destinação } \\
\text { Final }\end{array}$ & $\begin{array}{c}\text { Dificulda- } \\
\text { des }\end{array}$ \\
\hline CCSE & Caixa do cartucho & $\begin{array}{c}\text { Identificação } \\
\text { da caixa do } \\
\text { cartucho }\end{array}$ & $\begin{array}{c}\text { Almoxarifado da } \\
\text { Unidade }\end{array}$ & Patrimônio & $\begin{array}{c}\text { Almoxarifado } \\
\text { central }\end{array}$ & Não há \\
\hline $\begin{array}{c}\text { CCBS - } \\
\text { Campus II }\end{array}$ & Caixa do cartucho & $\begin{array}{c}\text { Identificação } \\
\text { da caixa do } \\
\text { cartucho }\end{array}$ & Sala da CAD & Patrimônio & $\begin{array}{c}\text { Almoxarifado } \\
\text { central }\end{array}$ & Não há \\
\hline CCBS - & Não ocorre & Não ocorre & Não ocorre & Não ocorre & $\begin{array}{c}\text { Não é en- } \\
\text { viado para o } \\
\text { patrimônio }\end{array}$ & $\begin{array}{c}\text { Logística } \\
\text { reversa }\end{array}$ \\
Ed. Física & \multicolumn{1}{|c|}{} \\
\hline
\end{tabular}




\begin{tabular}{|c|c|c|c|c|c|c|}
\hline CCBS - & Caixa do cartucho & $\begin{array}{c}\text { Identificação } \\
\text { da caixa do } \\
\text { cartucho }\end{array}$ & $\begin{array}{c}\text { Sala de informá- } \\
\text { tica }\end{array}$ & Patrimônio & $\begin{array}{c}\text { Almoxarifado } \\
\text { central }\end{array}$ & $\begin{array}{c}\text { Logística } \\
\text { reversa }\end{array}$ \\
\hline CCNT & Caixa do cartucho & $\begin{array}{c}\text { Identificação } \\
\text { da caixa do } \\
\text { cartucho }\end{array}$ & Sala improvisada & Patrimônio & $\begin{array}{c}\text { Almoxarifado } \\
\text { central }\end{array}$ & Não há \\
\hline CCPP & Caixa do cartucho & $\begin{array}{c}\text { Identificação } \\
\text { da caixa do } \\
\text { cartucho }\end{array}$ & Armário & Patrimônio & $\begin{array}{c}\text { Almoxarifado } \\
\text { central }\end{array}$ & Não há \\
\hline
\end{tabular}

A recomendação feita pelo Almoxarifado Central da UEPA é que, com o fim da vida útil, os cartuchos e toners devem ser acondicionados em caixas de papelão e armazenados temporariamente dentro das Unidades até destinação ambientalmente adequada. Contudo, foram observados descarte de toner juntamente aos resíduos sólidos urbanos em todas as Unidades visitadas, considerado inadequado pela PNRS.

Segundo Huang e Sartori (20I2), o armazenamento dos cartuchos de toners devem ocorrer de forma que não haja o contato direto com o pó de toner. Esse tipo de resíduo deve ser armazenados no invólucro aluminizado original ou clipe de proteção, longe de umidade, temperaturas elevadas e livre de quedas, a fim de evitar rachaduras nos cartuchos e possível vazamento de pó. Contudo, esses procedimentos de armazenamento não foram observados nas Unidades da UEPA.

Lourenço et al. (2019), ao analisarem os resíduos perigosos gerados em uma Instituição de Ensino Superior em Pelotas (RS), constataram que o acondicionamento temporário do pó de toner excedente é realizado em sacos plásticos alocados em caixas de papelão sobre uma mesa, para posterior destinação através de logística reversa. Na Universidade Federal do Pará (UFPA), Faria et al. (20I5) identificaram que os REEE não possuem uma gestão adequada, cenário similar ao observado na UEPA.

Na ausência de sistemas de logística reversa, Cirotto e Líbano (2019) enfatizam que as principais formas de reaproveitar toners e cartuchos de impressora são a recarga e a remanufatura, ressaltando que um cartucho pode ser recarregado até três vezes em sua vida útil e esse processo exige cuidado com o manuseio da tinta ou toner remanescente do cartucho para que não ocorra a contaminação de outros objetos, uma vez que o processo de descontaminação é de alto custo.

Segundo Santos (2019), a resina polimérica utilizada na produção do pó de toner é um copolímero de estireno e butadieno, sendo os componentes mais comuns relatados no pó de toner, resinas, cera, óxido de ferro (III), negro de fumo, pigmentos e metais de transição incluindo óxidos de Manganês (Mn), Níquel (Ni), Cromo (Cr) e Titânio (Ti), podem apresentar ainda os mais variados tipos de substâncias, incluindo Silício (Si) amorfo, dióxido de titânio, óxido de ferro III (Fe2O3), bem como Manganês ( $\mathrm{Mn})$, Ferro (Fe) e Cobre ( $\mathrm{Cu}$ ). Nesse contexto, é extremamente necessário o gerenciamento e a destinação final ambientalmente adequada deste tipo de REEE.

As pilhas e baterias utilizadas nas Unidades da UEPA são adquiridas de acordo com a demanda de cada Unidade através de recurso próprio (suprimento de fundo). Este procedimento é realizado por todas as Unidades da Universidade, havendo aquisição e armazenamento de excedentes. Os resíduos de pilhas e baterias são gerados quando há o fim da vida útil e substituição desses produtos. 
Nenhuma Unidade da UEPA possui logística reversa para destinar adequadamente de pilhas e baterias. O CCSE e CCBS - Campus II realizam acondicionamento dos resíduos de pilhas em caixas de papelão ou recipientes de plástico, posteriormente são armazenadas na sala da CAD até dispor de uma destinação ambientalmente adequada. Nas Unidades do CCBS - Ed. Física, CCBS -Enfermagem e CCNT, a geração ocorre sem gerenciamento adequado, havendo descarte junto aos RSU. O CCPP é a única Unidade da UEPA onde se observou a destinação das pilhas e baterias para coleta seletiva de uma Rede de Supermercados que recebe esse tipo de resíduos, contudo, as formas de tratamento realizadas por esta Rede são desconhecidas (Quadro 6).

Quadro 6. Procedimentos de gerenciamento de Equipamentos de consumo (pilhas e baterias) realizados nas Unidades da UEPA.

\begin{tabular}{|c|c|c|c|c|c|c|}
\hline $\begin{array}{c}\text { Unidade } \\
\text { da UEPA }\end{array}$ & $\begin{array}{c}\text { Acondiciona- } \\
\text { mento }\end{array}$ & $\begin{array}{c}\text { Identifica- } \\
\text { ção }\end{array}$ & $\begin{array}{c}\text { Armazena- } \\
\text { mento }\end{array}$ & $\begin{array}{c}\text { Coleta e } \\
\text { transporte } \\
\text { externos }\end{array}$ & $\begin{array}{c}\text { Destinação } \\
\text { Final }\end{array}$ & $\begin{array}{c}\text { Dificulda- } \\
\text { des }\end{array}$ \\
\hline CCSE & Caixa de papelão & $\begin{array}{c}\text { Sem } \\
\text { identificação }\end{array}$ & Sala da CAD & Não ocorre & Ainda não há & Não há \\
\hline $\begin{array}{c}\text { CCBS - } \\
\text { Campus II }\end{array}$ & Gaveta & $\begin{array}{c}\text { Sem } \\
\text { identificação }\end{array}$ & Sala da CAD & Não ocorre & Ainda não há & $\begin{array}{c}\text { Destinação } \\
\text { correta }\end{array}$ \\
\hline $\begin{array}{c}\text { CCBS - } \\
\text { Ed. Física }\end{array}$ & Não ocorre & Não ocorre & Não ocorre & Coleta pública & $\begin{array}{c}\text { Aterro } \\
\text { sanitário }\end{array}$ & $\begin{array}{c}\text { Logística } \\
\text { reversa }\end{array}$ \\
\hline $\begin{array}{c}\text { CCBS - } \\
\text { Enfermagem }\end{array}$ & Não ocorre & $\begin{array}{c}\text { Sem } \\
\text { identificação }\end{array}$ & Não ocorre & Coleta pública & $\begin{array}{c}\text { Aterro } \\
\text { sanitário }\end{array}$ & $\begin{array}{c}\text { Destinação } \\
\text { correta }\end{array}$ \\
\hline CCNT & Caixa de papelão & $\begin{array}{c}\text { Sem } \\
\text { identificação }\end{array}$ & Sala da CAD & $\begin{array}{c}\text { Acondicio- } \\
\text { namento e de } \\
\text { coleta externo }\end{array}$ & $\begin{array}{c}\text { Reciclagem } \\
\text { correta }\end{array}$ \\
\hline CCPP & Caixa de plástico & $\begin{array}{c}\text { Sem } \\
\text { identificação }\end{array}$ & Sala da CAD & $\begin{array}{c}\text { Ponto de } \\
\text { coleta externo }\end{array}$ & Reciclagem & Não há \\
\hline
\end{tabular}

A principal dificuldade no gerenciamento de pilhas e baterias declaradas pelas Unidades da UEPA é a destinação ambientalmente adequada. Como ressaltado, esses resíduos são considerados perigosos, e quando descartados inadequadamente podem gerar contaminação do meio ambiente e problemas de saúde (CONTE, 2016).

A Resolução CONAMA n 40I/2008 (anteriormente CONAMA n²57), classifica pilhas e eletrodos, determinando limites máximos de metais pesados e os critérios e padrões para o gerenciamento ambientalmente adequado dos diversos tipos de pilhas e baterias.

Por conter substâncias químicas tóxicas nocivas à saúde, pilhas e baterias pós-consumo devem ser acondicionadas em embalagens impermeáveis, como sacolas plásticas e depositadas em Pontos de Entrega Voluntária (PEVs), caso exista. Deve-se evitar que haja perfurações nas embalagens e exposição ao calor excessivo. Em caso de vazamentos, deve-se evitar contato da substância com a pele (XAVIER et al., 20I8).

A Instrução Normativa (IN) No 8 de 03/09/2012 do Instituto Brasileiro do Meio Ambiente e dos Recursos Naturais Renováveis (IBAMA), que regulamenta a Resolução CONAMA n 40I, define em seuArt. 10 que pilhas e baterias usadas ou inservíveis devem ser acondicionadas de forma a evitar vazamentos e contaminação do meio ambiente ou risco à saúde humana, portanto, devem ser gerenciadas separadamente do resíduo sólidos urbanos. 


\subsection{Equipamentos de iluminação}

Dentre os tipos de REEE, com geração mais significativa na categoria equipamentos de iluminação, estão às lâmpadas fluorescentes e Light Emitting Diode (LED). Esses equipamentos de iluminação são adquiridos pelas Coordenações Administrativas (CAD) das Unidades através de recurso próprio (suprimento de fundo) de acordo com a demanda interna. As lâmpadas LED são as mais utilizadas por todas as Unidades devido ao baixo consumo de energia elétrica.

As lâmpadas fluorescentes são raramente adquiridas pelas Unidades. Foram encontrados uma média de 10 (dez) lâmpadas fluorescentes, sem vida útil, no CCSE e CCBS - Enfermagem. Essas Unidades acondicionam as lâmpadas em caixas de papelão e as armazenam temporariamente em salas (depósitos) até que se encontre destinação ambientalmente correta.

As lâmpadas do tipo LED estão mais presentes nos resíduos de equipamentos de iluminação das Unidades e são substituídas quando chegam ao fim da sua vida útil. Como procedimento de gerenciamento, os resíduos são acondicionados em caixas de papelão ou sacolas plásticas pelas Unidades CCBS - Campus II e CCPP e são armazenadas em salas (depósitos) onde aguardam destinação adequada. Nas Unidades CCSE, CCBS - Ed. Física, CCBS - Enfermagem e CCNT, as lâmpadas são descartadas imediatamente após o fim da vida útil junto aos resíduos sólidos urbanos (Quadro 7).

Quadro 7. Procedimentos de gerenciamento de Equipamentos de iluminação (lâmpadas) realizados nas Unidades da UEPA.

\begin{tabular}{|c|c|c|c|c|c|c|}
\hline $\begin{array}{c}\text { Unidade } \\
\text { da UEPA }\end{array}$ & $\begin{array}{c}\text { Acondiciona- } \\
\text { mento }\end{array}$ & $\begin{array}{c}\text { Identifica- } \\
\text { ção }\end{array}$ & $\begin{array}{c}\text { Armazena- } \\
\text { mento }\end{array}$ & $\begin{array}{c}\text { Coleta e } \\
\text { transporte } \\
\text { externos }\end{array}$ & $\begin{array}{c}\text { Destinação } \\
\text { Final }\end{array}$ & Dificuldades \\
\hline CCSE & Caixas de papelão & Não ocorre & Sala da CAD & Não ocorre & Não há & $\begin{array}{c}\text { Não } \\
\text { informado }\end{array}$ \\
\hline $\begin{array}{c}\text { CCBS - } \\
\text { Campus II }\end{array}$ & Caixas de papelão & Não ocorre & Sala da CAD & Não ocorre & $\begin{array}{c}\text { Não é } \\
\text { destinado }\end{array}$ & $\begin{array}{c}\text { Destinação } \\
\text { correta }\end{array}$ \\
\hline $\begin{array}{c}\text { CCBS - } \\
\text { Ed. Física }\end{array}$ & Não ocorre & Não ocorre & Não ocorre & $\begin{array}{c}\text { Coleta } \\
\text { pública }\end{array}$ & $\begin{array}{c}\text { Aterro } \\
\text { sanitário }\end{array}$ & $\begin{array}{c}\text { Destinação } \\
\text { correta }\end{array}$ \\
\hline $\begin{array}{c}\text { CCBS - } \\
\text { Enfermagem }\end{array}$ & Caixas de papelão & Não ocorre & $\begin{array}{c}\text { Sala de } \\
\text { manutenção }\end{array}$ & $\begin{array}{c}\text { Coleta } \\
\text { pública }\end{array}$ & $\begin{array}{c}\text { Aterro } \\
\text { sanitário }\end{array}$ & $\begin{array}{c}\text { Destinação } \\
\text { correta }\end{array}$ \\
\hline CCNT & Não ocorre & Não ocorre & Não ocorre & $\begin{array}{c}\text { Coleta } \\
\text { pública }\end{array}$ & $\begin{array}{c}\text { Aterro } \\
\text { sanitário }\end{array}$ & $\begin{array}{c}\text { Destinação } \\
\text { correta }\end{array}$ \\
\hline CCPP & Caixas de papelão & Não ocorre & $\begin{array}{c}\text { Sala de } \\
\text { manutenção }\end{array}$ & Não ocorre & $\begin{array}{c}\text { Não é } \\
\text { destinado }\end{array}$ & $\begin{array}{c}\text { Destinação } \\
\text { correta }\end{array}$ \\
\hline
\end{tabular}

De acordo com o Art. 33 da PNRS, os fabricantes, importadores, distribuidores e comerciantes de lâmpadas fluorescentes, de vapor de sódio e mercúrio e de luz mista, entre outros itens são obrigados a estruturar e implementar sistemas de logística reversa, mediante retorno dos produtos após o uso pelo consumidor, de forma independente do serviço público de limpeza urbana e de manejo dos resíduos sólidos.

A Lei $N^{\circ} 10.888 / 200$ I dispõe sobre o descarte final de produtos potencialmente perigosos do resíduo urbano que contenham metais pesados, sendo estes as pilhas, baterias, lâmpadas fluorescentes e frascos de aerossóis em geral. Cabe ao consumidor devolver as lâmpadas após uso, para 
comerciantes ou pontos de coleta, acondicionando-as de forma correta e praticando a responsabilidade compartilhada.

Para a PNRS esses procedimentos configuram em um conjunto de atribuições individualizadas e encadeadas de consumidores para minimizar o volume de resíduos sólidos e rejeitos gerados, bem como para reduzir os impactos decorrentes do ciclo de vida dos produtos, cabendo a todos a responsabilidade pelas lâmpadas com mercúrio, enquanto estiver com a guarda do produto (fabricação, transporte, uso, armazenamento, reciclagem e destinação).

Segundo Monteiro et al. (200I), os procedimentos para o gerenciamento de lâmpadas que contêm mercúrio devem ser realizados por meio de armazenamento das lâmpadas que não estejam quebradas em uma área apropriada, acondicionadas em caixas de papelão, preferencialmente na embalagem original do resíduo.

De acordo com Zavariz (200l), resíduos de lâmpadas quebradas devem ser separados, e acondicionados em recipientes hermeticamente fechados com resistência à pressão e revestidos internamente com saco plástico especial para evitar contaminação com mercúrio no ambiente. O manuseio desses resíduos deve ser realizado com uso de Equipamentos de Proteção Individual (EPI) apropriado e, em caso de quebra acidental das lâmpadas, deve-se providenciar:

- A coleta imediata;

- Limpeza local;

- Abertura de portas e janelas para a circulação do ar;

- Coleta das gotas de mercúrio com seringa (sem agulha) ou folha de papel evitando contato manual com o produto, colocando-as em recipiente de plástico resistente, o qual deverá ser fechado hermeticamente.

Em estudo realizado por Cestari e Martins (20I5) na Universidade Estadual de Maringá (UEM), observou-se que a Instituição armazena suas lâmpadas fluorescentes, após fim da vida útil, em caixas de papelão, até destinar corretamente esses resíduos. Apresentando a mesma forma de gerenciamento de lâmpadas observado nas Unidades CCSE e CCBS - Enfermagem.

Assim como na UEPA, Schoeler et al. (2019) após avaliar o gerenciamento e gestão integrada das lâmpadas em uma Instituição de Ensino Superior (IES) Multicampi no estado do Rio Grande do Sul, constataram que o gerenciamento utilizado pela IES não está em conformidade com as condições ideais de armazenamento de lâmpadas no pós-consumo, pois as lâmpadas não estavam acondicionadas adequadamente, sendo empilhadas sobre caixas de papelão com fitas adesivas e sem a segregação por formato e tipo. 


\subsection{Equipamentos de informática e telecomunicações}

De acordo com a Diretoria de Administração de Recursos Materiais (DARM) da Universidade do Estado do Pará, os Equipamentos de informática e telecomunicações, assim como os Grandes e Pequenos eletrodomésticos são adquiridos através de processos licitatório de acordo com a Instrução Normativa $n^{\circ}$. 01/2010.

Os resíduos de equipamentos de informática e telecomunicações são gerados após o fim da vida útil. Esses resíduos são geralmente armazenados em espaços improvisados (depósitos) dentro das Unidades, abrigados de chuva e outras externalidades. Foram observados casos específicos de transporte de resíduos de equipamentos de informática e telecomunicações para o Almoxarifado Central da Universidade e posterior acondicionamento no local (Quadro 8).

Quadro 8. Procedimentos de gerenciamento de informática e telecomunicações realizado nas Unidades da UEPA.

\begin{tabular}{|c|c|c|c|c|c|c|}
\hline $\begin{array}{c}\text { Unidade } \\
\text { da UEPA }\end{array}$ & $\begin{array}{c}\text { Acondiciona- } \\
\text { mento }\end{array}$ & $\begin{array}{c}\text { Identifica- } \\
\text { ção }\end{array}$ & $\begin{array}{c}\text { Armazena- } \\
\text { mento }\end{array}$ & $\begin{array}{c}\text { Coleta e } \\
\text { transporte } \\
\text { externos }\end{array}$ & $\begin{array}{c}\text { Destinação } \\
\text { Final }\end{array}$ & $\begin{array}{c}\text { Dificulda- } \\
\text { des }\end{array}$ \\
\hline CCSE & Não ocorre & $\begin{array}{c}\text { Sem } \\
\text { identificação }\end{array}$ & Corredores & Patrimônio & $\begin{array}{c}\text { Almoxarifado } \\
\text { central }\end{array}$ & Não há \\
\hline $\begin{array}{c}\text { CCBS - } \\
\text { Campus II }\end{array}$ & Não ocorre & $\begin{array}{c}\text { Sem } \\
\text { identificação }\end{array}$ & $\begin{array}{c}\text { Almoxarifado da } \\
\text { Unidade e locais } \\
\text { abertos }\end{array}$ & Patrimônio & $\begin{array}{c}\text { Almoxarifado } \\
\text { central }\end{array}$ & $\begin{array}{c}\text { Falta de } \\
\text { espaço para } \\
\text { armazenar }\end{array}$ \\
\hline $\begin{array}{c}\text { CCBS - } \\
\text { Ed. Física }\end{array}$ & Não ocorre & Não há & $\begin{array}{c}\text { Lugares impro- } \\
\text { visados na Uni- } \\
\text { dade }\end{array}$ & Patrimônio & $\begin{array}{c}\text { Almoxarifado } \\
\text { central }\end{array}$ & $\begin{array}{c}\text { Burocracias } \\
\text { de bem } \\
\text { público }\end{array}$ \\
\hline $\begin{array}{c}\text { CCBS - } \\
\text { Enfermagem }\end{array}$ & Não ocorre & $\begin{array}{c}\text { Sem } \\
\text { identificação }\end{array}$ & $\begin{array}{c}\text { Protegidos de } \\
\text { chuva e sol ao } \\
\text { lado do almoxa- } \\
\text { rifado da } \\
\text { Unidade }\end{array}$ & Patrimônio & $\begin{array}{c}\text { Almoxarifado } \\
\text { central }\end{array}$ & Não há \\
\hline CCNT & Não ocorre & $\begin{array}{c}\text { Sem } \\
\text { identificação }\end{array}$ & Sala de depósito & Patrimônio & $\begin{array}{c}\text { Almoxarifado } \\
\text { central }\end{array}$ & Coleta \\
\hline CCPP & Não ocorre & $\begin{array}{c}\text { Sem } \\
\text { identificação }\end{array}$ & Sala de depósito & Patrimônio & $\begin{array}{c}\text { Almoxarifado } \\
\text { central }\end{array}$ & Não há \\
\hline
\end{tabular}

Resíduos de equipamentos de informática e telecomunicações são considerados tóxicos e, quando descartado de maneira inadequada, podem gerar impactos negativos ao meio ambiente. Portanto, é fundamental que a indústria produtora de equipamentos eletroeletrônicos, adote juntamente com o consumidor um sistema de logística reversa para tratamento, reaproveitamento e destinação final adequada a cada produto deste tipo resíduo (SANTOS; SILVA; LOUREIRO, 20I5).

A PNRS determina que todos os REEE sejam inseridos em sistema de logística reversa, realizada independentemente do serviço público e do manejo de resíduos sólidos, de forma a viabilizar a coleta e a restituição dos REEE para a indústria (PEREIRA et al., 2017). O Decreto Federal $n^{\circ}$. 99.658/1990 estabelece normas para o desfazimento de bens públicos e possui alterações no Decreto Federal $n^{\circ}$.6.087/2007, o qual emite soluções necessárias para os desfazimentos de equipamentos de informática e telecomunicações garantindo a agilidade no descarte desses resíduos (SANTOS, 2018). 
Paes (20I5), ao analisar a gestão de resíduos de equipamentos de informática e logística reversa na Universidade Federal de Itajubá (UNIFEI), observou que esta categoria é geralmente transportada até o almoxarifado desta IES e armazenada com outros equipamentos inservíveis. Procedimento de gerenciamento similar ao observado na UEPA.

Watanabe et al. (2019) e Santos (2018) concluíram que uma das principais dificuldades encontradas pelas Universidades públicas no gerenciamento de resíduos de equipamentos de informática e telecomunicações é a falta de espaço para armazená-los e a inexistência de uma destinação ambientalmente adequada. Dificuldade similar é observada em todas as Unidades da UEPA.

\section{CONSIDERAÇÕES FINAIS}

O gerenciamento de REEE na UEPA ocorre de diferentes formas, dependendo de cada Unidade. Em algumas, existe a preocupação da gestão local para que o processo ocorra da forma mais correta, efetuando todos os esforços necessários, seja em todas ou apenas algumas categorias dos REEE. $O$ acúmulo de resíduos de equipamentos de informática é uma realidade em todas as Unidades. Resíduos de lâmpadas, pilhas e baterias não são descartados corretamente após a sua vida útil. Possivelmente estes resíduos têm como destino final o aterro sanitário juntamente com os resíduos sólidos urbanos. Ademais a implantação da logística reversa é a principal dificuldade observada para a gestão adequada dos REEE na UEPA. 


\section{CAPÍTULO 4}

DIAGNÓSTICO DA GESTÃO DE RESIIDUOS DE SERVICOS DE SAÚDE DA UEPA

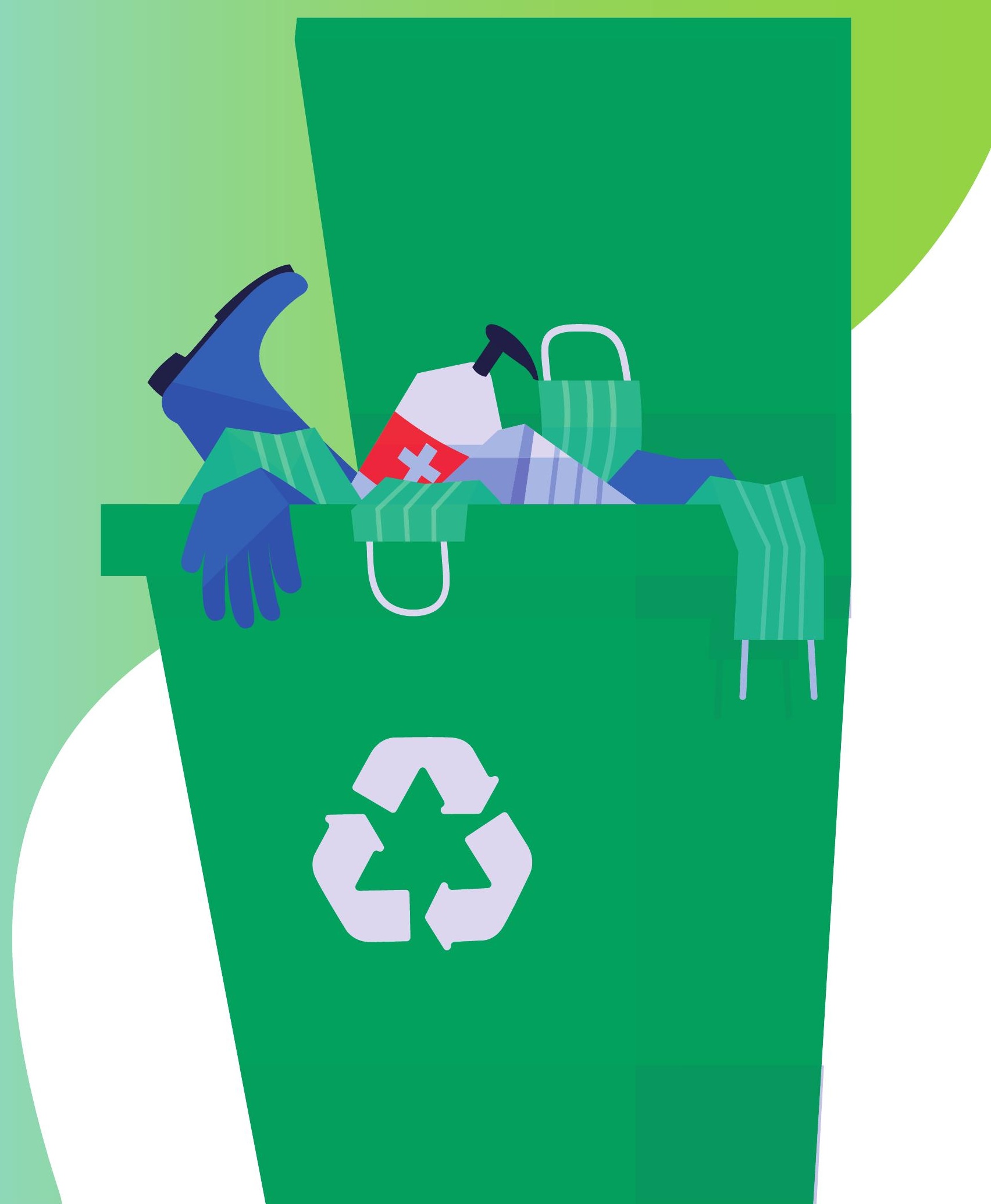




\section{INTRODUÇÃO}

Nos Capítulos 2 e 3, foi discutida a gestão dos RSU e REEE e, além desses grupos de resíduos, destacam-se os resíduos de serviços de saúde (RSS). Os RSS, apesar de representarem cerca de I a $2 \%$ do total global de resíduos sólidos gerados, revelam-se como um importante componente na gestão de resíduos sólidos, em razão da possibilidade de contaminação do ambiente e do risco à saúde pública (UEHARA et al., 2019).

A geração de RSS, embora seja relativamente pequena em relação aos RSU, torna-se representativa quando considerado o potencial de risco que lhes é associado, devido à presença de organismos patogênicos e/ou de suas toxinas, produtos químicos de natureza diversa (fármacos, quimioterápicos, solventes, entre outros), bem como riscos radiológicos (SCHNEIDER, STEDILE, 20I5).

De acordo com Stedile et al. (2018), a problemática dos RSS é decorrente ainda de outros fatores, tais como a mistura de resíduos de natureza diversa, somada às formas inadequadas de gerenciamento desses resíduos. Tais inadequações no gerenciamento dos RSS na sociedade contemporânea comprometem a qualidade de vida da população e a qualidade do meio ambiente, do que resultam riscos à saúde física (doenças infecciosas, degenerativas), à saúde mental (crises de ansiedade, crises de pânico, depressão) e a desintegração social (isolamento social, exacerbação da violência, entre outros).

A Resolução da Diretoria Colegiada (RDC) n 306/2004 da Agência Nacional de Vigilância Sanitária (ANVISA) e a Resolução n 358/2005 do Conselho Nacional de Meio Ambiente (CONAMA) definem os RSS como todo resíduo gerado em qualquer serviço prestador de assistência médica humana ou animal, e classifica-os em cinco grupos (BRASIL, 2004; 2005):

- Grupo A: resíduos com a possível presença de agentes biológicos que, por suas características, podem apresentar risco de infecção;

- Grupo B: resíduos que contêm substâncias químicas que podem apresentar risco à saúde pública ou ao meio ambiente, dependendo de suas características de inflamabilidade, corrosividade, reatividade e toxicidade;

- Grupo C: quaisquer materiais resultantes de atividades humanas que contenham radionuclídeos em quantidades superiores aos limites de isenção especificados nas normas da Comissão Nacional de Energia Nuclear - CNEM e para os quais a reutilização é imprópria ou não-prevista;

- Grupo D: resíduos que não apresentam risco biológico, químico ou radiológico à saúde ou ao meio ambiente, podendo ser equiparados aos resíduos domiciliares;

- Grupo E: materiais perfurocortantes ou escarificantes, todos os utensílios de vidro quebrado no laboratório e outros similares.

Ainda, a RDC n 306/2004 determina que todos os serviços de saúde devem ser gerenciados sob um Plano de Gestão ou Gerenciamento de RSS que se constitui em um conjunto de procedimentos de gestão, planejados e implementados a partir de bases científicas e técnicas, norma- 
tivas e legais, com o objetivo de minimizar a produção de resíduos e proporcionar aos resíduos gerados um encaminhamento seguro, de forma eficiente, visando à proteção dos trabalhadores, à preservação da saúde pública, dos recursos naturais e do meio ambiente (BRASIL, 2004).

Em hospitais e centros universitários de saúde, a geração de RSS ocorre da mesma forma que em outros estabelecimentos públicos e privados de saúde e devem ser adotadas medidas de gerenciamento adequadas. A falta de um efetivo acompanhamento do sistema de gestão, principalmente em centros universitários de saúde que oferecem atividades de ensino e também assistência à população, resulta em um gerenciamento inadequado, podendo contribuir com riscos à saúde dos servidores, estudantes e ao meio ambiente.

Ao estudar a geração de RSS do Hospital Universitário Regional de Maringá (HUM), Nagashima et al. (2007) constataram que o HUM desenvolve um sistema de gerenciamento de RSS indicado pelos procedimentos: segregação na origem e acondicionamento diferenciado de resíduos perfurocortantes, autoclavagem das culturas microbiológicas e resíduos infectantes, acondicionamento diferenciado para resíduos comuns e infectantes e prática de separação de material reciclável, principalmente papel e papelão. Ademais, os autores também observaram que cerca de $53 \%$ dos RSS do HUM são considerados resíduos contaminados (biológicos, químicos e perfurocortantes).

No caso da Universidade do Estado do Pará, na capital encontram-se 4 (quatro) Unidades que oferecem serviços de ensino e assistência em saúde para a população e, consequentemente, geram RSS: CCBS - Campus II; CCBS - Enfermagem, CSE e UEAFTO. Nesse sentido, este Capítulo possui o objetivo de diagnosticar a gestão dos RSS que é realizada nessas Unidades da UEPA.

\section{METODOLOGIA}

\section{I Coleta e Análise de dados}

Este Capítulo possui um perfil metodológico descritivo, exploratório, documental e de abordagem qualitativa. Para a coleta de dados foram realizadas visitas técnicas nas 4 (quatro) Unidades, junto aos CAD locais, para identificar as formas de gerenciamento dos RSS que são adotadas, baseado no método do Instrumento de Avaliação Rápida do Gerenciamento de Resíduos de Serviços de Saúde (Health-Care Waste Management-Rapid Assessment Tool - HCWM-RAT), da Organização Mundial da Saúde (OMS). Para esta investigação, foi utilizada a seção do HCWM-RAT denominada de "Questionários para coletar dados do pessoal dos Estabelecimentos de Saúde (ES)” (SILVA, 20I I).

Foi utilizado um modelo como estratégia de análise das informações para melhor entendimento da gestão de RSS. O modelo utilizado foi o FPSEEA, que é composto pelos elementos: Força Motriz, Pressão, Situação, Exposição, Efeito, Ações. Ele é utilizado como recurso para elaboração de indicadores de saúde ambiental proposto pela OMS, o qual tem sido utilizado como ferramenta no gerenciamento ambiental em todo mundo, passando a ser recomendado também no Brasil pelo Ministério da Saúde. Desde então tem sido utilizado no âmbito dos governos e organizações não governamentais como estratégia de enfrentamento dos problemas ambientais decorrentes 
do modelo de desenvolvimento (STEDILE et al., 20I8; BRASIL, 20I I; OLIVEIRA, FARIA, 20I2).

O objetivo do modelo é fornecer um instrumento para o entendimento das relações abrangentes e complexas entre saúde e ambiente, permitindo analisar os problemas de saúde ambiental em toda sua cadeia causal. Possibilita compreender e mensurar os determinantes ambientais de saúde que contribuem para a nitidez dos processos decisórios voltados para o controle de riscos e formular indicadores que favorecem a integração dos sistemas de informação e a tomada de decisões por profissionais e gestores (OLIVEIRA, FARIA, 20I2).

Ademais, foi solicitado a Assessoria de Planejamento (ASPLAN) do CCBS - Campus II informações documentais acerca da gestão atual dos RSS da Universidade.

\section{RESULTADOS}

O Quadro 9 sintetiza o gerenciamento que é realizado nas Unidades CCBS - Campus II, CCBS - Enfermagem, CSE e UEAFTO. O RSS dos grupos A e E são os mais gerados em todas as Unidades, principalmente no CSE. Os RSS dos grupos B e C não foram identificados. Atualmente a UEPA possui um Contrato de prestação de serviços de coleta, tratamento e destinação final com uma empresa especializada(Contrato n. 006/2016-UEPA) para o gerenciamento externo dos RSS.

Quadro 9. Gerenciamento dos RSS realizados nas Unidades de saúde da UEPA.

\begin{tabular}{|c|c|c|c|c|}
\hline RSS & Segregação & Acondicionamento & $\begin{array}{l}\text { Coleta e armazenamento } \\
\text { interno }\end{array}$ & $\begin{array}{l}\text { Coleta e Trata- } \\
\text { mento externo e } \\
\text { disposição final }\end{array}$ \\
\hline Grupo A & $\begin{array}{l}\text { Lixeiras e sacos bran- } \\
\text { cos identificados com } \\
\text { símbolos }\end{array}$ & $\begin{array}{l}\text { Sacos brancos identi- } \\
\text { ficados com símbolos }\end{array}$ & $\begin{array}{c}\text { Contêiner identificados com } \\
\text { símbolos, de } 270 \text { litros branco } \\
\text { com tampa }\end{array}$ & $\begin{array}{c}\text { Empresa terceirizada } \\
\text { especializada }\end{array}$ \\
\hline Grupo B & Não identificado & Não identificado & Não identificado & - \\
\hline Grupo C & Não identificado & Não identificado & Não identificado & - \\
\hline $\begin{array}{c}\text { Grupo } \\
\text { D }\end{array}$ & Sacos e lixeiras pretas & Sacos pretos & Sem armazenamento interno & Coleta pública \\
\hline Grupo E & $\begin{array}{c}\text { Caixas específicas } \\
\text { para perfurocortantes } \\
\text { (Descatex) }\end{array}$ & $\begin{array}{c}\text { Caixas específicas } \\
\text { para perfurocortantes } \\
\text { (Descatex) }\end{array}$ & $\begin{array}{c}\text { Contêiner identificados com } \\
\text { símbolos, de } 270 \text { litros branco } \\
\text { com tampa }\end{array}$ & $\begin{array}{c}\text { Empresa terceirizada } \\
\text { especializada }\end{array}$ \\
\hline
\end{tabular}

Foram encontrados RSS do grupo A e E acondicionados juntamente aos do grupo D, o que demonstra que a segregação dos RSS não estão sendo realizada de forma adequada pelos servidores das Unidades. O manejo adequado e seguro dos RSS está relacionado com uma identificação adequada dos sacos plásticos e recipientes que acondicionam esses resíduos. Para tanto, estes devem estar identificados de forma que permitam o reconhecimento dos resíduos descartados.

A segregação incorreta pode estar relacionada com a falta de identificação adequada dos sacos plásticos e recipientes que acondicionam os RSS. 
O modelo FPSEEA demonstrou esquematicamente a implicação da geração de RSS para cada elemento. Dado o contexto econômico, social e cultural que produzem pressões no estado de saúde da população, esta pressão resulta em aumento dos atendimentos em serviço de saúde e, consequentemente, na geração de RSS (Quadro 10).

Quadro 10.Aplicação do modelo FPSEEA.

\begin{tabular}{|l|l|}
\hline Força Motriz & Modelo econômico e sistema único de saúde \\
\hline Pressão & Consultas, atendimentos e geração de RSS \\
\hline Situação & Contaminação ambiental, riscos de acidentes laborais e infecções \\
\hline Exposição & População exposta, elementos naturais contaminados e exposição a RSS \\
\hline Efeito & Alterações no estado de saúde \\
\hline Ações & Formular ações para observando cada fase (proposições). \\
\hline
\end{tabular}

Adaptado de Stedile et al. (2018).

Assim, a situação resultante pode ser percebida por meio de contaminação ambiental, de acidentes laborais e de infecções. Esta situação expõe a população a fatores que determinam acometimentos no estado de saúde, elementos naturais contaminados e poluídos, exposição a patógenos e resíduos perigosos. E por fim, o efeito de toda essa rede serão as alterações no estado de saúde, com com o surgimento de doenças que terão impacto na Saúde Pública.

Não foi possível mensurar precisamente a quantidade de RSS que são gerados, contudo a estimativa definida pela ASPLAN/CCBS foi entre 100 ate $700 \mathrm{~kg}$ por mês, somando as 4 (quatro) Unidades da UEPA.

\section{CONIDERAÇÕES FINAIS}

O gerenciamento realizado aos RSS da UEPA é satisfatório, com exceção da segregação dos RSS que são dispostos inadequadamente nos sacos e recipientes. 


\section{CAPÍTULO 5}

PROGNÓSTICO DO

PLANO DE GESTÃO

INTEGRADA DE

RESİDUOS SÓLIDOS

DA UEPA
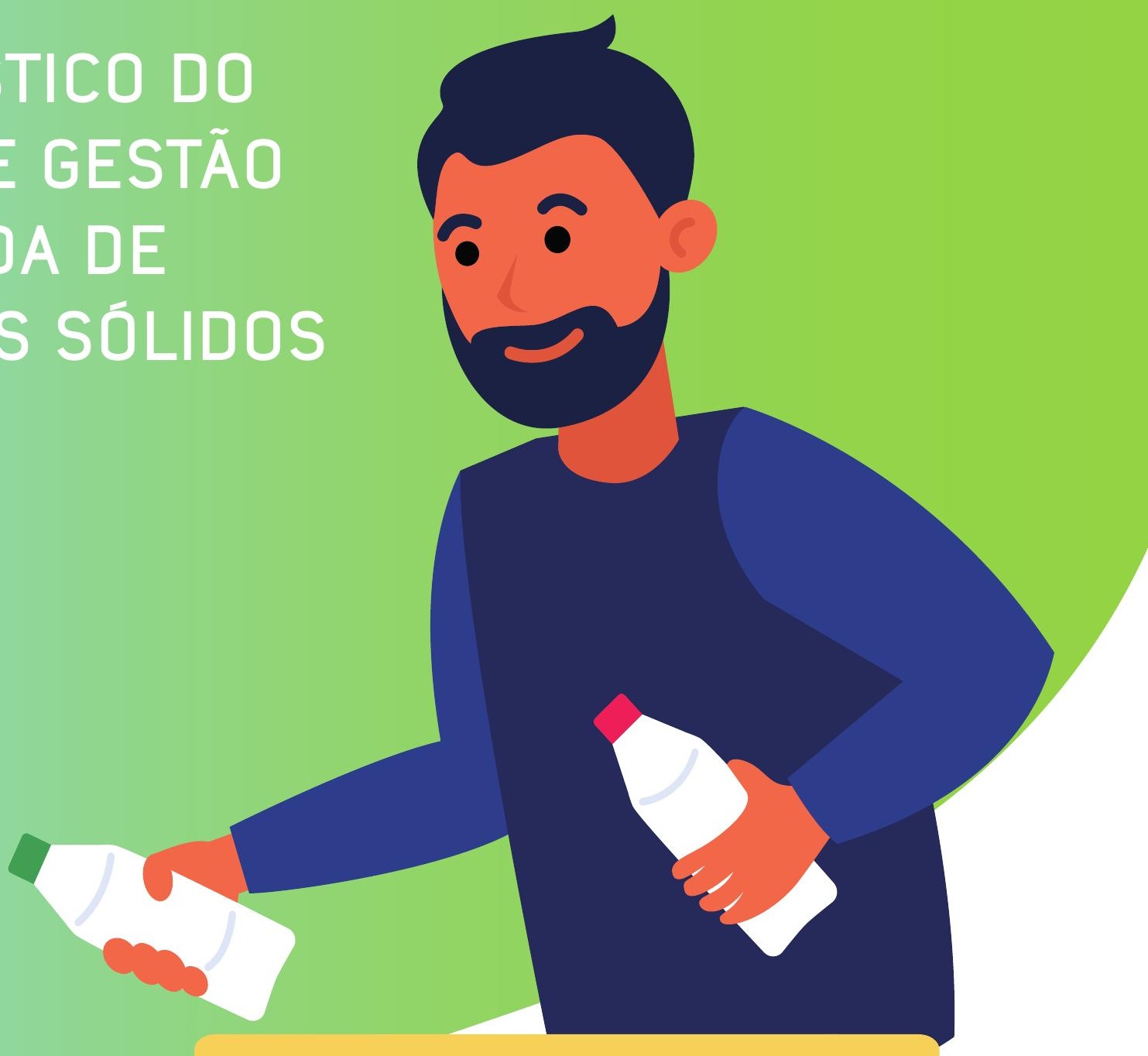


\section{INTRODUÇÃO}

O prognóstico constitui um instrumento de prospecção sobre o comportamento dos elementos definidores dos requisitos de infraestrutura necessários ao planejamento dos sistemas de gerenciamento dos resíduos sólidos (RS) gerados nas Unidades da UEPA na Capital do Estado. De acordo com a PNRS, Lei $n^{\circ} 12.305 / 2010$, o prognóstico deve contemplar a projeção de um cenário futuro que permita orientar o processo de planejamento, identificando as soluções que se adequem ao crescimento físico e institucional da UEPA.

O aumento na geração de RS sofre influência direta do crescimento populacional e da expansão de infraestrutura da Instituição. Nesse sentido, a utilização de modelos matemáticos é necessária para prever cenários futuros, auxiliar na avaliação do atual sistema de gestão e na comparação e escolha de alternativas de mudanças (PAIVA et al., 2019).

As ferramentas e técnicas de projeção podem ser qualitativas ou quantitativas.As qualitativas utilizam a opinião de especialistas e/ou o julgamento pessoal, enquanto que as quantitativas tomam como base os modelos matemáticos. Estes modelos podem ser usados, por exemplo, para estimar o crescimento populacional de cada Unidade ou projetar a geração per capita de RS em longo prazo (YOUNES et al., 2016).

Estruturas e abordagens de modelagem estão se tornando cada vez mais aplicadas no mundo todo. Essas aplicações garantem uma representação mais precisa dos sistemas de gestão de RS, principalmente os RSU, em situações onde muitos fluxos de resíduos devem ser considerados por diferentes fontes e em várias escalas do tempo, envolvendo várias formas possíveis de gerenciamento dentre coleta, acondicionamento temporário, transporte e tratamento (LEVIS et al., 2013).

Nesse sentido, o planejamento e a gestão adequada dos resíduos sólidos são afetados pela avaliação dos fluxos de RSU e por previsões mais precisas das quantidades de resíduos possíveis de serem gerados (GHINEA et al., 2016).

Uma vez que o prognóstico das quantidades de resíduos sólidos representa um desafio cada vez maior para os formuladores de políticas e planejamento, diversos modelos simples e complexos foram desenvolvidos para garantir o planejamento, a gestão e a valorização sustentáveis dos RS, como os que foram aplicados neste Capítulo (PAIVA et al., 2019; GHINEA et al., 2016).

O cenário futuro que se pretende formular contempla as principais tendências de desenvolvimento observadas na UEPA Capital, utilizando-se como principal base de dados o Pré-Diagnóstico da Gestão de RS, os Diagnósticos da Gestão de cada tipo de RS, e o Plano de Desenvolvimento Institucional da UEPA (PDI 2017-2027).

Este Capítulo tem como objetivo apresentar o Prognóstico do PGIRS da UEPA com ênfase nos RSU, considerado através dos diagnósticos (Capítulo I, 2, 3 e 4) como principal tipo de RS gerado pela UEPA. Com base na elaboração do provável cenário de geração de RSU para os próximos 10 anos (2020-2030) e nos demais diagnósticos, será realizada a Proposição (Capítulo 6) de estratégias para a gestão adequada e integrada dos resíduos sólidos da UEPA na Capital. 


\section{METODOLOGIA}

Este Prognóstico levou em consideração duas variáveis bases:

- A projeção da população da UEPA e;

- A geração de resíduos sólidos urbanos.

Estes dados permitiram o desenvolvimento do produto central deste Prognóstico que se refere à geração de resíduos sólidos urbanos por Unidade da UEPA em um horizonte de 10 anos.

\section{I Projeção do crescimento populacional}

A variável de projeção da geração de RS produzido por um grupo possui um elevado grau de correlação com o crescimento populacional (PAIVA et al., 2019). Diante disso, foi calculada a projeção da população acadêmica da UEPA levando em consideração o número anual de servidores ativos (efetivos, temporários, estagiários) e alunos (matriculados) entre os anos de 2016 a 2020.

Foi calculada a taxa média geométrica de crescimento (TMGC) anual da população da UEPA. A TMGC foi calculada a partir da população total (Pop. total) da UEPA, incluindo todas as Unidades, a partir dos dados disponibilizados pelos Relatórios de Gestão (2016-2020) da Diretoria de Planejamento Estratégico da Pró-Reitoria de Gestão e Planejamento (DIPE/PROGESP) apresentados na Tabela 3.

Tabela 3. Descrição anual da quantidade de servidores, alunos e população total (Pop. total) entre os anos de 2016 a 2020.

\begin{tabular}{cccc}
\hline Ano & Servidores & Alunos & Pop. total \\
\hline 2016 & 2.462 & 13.291 & 15.753 \\
2017 & 2.764 & 15.317 & 18.081 \\
2018 & 2.826 & 19.015 & 21.841 \\
2019 & 2.808 & 15.281 & 18.089 \\
2020 & 2.115 & 15.281 & 17.396 \\
\hline
\end{tabular}

Fonte: Relatórios de Gestão (2016-2020) DIPE/PROGESP.

A TMGC refere-se à média anual obtida para um período de anos compreendido entre dois momentos, para indicar o ritmo de crescimento populacional. Ela é utilizada para analisar variações geográficas e temporais do crescimento populacional. Realizar estimativas e projeções populacionais, para períodos curtos e subsidiar processos de planejamento, gestão e avaliação de políticas públicas específicas. A TMGC da UEPA foi calculada a partir do seguinte modelo:

$$
T M G C^{\text {anual }}=\left(\left(\frac{\text { Pop } \mathrm{t}}{\text { Pop } 0}\right)^{\left(\frac{1}{\text { Anot }- \text { Ano0 }}\right)}-1\right) \times 100
$$


Onde:

$T M G C^{\text {anual }}=$ taxa média geométrica de crescimento anual, entre os anos;

Popt $=$ População do ano atual;

Popo = População no início do período considerado;

Anot = Data do ano atual;

$A n o 0=$ Data do ano inicial do período considerado.

A partir da determinação da TMGC, foi calculada a projeção de crescimento da população acadêmica por Unidade da UEPA utilizando o valor da quantidade de servidores ativos e estudantes de cada Unidade. Foram adotados os valores da população referente ao ano de 2019, mesmo ano em que foi realizado o diagnóstico da gestão dos RSU na Capital (Capítulo 2). Os valores de público externo não foram considerados neste método (Tabela 4).

Tabela 4. Descrição das Unidades da UEPA, quantidade de servidores, alunos e população total (Pop. total) no ano de 2019.

\begin{tabular}{l|c|r|c|}
\hline Unidades & Servidores & Alunos & Pop. total \\
\hline Reitoria & 340 & 0 & 340 \\
\hline CCSE & 160 & 3.173 & 3333 \\
\hline CCBS- Campus II & 154 & 1.055 & 1209 \\
\hline CCBS- Enfermagem & 50 & 440 & 490 \\
\hline CCBS- Ed. Física & 135 & 654 & 789 \\
\hline CSE/UEAFTO & 120 & 0 & 120 \\
\hline CCNT & 73 & 773 & 846 \\
\hline CCPP & 47 & 0 & 47 \\
\hline Almoxarifado & 09 & 0 & 9 \\
\hline Arquivo/Patrimônio & 10 & 0 & 10 \\
\hline EDUEPA/Confúcio & 17 & 425 & 442 \\
\hline Total & 1.115 & 6.520 & 7.635 \\
\hline
\end{tabular}

Fonte: Coordenações administrativas das Unidades (CAD) e DIPE/PROGESP

A seguir é apresentado o modelo utilizado para o calculo da projeção de crescimento da população da UEPA por Unidade até o ano de 2030:

$$
\text { Projeção }{ }^{\text {anual }}=A n o t \times\left(1+T M G C^{\text {anual }}\right)^{(\text {Anoy }-A n o t)}
$$

Onde:

Projeção $o^{\text {anual }}=$ Ano que se deseja estimar a população;

$T M G C^{\text {anual }}=$ Taxa média geométrica de crescimento anual;

Anot $=$ Data do ano atual;

Anoy $=$ Data do ano que se deseja estimar a população (ex: 2025; 2030). 


\subsection{Projeção do crescimento da geração dos RSU}

Para definição da projeção do crescimento da geração/produção de RSU foram adotados métodos propostos na literatura e no Plano de Gestão Integrada de Resíduos Sólidos do Estado do Pará (PEGIRS) a fim de estabelecer o melhor modelo matemático para esta estimativa no cenário de $10(\mathrm{dez})$ anos.

Inicialmente foi testado o método proposto no PEGIRS que estima a geração relativa de RSU $\left(\mathrm{kg} / \mathrm{hab} \mathrm{dia}^{-1}\right)$ em função do Produto Interno Bruto (PIB) per capita. Essa metodologia realiza a projeção de crescimentos dos RSU através da utilização do gráfico Atlas D-Waste, a partir do conhecimento dos valores à geração PIB per capita, obtendo dados correspondentes ao parâmetro de geração de RSU per capita no gráfico. Entretanto, este método não foi adotado por conta da ausência de dados referentes à UEPA.

Posteriormente, buscou-se na literatura um modelo que estivesse adequado às variáveis disponíveis a partir do diagnóstico de RSU da Instituição. Foi utilizado o método proposto por Mello (20l4). Este modelo foi estabelecido para populações inferiores a 100 (cem) mil habitantes, contendo os coeficientes de ajustes e utilizado inicialmente em municípios do Estado de São Paulo:

$$
T G P=0,0225 \cdot \operatorname{Ln}(P o p)+0,1154
$$

Onde:

$$
\begin{aligned}
& \text { TGP = Taxa de Geração Per capita (kg/hab.dia); } \\
& \text { Pop = População. }
\end{aligned}
$$

A partir dos cálculos realizados utilizando o modelo proposto, concluiu-se que havia necessidade de simplificar e adaptar o modelo para uma equação que permitisse uma visão mais específica da Instituição. Com objetivo de representar tanto a projeção da produção de RSU quanto a projeção per capita de RSU por Unidade da UEPA, foram definidos 2 (dois) novos modelos, onde o modelo proposto por Mello (20l4) assume as formas das equações:

$$
\begin{aligned}
& \operatorname{Produção} o^{\text {estimada }}=\left(\frac{\text { Pop }_{\text {est } . R S U_{\text {atual }}}}{\text { Pop }_{\text {atual }}}\right) \\
& \operatorname{Produção} o^{\text {per cap }}=\left(\frac{\text { Pop }_{\text {est } . R S U_{\text {per } c a p}}}{P o p_{\text {atual }}}\right)
\end{aligned}
$$

Onde:

Produção ${ }^{\text {estimada }}=$ Estimativa da produção de RSU por Unidade $(\mathrm{kg} / \mathrm{dia})$;

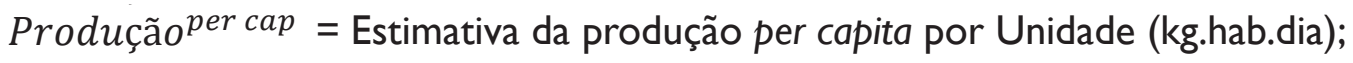

Popest = População estimada para o ano (ex: 2024, 2028);

Popatual = População do ano atual (referência 2019);

$R S U_{\text {atual }}=$ Produção atual de RSU da Unidade $(\mathrm{kg} / \mathrm{dia})$;

$R S U_{\text {per cap }}=$ Produção per capita atual de RSU da Unidade ( $\left.\mathrm{kg} / \mathrm{hab} / \mathrm{dia}\right)$. 
Além das projeções realizadas através dos modelos matemáticos propostos, foi realizada uma análise qualitativa de caráter exploratório no Plano de Desenvolvimento Institucional (PDI 2017 2027) da Universidade do Estado do Pará. Esta análise levou em consideração as projeções de crescimento populacional e de geração de RSU nas Unidades da UEPA-Capital, para estabelecer um cenário futuro da geração de RSU até 2030.

\section{RESULTADOS}

\section{I Projeção populacional por Unidade da UEPA}

A TMGC para a população da Universidade do Estado do Pará foi de 2,5 I\% ao ano.A partir deste valor, a Tabela 5 apresenta a projeção de crescimento populacional da UEPA por Unidade para os próximos 30 anos.

Tabela 5. Projeção de crescimento populacional da UEPA por Unidade até 2030.

\begin{tabular}{l|c|c|c|c|c|}
\hline \multirow{2}{*}{ Unidades } & \multicolumn{5}{c}{ População } \\
\cline { 2 - 7 } & $\mathbf{2 0 1 9}$ & $\mathbf{2 0 2 2}$ & $\mathbf{2 0 2 5}$ & $\mathbf{2 0 2 8}$ & $\mathbf{2 0 3 0}$ \\
\hline Reitoria & 340 & 366 & 395 & 425 & 447 \\
\hline CCSE & 3.333 & 3.590 & 3.868 & 4.167 & 4.378 \\
\hline CCBS- Campus II & 1.209 & 1.302 & 1.403 & 1.511 & 1.588 \\
\hline CCBS- Enfermagem & 490 & 528 & 569 & 613 & 644 \\
\hline CCBS- Ed. Física & 789 & 850 & 916 & 986 & 1.036 \\
\hline CSE/UEAFTO & 120 & 129 & 139 & 150 & 158 \\
\hline CCNT & 846 & 911 & 982 & 1.058 & 1.111 \\
\hline CCPP & 47 & 51 & 55 & 59 & 62 \\
\hline Almoxarifado & 9 & 10 & 10 & 11 & 12 \\
\hline Arquivo/Patrimônio & 10 & 11 & 12 & 13 & 13 \\
\hline EDUEPA/Confúcio & 442 & 476 & 513 & 553 & 581 \\
\hline
\end{tabular}

\subsection{Projeção da geração de RSU por Unidade da UEPA}

Através dos dados da projeção de crescimento populacional da UEPA e dos dados quantitativos do diagnóstico de RSU foi possível estimar a projeção da geração de RSU (kg/dia) por Unidade até 2030 (Tabela 6).

Tabela 6. Projeção da geração de RSU (kg/dia) por Unidade da UEPA até 2030.

\begin{tabular}{l|ccc|c|c|}
\hline \multirow{2}{*}{ Unidades } & \multicolumn{5}{c}{ RSU (kg/dia) } \\
\cline { 2 - 6 } & $\mathbf{2 0 1 9}$ & $\mathbf{2 0 2 2}$ & $\mathbf{2 0 2 5}$ & $\mathbf{2 0 2 8}$ & $\mathbf{2 0 3 0}$ \\
\hline Reitoria & 20,76 & 22,36 & 24,09 & 25,95 & 27,27 \\
\hline CCSE & 20,25 & 21,81 & 23,50 & 25,31 & 26,60 \\
\hline CCBS- Campus II & 30,32 & 32,66 & 35,19 & 37,90 & 39,83 \\
\hline CCBS- Enfermagem & 11,4 & 12,28 & 13,23 & 14,25 & 14,98 \\
\hline
\end{tabular}




\begin{tabular}{l|c|c|c|c|c|}
\hline \multicolumn{1}{l}{ CCBS- Ed. Física } & $33, \mathrm{I}$ & 35,66 & $38,4 \mathrm{I}$ & $4 \mathrm{I}, 38$ & 43,48 \\
\hline CSE/UEAFTO & 22,4 & 24,13 & 25,99 & 28,00 & 29,43 \\
\hline CCNT & 18,16 & 19,56 & 21,07 & 22,70 & 23,86 \\
\hline CCPP & $\mathrm{I}, 88$ & 2,03 & 2,18 & 2,35 & 2,47 \\
\hline Almoxarifado & $\mathrm{I}, 7$ & $\mathrm{I}, 83$ & 1,97 & 2,13 & 2,23 \\
\hline Arquivo/Patrimônio & $\mathrm{I}, 15$ & $\mathrm{I}, 24$ & 1,33 & $\mathrm{I}, 44$ & $1,5 \mathrm{I}$ \\
\hline EDUEPA/Confúcio & 0,3 & 0,32 & 0,35 & 0,38 & 0,39 \\
\hline
\end{tabular}

\subsection{Projeção da geração per capita de RSU por Unidade da UEPA}

Ademais, estimou-se a geração per capita de RSU (kg/hab.dia) até 2030 através da projeção de geração dos RSU, como observado na Tabela 7.

Tabela 7. Projeção da geração per capita de RSU por Unidade da UEPA até 2030.

\begin{tabular}{|c|c|c|c|c|c|}
\hline \multirow{2}{*}{ Unidades } & \multicolumn{5}{|c|}{ RSU per capita (kg/hab.dia) } \\
\hline & 2019 & 2022 & 2025 & 2028 & 2030 \\
\hline Reitoria & 0,061 & 0,066 & 0,071 & 0,076 & 0,080 \\
\hline CCSE & 0,006 & 0,007 & 0,007 & 0,008 & 0,008 \\
\hline CCBS- Campus II & 0,025 & 0,027 & 0,029 & 0,031 & 0,033 \\
\hline CCBS- Enfermagem & 0,023 & 0,025 & 0,027 & 0,029 & 0,031 \\
\hline CCBS- Ed. Física & 0,042 & 0,045 & 0,049 & 0,052 & 0,055 \\
\hline CSE/UEAFTO & 0,187 & 0,201 & 0,217 & 0,233 & 0,245 \\
\hline CCNT & 0,021 & 0,023 & 0,025 & 0,027 & 0,028 \\
\hline CCPP & 0,040 & 0,166 & 0,179 & 0,193 & 0,203 \\
\hline Almoxarifado & 0,189 & 0,203 & 0,219 & 0,236 & 0,248 \\
\hline Arquivo/Patrimônio & 0,115 & 0,124 & 0,133 & 0,144 & 0,151 \\
\hline EDUEPA/Confúcio & 0,001 & 0,001 & 0,001 & 0,001 & 0,001 \\
\hline
\end{tabular}

\subsection{As Projeções frente ao Plano de Desenvolvimento Institucional}

A Universidade do Estado do Pará, com objetivo de mensurar e melhorar seu desempenho organizacional, à luz da sua missão e visão de futuro, definiu em uma escala de 10 (dez) anos sua atuação, objetivos, metas e estratégias através do PDI.

O PDI atual foi elaborado para atender o período de 2017-2027, e diante de seus objetivos, metas e estratégias institucionais foram destacados alguns eixos importantes frente às projeções da geração de RSU.

A implantação de novos cursos e o desenvolvimento da gestão acadêmica é um dos eixos que, de acordo com Paiva et al. (2019), tem influencia direta na geração de RSU da Instituição. A expansão e a implantação de cursos para o período de 2017-2027 pretende ampliar o acesso aos cursos de graduação com a oferta de 730 vagas distribuídas em 13 (treze) novos cursos de graduação na Capital, conforme a Tabela 8. 
Tabela 8. Expansão e ampliação de cursos de graduação (2017-2027), número de vagas e ano de implantação na UEPA Capital.

\begin{tabular}{lcc}
\hline \multicolumn{1}{c}{ Curso } & $\begin{array}{c}\mathrm{N}^{\circ} \text { de } \\
\text { Vagas }\end{array}$ & $\begin{array}{c}\text { Ano de } \\
\text { Implantação }\end{array}$ \\
\hline Bacharelado em Sistema de Informação & 150 & 2018 \\
Bacharelado em Educação Física & 40 & 2021 \\
Bacharelado em Biotecnologia & 40 & 2021 \\
Bacharelado em Ciências Sociais & 40 & 2018 \\
Bacharelado em Filosofia & 40 & 2018 \\
Bacharelado em Engenharia de Transporte & 50 & 2023 \\
Bacharelado em Empreendedorismo e Turismo & 50 & 2023 \\
Bacharelado em Fonoaudiologia & 40 & 2026 \\
Bacharelado em Nutrição & 120 & 2026 \\
Bacharelado em Saúde Coletiva & 40 & 2020 \\
Licenciatura em Química & 40 & 2019 \\
Licenciatura em Física & 40 & 2019 \\
Licenciatura em Biologia & 40 & 2019 \\
\hline Total & 730 & - \\
\hline
\end{tabular}

Fonte: PDI/PROGRAD (2016).

O reflexo da criação de novos cursos na geração de RSU prevê um aumento significativo na quantidade de resíduos tanto orgânicos quanto recicláveis. A projeção da população total da Capital para o ano de 2027, incluindo a previsão de criação de novos cursos de graduação pelo PDI, é de 10.041 . Esse cenário implica no aumento de até $\mathbf{2 2}$ \% na geração RSU, comparado ao diagnóstico da geração atual.

Ademais, outro eixo descrito no planejamento do PDI é a infraestrutura física da Instituição. A Tabela 9 apresenta o levantamento atual da área construída realizado em 2019 pela Diretoria de Administração e Serviços (DAS) nas Unidades de Belém.

Tabela 9. Infraestrutura física das Unidades da UEPA Capital.

\begin{tabular}{l|c|c|}
\hline \multicolumn{1}{|c}{$\begin{array}{c}\text { Área total } \\
\text { Uproximada }\left(\mathrm{m}^{2}\right)\end{array}$} & $\begin{array}{c}\text { Área total } \\
\text { construída }\left(\mathrm{m}^{2}\right)\end{array}$ \\
\hline Reitoria & $3.547,17$ & $3.952,66$ \\
\hline CCSE & $7.384,25$ & $9.533,57$ \\
\hline CCBS- Campus II & $36.934,98$ & $19.713,69$ \\
\hline CCBS- Enfermagem & $4.524,39$ & $6.549,00$ \\
\hline CCBS- Ed. Física & $39.583,64$ & $36.069,36$ \\
\hline CSE/UEAFTO & $3.427,03$ & $1.323,97$ \\
\hline CCNT & $4.387,00$ & $5.614,46$ \\
\hline CCPP & $13.339,07$ & $2.722,04$ \\
\hline Almoxarifado/Arquivo/ & 856,11 & 1039,5 \\
Patrimônio & 332,96 & 504,55 \\
\hline EDUEPA/Confúcio &
\end{tabular}

De acordo com o PDI, não há previsão para a construção de novas Unidades na Capital até 2027. Nesse sentido, a gestão dos espaços físicos diante da geração de RSU deve considerar o 
sistema de gerenciamento de resíduos de podas e varrição gerados em áreas abertas dentro das Unidades da UEPA. Além disso, o cenário indica uma prioridade no gerenciamento dos espaços das Unidades CCBS- Campus II e CCBS- Ed. Física, pois apresentam as maiores áreas $\left(\mathrm{m}^{2}\right)$ da Instituição.

\section{CONSIDERAÇÕES FINAIS}

A partir dos modelos matemáticos foi possível calcular as projeções de crescimento populacional e a geração de RSU por Unidade da UEPA na Capital. O cenário apresentado é o mais aceitável e indicado para subsidiar as Proposições que serão determinadas neste Plano. $\bigcirc$ uso do PDI como indicador do planejamento em longo prazo foi fundamental para prever os possíveis cenários de aumento na geração do RSU a partir da criação de novos cursos e ampliação da infraestrutura.

Por fim, conclui-se que o cenário futuro previsto para a Instituição é de um aumento anual significativo na geração de RSU em todas as Unidades da Universidade até 2030. 


\section{CAPÍTULO 6}

PROPOSIÇÕES DO PLANO DE

GESTÃO INTEGRADA DE RESİDUOS SÓLIDOS DA UEPA

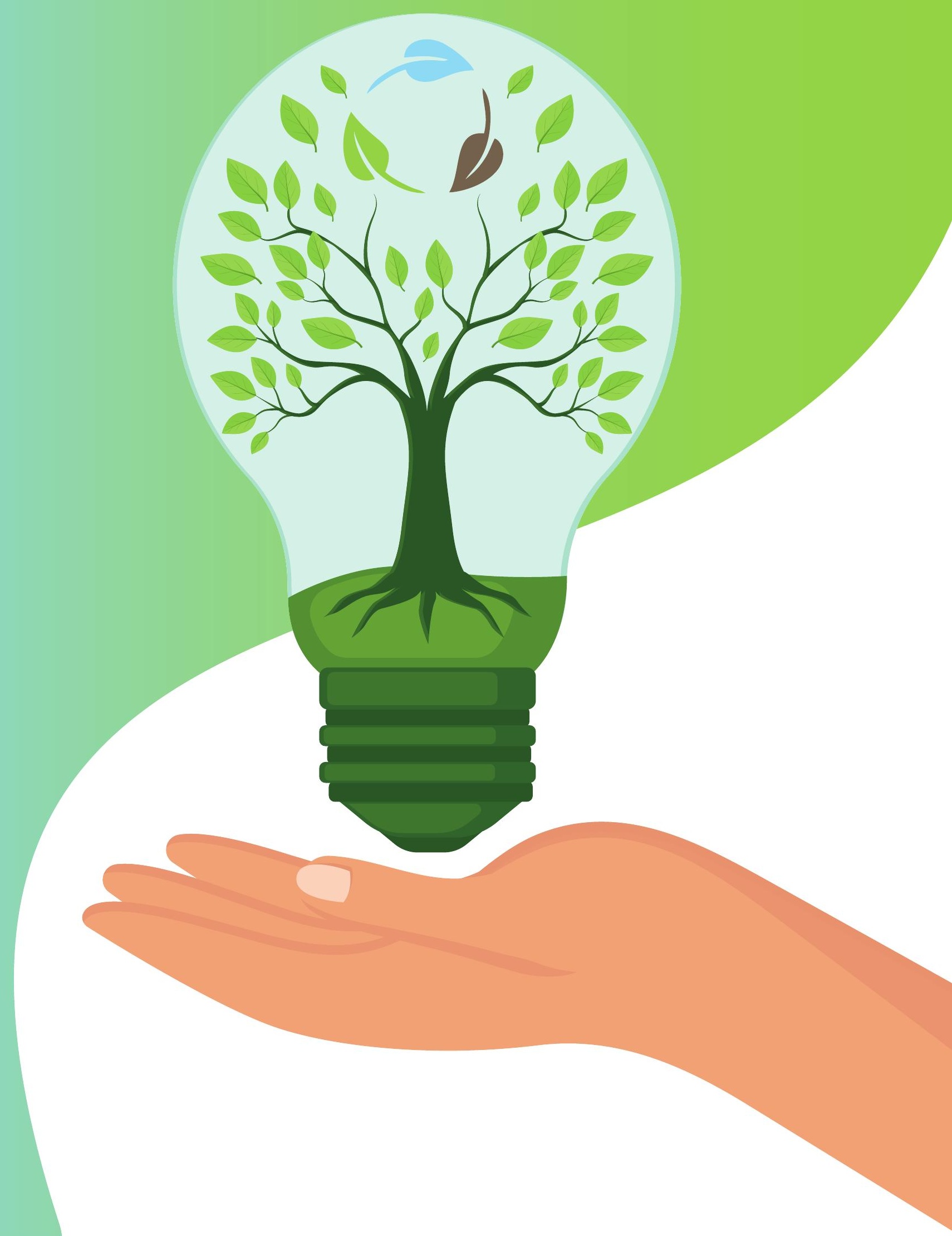




\section{INTRODUÇÃO}

O relatório das Proposições é o produto final e conclusivo da estruturação do Plano de Gestão Integrada de Resíduos Sólidos da UEPA - Capital. Nesta etapa estão concebidas e explicitadas as estratégias que darão direcionamento às metas, projetos e ações de 4 (quatro) Eixos de gestão e gerenciamento dos resíduos sólidos para as 14 (quatorze) Unidades da UEPA na Capital.

Como estratégia metodológica e atendendo as orientações da PNRS, Lei n. 12.305/2010, para definição das Proposições como elementos direcionadores do processo de mudanças a serem implementadas na gestão de resíduos sólidos da UEPA, tomou-se como base os Diagnósticos da gestão atual de RS e o Prognóstico de projeções do futuro. Além disso, o uso do Plano de Desenvolvimento Institucional (PDI 2017-2027) é necessário com objetivo de interconectar as definições das proposições ao desenvolvimento estratégico da Instituição.

$\mathrm{Na}$ perspectiva do planejamento estratégico, este Plano levará suas proposições de metas e ações a um horizonte de 10 anos (2021-2030), prevendo suas execuções em escalas temporais de curto, médio e longo prazo.A Figura 8 representa os estágios de evolução e estruturação do Plano.

Figura 8. Estágios de evolução do Plano de Gestão Integrada da UEPA.

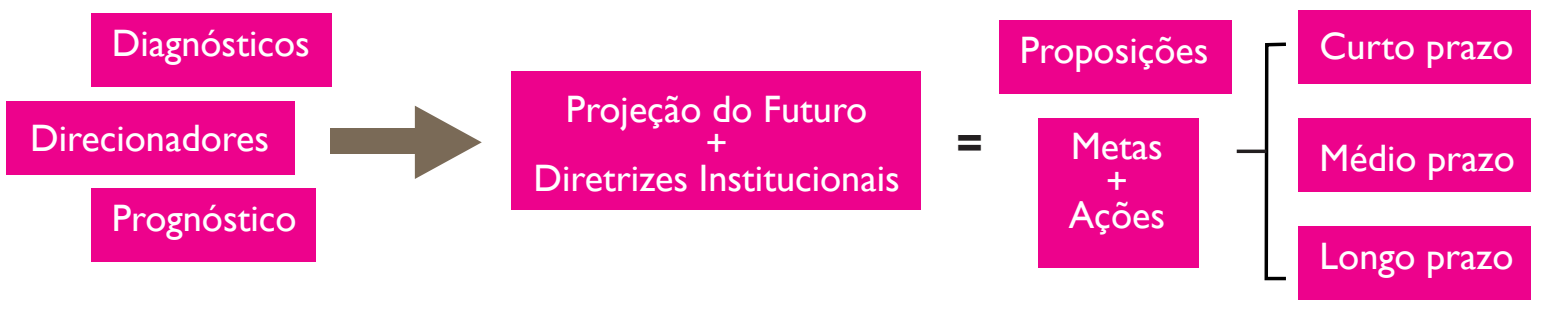

De acordo com o Guia para elaboração dos Planos de Gestão de Resíduos Sólidos (20II) do Ministério do Meio Ambiente, como base conceitual para o entendimento e caracterização das proposições, entende-se como:

- Diretrizes e Estratégias: conjunto de definições norteadores e meios que asseguram a implementação do Plano e garantem o alcance das condições interpretadas a partir dos diagnósticos e prognóstico;

- Metas: alcance dos objetivos em um determinado prazo.As metas devem ser quantificáveis, de modo que seu alcance seja mensurável e, por consequência, aferido;

- Ações: visam atingir as metas estabelecidas e podem ser desenvolvidas dentro de um projeto com objetivo estratégico definido.

A temporalidade das proposições está vinculada às propostas políticas e metodológicas do planejamento e definida na PNRS. Para este planejamento a nível Institucional como autarquia de administração indireta em esfera Estadual, adota-se a temporalidade de vigência de 10 anos do Plano a partir de sua publicação e deverá ser revisado no ultimo ano de vigência. 
O monitoramento, controle e avaliação da implementação do Plano envolverá ferramentas como:

- Elaboração da agenda de implementação e acompanhamento do cumprimento dos objetivos definidos no Plano;

- A observância dos dispositivos legais aplicáveis à gestão dos resíduos sólidos;

- A identificação dos pontos fortes e fracos do Plano elaborado e das oportunidades e entraves à sua implementação;

- A efetividade da implementação do Plano por meio da aferição das metas estabelecidas;

- Construção de indicadores de desempenho operacional e socioambiental;

- Meios para controle, monitoramento e fiscalização das atividades que garantirão a qualidade da gestão;

- Proposição de adequações e demais ajustes necessários.

Caberá ao Programa de Gestão UEPA Ambiental monitorar, controlar e avaliar a implementação do Plano de Gestão Integrada de Resíduos Sólidos da UEPA- Capital.

\section{METODOLOGIA}

A metodologia adotada para a formulação das Proposições se fundamentou com base nos Diagnósticos (Capítulo I, 2, 3 e 4), no Prognóstico (Capítulo 5) e no Plano de Desenvolvimento Institucional (PDI). Além disso, também foi utilizado o método da "árvore de problemas" como descrito em Vercezi et al. (2019) e Oliveira et al. (2016).

método da árvore de problemas é um instrumento utilizado para análise de problemas através de um diagrama que permite a visualização de uma situação-problema e as relações de causa-efeito entre as problemáticas mais relevantes. $O$ método parte de um único problema central, para garantir o foco estratégico da análise (VERCEZI et al., 2019).

método contempla um momento explicativo, que tem objetivo de descrever a realidade mediante a seleção de problemas relevantes, buscando-se a compreensão ampla do porquê esses ocorrem e identificando-se os nós-críticos (NC), que representam os centros práticos de ação (MELLEIRO, 2005).

Segundo Matus (1996), o momento explicativo pode ser sintetizado como Fluxograma Situacional, no qual estão inseridos os seguintes aspectos:

- A elaboração do problema realizada com clareza e objetividade;

- A presença do ator responsável pela explicação e articulação das ações, no sentido de conceber e operar as intervenções para a solução do problema; 
- Os descritores do problema, representados preferencialmente por indicadores de caráter quantitativo, monitoráveis ao longo do tempo e que possibilitem verificar como o problema se comporta numa dada realidade situacional;

- As consequências do problema, constando de um exercício de análise e de uma discussão, tendo como produto a síntese dos principais efeitos do problema.

A relevância e a precisão do estabelecimento dos NC justifica-se pelo fato de que os mesmos serão os focos a serem trabalhados na elaboração dos eixos, objetivos, metas, projetos e ações nesta etapa de Proposições do Plano.

A partir da análise da árvore de problemas, foi definida a apresentação das proposições dentro das diretrizes que consideram a Política Nacional de Resíduos Sólidos e o Plano de Desenvolvimento Institucional da UEPA. Através das informações dos Diagnósticos (Capítulo I, 2, 3 e 4), as Proposições foram elaboradas em 4 (quatro) Eixos a fim de atender os diferentes tipos de resíduos sólidos gerados pela Instituição: Resíduos Sólidos Urbanos (RSU), Resíduos de Equipamentos Eletroeletrônicos (REEE), Resíduos de Serviços de Saúde (RSS) e Educação Ambiental (EA) como ferramenta reguladora dos demais Eixos. O Quadro II apresenta a hierarquização estratégica, prazos e descrições.

Quadro I I. Hierarquização dos níveis, prazos e descrição.

\begin{tabular}{|l|l|}
\hline \multicolumn{1}{|c|}{ Nível } & \multicolumn{2}{c|}{ Descrição } \\
\hline Eixo & Define as estratégias para cada tipo de resíduo sólido \\
\hline Objetivo & Um objetivo único por eixo \\
\hline Meta & Para cada eixo é formulada, pelo menos, uma Meta \\
\hline Projeto & Cada eixo será composto por seus projetos específicos \\
\hline Ações & Várias ações poderão compor o projeto para alcançar o objetivo \\
\hline Curto Prazo & \\
\hline Médio & I a 3 anos \\
\hline Longo & 4 a 6 anos \\
\hline
\end{tabular}

A partir da definição das proposições, foram descritos o detalhamento de todas as metas estabelecidas quantificando e mensurando sua aplicação dentro do prazo determinado. Ademais, para garantir o alcance das metas propostas, foram detalhados os planos de ação demonstrando os produtos, prazos, setores responsáveis e resultado esperados. 


\section{EXPLICITAÇÃO DA ÁRVORE DE PROBLEMAS}

A árvore de problemas foi elaborada a partir do problema central: Gestão de Resíduos Sólidos na UEPA-Capital é deficiente. Nesse sentido foram identificados 5 (cinco) Vetores de Descrição de Problema (VDP):

VDPI - 99\% dos RSU não são destinados a reciclagem;

VDP2 - Ausência de lixeiras seletivas em 100\% das Unidades;

VDP3 - Descarte inadequado de 90 \% de resíduos eletroeletrônicos;

VDP4 - 10 \% dos Resíduos de Saúde descartados junto aos resíduos recicláveis;

VDP5 - Grande parte da comunidade acadêmica possui parco conhecimento a respeito do descarte correto.

A Figura 9 apresenta todos os VDP, as causas de fluxo, causas de acumulações e causas de regras e suas respectivas consequências dentro da UEPA.

A partir da análise da árvore de problemas foram identificados 7 sete nós-críticos (Figura 9) que foram alvo de discussão para definição das proposições do Plano. A "Ausência de um sistema de coleta seletiva" é um nó-critico de alto impacto na gestão dos resíduos sólidos urbanos da UEPA. Para atender a PNRS nas dimensões ambientais e sociais, a coleta seletiva visa a segregação dos resíduos sólidos na fonte geradora, encaminhando os resíduos recicláveis para cooperativas de catadores de materiais recicláveis da região.

Essa causa direta parte de outro nó-crítico como causa de regra, que é a "Inexistência de um Plano específico no âmbito da Gestão". Este nó-crítico demonstra a ligação direta e indireta desta causa com as demais causas que geram todos os VDP. Como efeitos, a árvore de problema apresenta as consequências significativas destas causas no âmbito da qualidade ambiental e saúde da comunidade acadêmica (Figura 9). 
Figura 9. Árvore de Problemas

ATOR: UEPA

CAUSAS
PROBLEMA CENTRAL CONSEQUÊNCIAS
Gestão de Resíduos Sólidos

na UEPA-Capital é deficiente

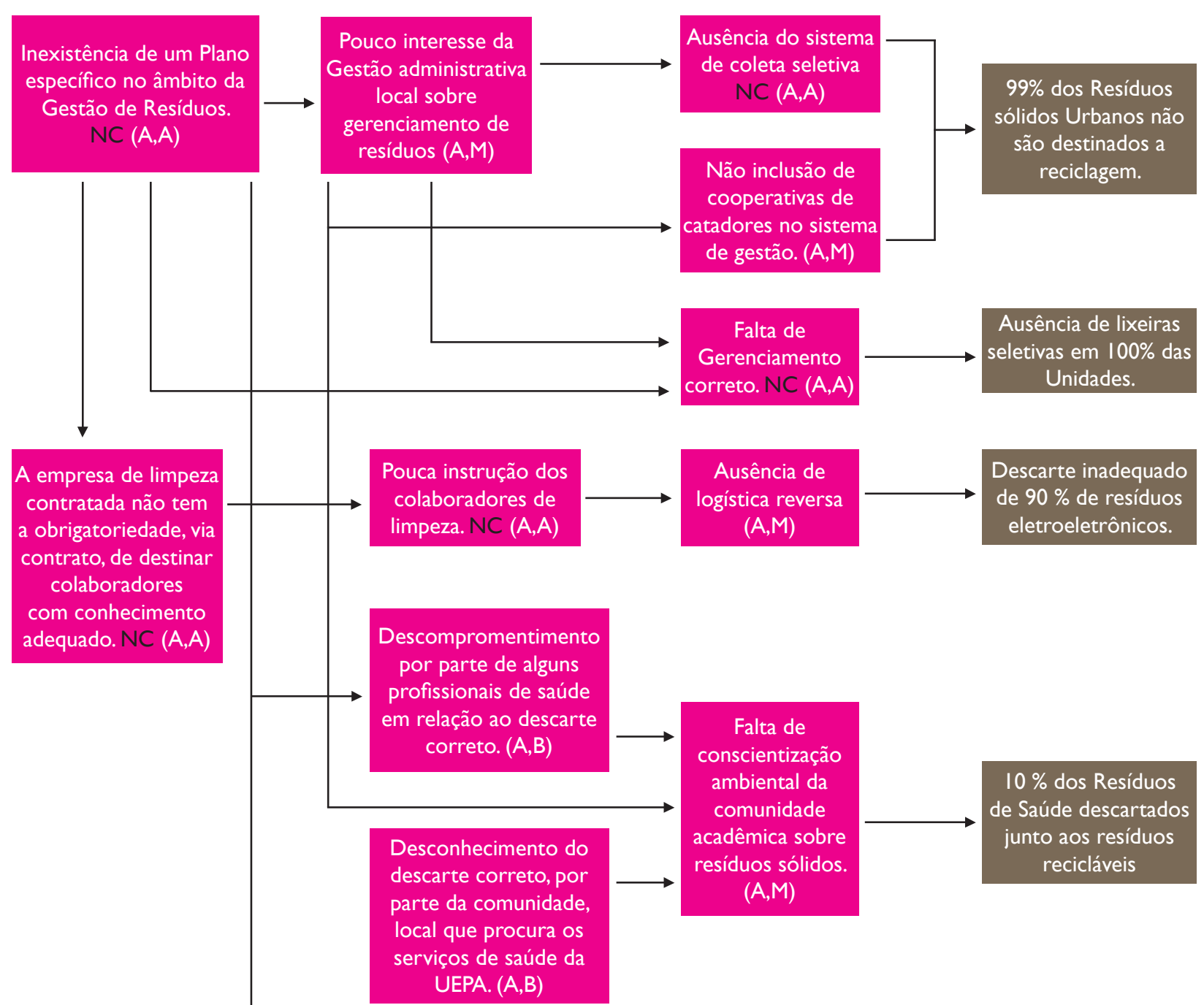

colaboradores da limpeza quanto o descarte correto.(A,M)

Inexistência de orientação aos

servidores da UEPA NC (A, A)

Nâo há um planejamento de treinos,

orientações, comunicação e divulgação e

institucional a respeito do assunto. NC (A,A)

70 Plano de Gestão Integrada de Resíduos Sólidos 
O Quadro 12 apresenta as Proposições organizadas em 4 Eixos e a partir de cada Eixo foram definidos seus objetivos estratégicos, metas, projetos e ações.

Quadro I 2. Definição das Proposições do Plano (2021-2030).

\begin{tabular}{|c|c|c|}
\hline Eixo & Identificação & Descrição \\
\hline \multirow{8}{*}{$\begin{array}{l}\text { Resíduos } \\
\text { Sólidos } \\
\text { Urbanos }\end{array}$} & $\begin{array}{l}\text { Objetivo } \\
\text { Estratégico }\end{array}$ & Gerir adequadamente os RSU produzidos pela UEPA-Capital \\
\hline & Metal & Realizar coleta seletiva em $100 \%$ das Unidades da UEPA-Capital \\
\hline & Meta 2 & $\begin{array}{l}\text { Destinar às cooperativas de catadores } 75 \% \text { dos materiais recicláveis de todos } \\
\text { os RSU produzidos pela UEPA-Capital }\end{array}$ \\
\hline & Projeto & Sistema de coleta seletiva da UEPA-Capital \\
\hline & \multirow{4}{*}{ Ações } & Instalar em todas as Unidades da UEPA lixeiras seletivas \\
\hline & & Desativar as lixeiras comuns \\
\hline & & Capacitar todos os colaboradores de limpeza da UEPA \\
\hline & & $\begin{array}{l}\text { Acompanhar o processo de transporte e recepção dos resíduos recicláveis nos } \\
\text { galpões das cooperativas. }\end{array}$ \\
\hline \multirow{8}{*}{$\begin{array}{l}\text { Resíduos de } \\
\text { Equipamentos } \\
\text { Eletroele- } \\
\text { trônicos }\end{array}$} & $\begin{array}{c}\text { Objetivo } \\
\text { Estratégico }\end{array}$ & Gerir adequadamente os REEE produzidos pela UEPA-Capital. \\
\hline & Metal & $\begin{array}{l}\text { Implementar o sistema de logística reversa para os REEE em I00\% das Unida- } \\
\text { des da UEPA-Capital. }\end{array}$ \\
\hline & Meta 2 & Enviar 100\% dos REEE da UEPA- Capital para a destinação adequada. \\
\hline & Projeto & Sistema de logística reversa da UEPA-Capital. \\
\hline & \multirow{4}{*}{ Ações } & $\begin{array}{l}\text { Instalar em todas as Unidades da UEPA lixeiras especificas para pilhas e bate- } \\
\text { rias. }\end{array}$ \\
\hline & & $\begin{array}{l}\text { Definir um espaço físico para acondicionamento temporário dos resíduos de } \\
\text { equipamentos de iluminação, telecomunicações, etc. }\end{array}$ \\
\hline & & $\begin{array}{l}\text { Estabelecer parceria/contrato com empresas especializadas na recepção e tra- } \\
\text { tamento dos REEE. }\end{array}$ \\
\hline & & Destinar à cooperativas especializadas os REEE de acordo com sua capacidade. \\
\hline \multirow{7}{*}{$\begin{array}{l}\text { Resíduos de } \\
\text { Serviços de } \\
\text { Saúde }\end{array}$} & $\begin{array}{l}\text { Objetivo } \\
\text { Estratégico }\end{array}$ & $\begin{array}{l}\text { Gerir adequadamente os RSS produzidos pelas Unidades CSE; UEAFTO; CCBS: } \\
\text { Enfermagem e Campus II }\end{array}$ \\
\hline & Metal & $\begin{array}{l}\text { Realizar a coleta e encaminhar 100\% dos RSS das Unidades CSE; UEAFTO; } \\
\text { CCBS: Enfermagem e Campus II para a destinação adequada. }\end{array}$ \\
\hline & Meta 2 & $\begin{array}{l}\text { Implantar medidas eficientes para o descarte correto dos Resíduos de Serviços } \\
\text { de Saúde no âmbito da Uepa Capital. }\end{array}$ \\
\hline & Projeto & Descarte consciente dos Resíduos de Serviços de Saúde \\
\hline & \multirow{3}{*}{ Ações } & Instruir os servidores da saúde a realizar o descarte adequado dos RSS \\
\hline & & $\begin{array}{l}\text { Disponibilizar lixeiras e embalagens para o descarte dos RSS de acordo com a } \\
\text { legislação específica. }\end{array}$ \\
\hline & & $\begin{array}{l}\text { Possuir um contrato específico com empresa especializada no tratamento e } \\
\text { disposição final dos RSS }\end{array}$ \\
\hline
\end{tabular}




\begin{tabular}{|c|c|l|}
\hline \multirow{4}{*}{$\begin{array}{c}\text { Educação } \\
\text { Ambiental }\end{array}$} & $\begin{array}{c}\text { Objetivo } \\
\text { Estratégico }\end{array}$ & $\begin{array}{l}\text { Conscientizar e sensibilizar a comunidade acadêmica em relação à gestão cor- } \\
\text { reta dos resíduos sólidos }\end{array}$ \\
\cline { 2 - 3 } & Meta I & $\begin{array}{l}\text { Promover ações educativas que envolvam 100\% dos servidores e alunos da } \\
\text { UEPA Capital }\end{array}$ \\
\cline { 2 - 3 } & \multirow{2}{*}{ Ações } & $\begin{array}{l}\text { Descarte consciente } \\
\text { Orientar os servidores à não gerar e descartar corretamente os resíduos nas } \\
\text { lixeiras seletivas }\end{array}$ \\
\cline { 2 - 3 } & $\begin{array}{l}\text { Orientar os alunos à não gerar e descartar corretamente os resíduos nas lixei- } \\
\text { ras seletivas }\end{array}$ \\
\cline { 2 - 3 } & $\begin{array}{l}\text { Realizar eventos acadêmicos para disseminar conhecimento sobre resíduos } \\
\text { sólidos }\end{array}$ \\
\hline
\end{tabular}

Para o Eixo Resíduos Sólidos Urbanos foram definidos I (um) Objetivo Estratégico e 2 (duas) Metas voltadas para a coleta seletiva e a inclusão social dos resíduos recicláveis. Para atingir estas Metas foi estabelecido I (um) Projeto que contempla 4 (quatro) Ações com execução prevista em curto e médio prazo.

No Eixo Resíduos de Equipamentos Eletroeletrônicos também foram definidos I (um) Objetivo Estratégico e 2 (duas) Metas com foco na Logística Reversa. Nesse sentido, I (um) Projeto foi estabelecido contemplando 4 (quatro) Ações para alcance das Metas em curto e longo prazo.

Resíduos de Serviços de Saúde é o terceiro Eixo apresentado no Quadro, contempla I (um) Objetivo Estratégico, e as 2 (duas) Metas definidas neste Eixo visam destinar os RSS para tratamento adequado. Nesse sentido, I (um) Projeto foi estabelecido com 3 (três) Ações a fim de alcançar estas Metas em curto prazo.

Por fim, o Eixo Educação Ambiental apresenta, além do Objetivo Estratégico, I (uma) Meta com caráter educativo aos servidores e alunos. Para tal, I (um) Projeto foi estabelecido englobando 3 (três) Ações que deverão ser executadas em curto prazo para alcançar a Meta deste Eixo.

\section{I Indicadores}

Os indicadores que irão subsidiar o monitoramento, controle das ações e alcance das metas ainda deverão ser definidos e testados para uma metodologia mais adequada e melhor eficiência na apresentação de resultados de monitoramento. Nesse sentido, será construído um documento com detalhamento dos indicadores posterior à publicação deste Plano, durante seu primeiro ano de execução (202I).

\subsection{Detalhamento das Metas}

Para cada Eixo e Objetivo Estratégico apresentado no Quadro 12, foram definidas as Metas que permitem o alcance dos seus objetivos. Para quantificação das Metas e posterior aferimento, a Tabela 10 apresenta o detalhamento das Metas incluindo seu alcance dentro de um prazo estabelecido a partir da realidade de execução das Ações pela Universidade.

O detalhamento é apresentado a partir de um horizonte temporal que apresenta um índice de 
referência (2019) e os resultados esperados nos anos seguintes de vigência do Plano (202I-2030).

Dentre todas as Metas definidas, a "Enviar 100\% dos REEE da UEPA- Capital para a destinação adequada" possui uma estratégia em longo prazo. Esta definição parte da expressiva dificuldade em direcionar os REEE para a indústria via sistema de logística reversa. Nesse sentido, um longo prazo foi adotado para não comprometer a Meta pretendida.

A Meta "Promover ações educativas que envolvam 100\% dos servidores e alunos da UEPA Capital" possui um prazo curto para seu alcance e um caráter contínuo dentro da perspectiva da Política Nacional de Educação Ambiental.

Já a Meta "Realizar a coleta e encaminhar 100\% dos RSS das Unidades CSE; UEAFTO; CCBS: Enfermagem e Campus II para a destinação adequada" deverá ser atingida no primeiro ano de vigência deste Plano para atender o disposto na PNRS e nas Resoluções da ANVISA sobre RSS. 


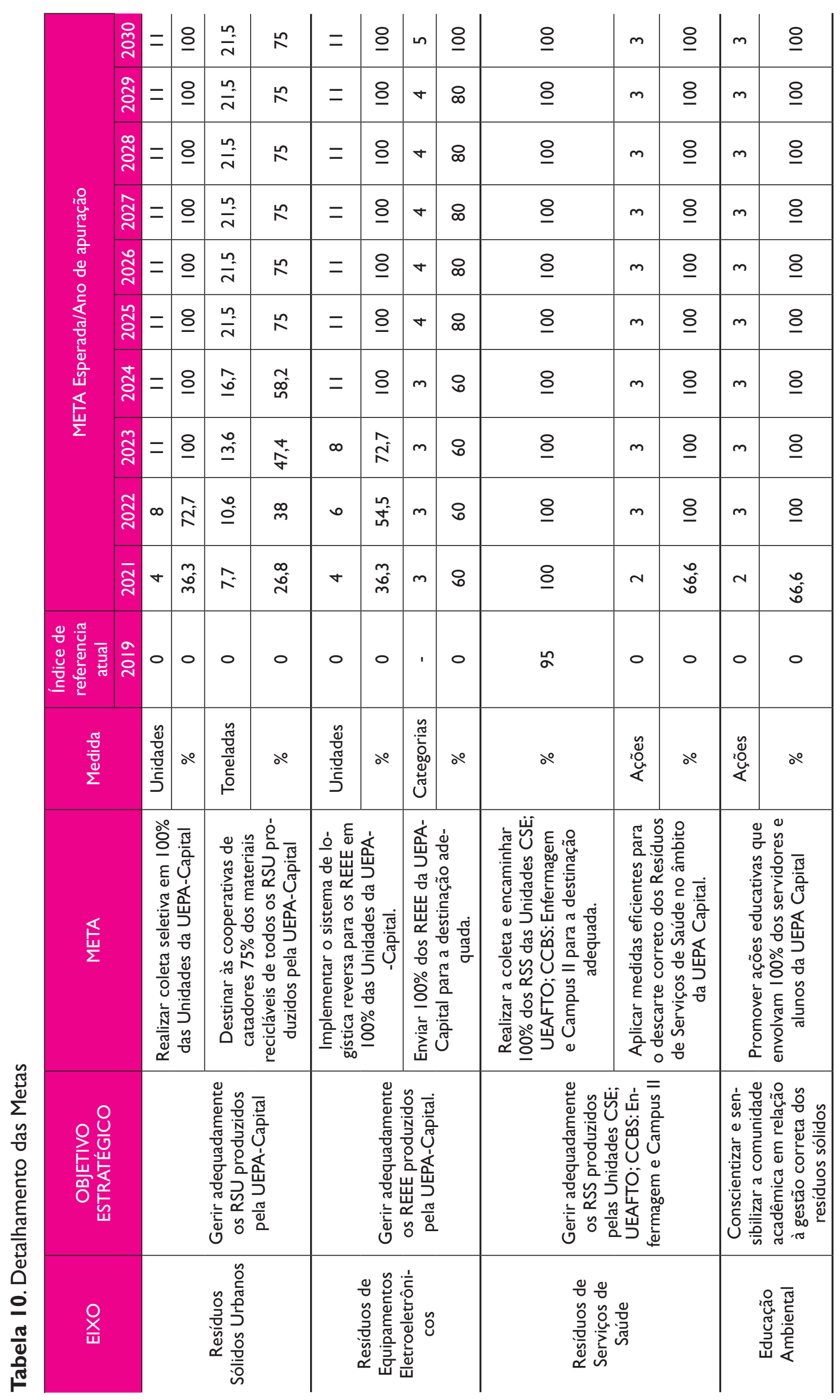




\subsection{Detalhamento dos Planos de Ações}

Para cada Eixo estabelecido nas Proposições (Quadro 12) foram elaborados os Planos de Ações com a especificação de todas as ações necessárias para atingir os Objetivos e Metas, bem como os produtos, os prazos, os responsáveis e os resultados esperados. Este detalhamento permite definir de forma clara como serão executadas as ações de cada Eixo. Contudo, todos os projetos estabelecidos deverão ser estruturados operacionalmente após a publicação deste Plano.

O Quadro 13 apresenta o detalhamento do Plano de Ações do Eixo "Resíduos Sólidos Urbanos". A partir do Objetivo Estratégico e das Metas definidas, este detalhamento contempla 6 Ações onde um dos seus resultados esperados é "RSU coletados adequadamente e destinados às cooperativas". Diante disso, espera-se que o gerenciamento dos RSU produzidos na UEPA-Capital seja ambientalmente adequado de acordo com a PNRS.

Quadro I3. Plano de Ações dos Resíduos Sólidos Urbanos - RSU

\begin{tabular}{|c|c|c|c|c|}
\hline \multicolumn{5}{|c|}{ Eixo: Resíduos Sólidos Urbanos } \\
\hline \multicolumn{5}{|c|}{ Objetivo Estratégico: Gerir adequadamente os RSU produzidos pela UEPA-Capital } \\
\hline \multirow{2}{*}{\multicolumn{4}{|c|}{$\begin{array}{l}\text { Meta I: Realizar coleta seletiva em } 100 \% \text { das Unidades da UEPA-Capital } \\
\text { Meta 2: Destinar às cooperativas de catadores } 75 \% \text { dos materiais recicláveis de todos } \\
\text { os RSU produzidos pela UEPA-Capital. }\end{array}$}} & $\begin{array}{l}\text { Período de Execução: } \\
\text { 2021-2030 }\end{array}$ \\
\hline & & & & $\begin{array}{l}\text { Período de Execução: } \\
\text { 2021-2030 }\end{array}$ \\
\hline Ação & Produto & Prazo & Responsável & Resultado Esperado \\
\hline $\begin{array}{l}\text { Implantar o Projeto "Sistema de cole- } \\
\text { ta seletiva da UEPA-Capital" }\end{array}$ & $\begin{array}{l}\text { 0I Projeto } \\
\text { Implantado }\end{array}$ & 2021 & $\begin{array}{l}\text { PROGESP/ } \\
\text { UEPA } \\
\text { Ambiental }\end{array}$ & $\begin{array}{l}\text { RSU coletados } \\
\text { adequadamente e } \\
\text { destinados às } \\
\text { cooperativas. }\end{array}$ \\
\hline $\begin{array}{l}\text { Instalar em todas as Unidades da } \\
\text { UEPA lixeiras seletivas }\end{array}$ & $\begin{array}{l}6 \text { Lixeiras } \\
\text { seletivas } \\
\text { implantadas* } \\
23 \text { Contêineres } \\
\text { implantados* } \\
\end{array}$ & $\begin{array}{l}2021- \\
2023\end{array}$ & $\begin{array}{l}\text { UEPA } \\
\text { Ambiental/ } \\
\text { CAD }\end{array}$ & $\begin{array}{l}\text { Segregação dos RSU } \\
\text { garantida }\end{array}$ \\
\hline Desativar as lixeiras comuns & $\begin{array}{l}\text { Aprox. } 2100 \\
\text { Lixeiras } \\
\text { desativadas }\end{array}$ & 2021 & $\begin{array}{l}\text { UEPA } \\
\text { Ambiental/ } \\
\text { CAD }\end{array}$ & $\begin{array}{l}\text { Contaminação de resí- } \\
\text { duos recicláveis evitada }\end{array}$ \\
\hline $\begin{array}{l}\text { Capacitar todos os colaboradores de } \\
\text { limpeza e asseio da UEPA }\end{array}$ & $\begin{array}{l}65 \text { Colabora- } \\
\text { dores } \\
\text { capacitados* }\end{array}$ & $\begin{array}{l}2021- \\
2030\end{array}$ & $\begin{array}{l}\text { UEPA } \\
\text { Ambiental/ } \\
\text { COODEPE }\end{array}$ & $\begin{array}{l}\text { Gerenciamento } \\
\text { correto dos resíduos } \\
\text { realizado }\end{array}$ \\
\hline $\begin{array}{l}\text { Realizar coleta periódica dos resí- } \\
\text { duos recicláveis }\end{array}$ & $\begin{array}{l}\text { Coletas } \\
\text { realizadas }\end{array}$ & $\begin{array}{l}2021- \\
2030\end{array}$ & & $\begin{array}{l}\text { RSU coletados } \\
\text { adequadamente e } \\
\text { destinados às } \\
\text { cooperativas. }\end{array}$ \\
\hline $\begin{array}{l}\text { Acompanhar o processo de trans- } \\
\text { porte e recepção dos resíduos reci- } \\
\text { cláveis nos galpões das cooperativas. }\end{array}$ & $\begin{array}{l}\text { Monitoramento } \\
\text { implantado }\end{array}$ & $\begin{array}{l}2021- \\
2030\end{array}$ & $\begin{array}{l}\text { UEPA } \\
\text { Ambiental }\end{array}$ & $\begin{array}{l}\text { Resíduos destinados às } \\
\text { cooperativas. }\end{array}$ \\
\hline
\end{tabular}

*Descrição da distribuição, quantidade das lixeiras e colaboradores de Limpeza por Unidade são apresentados na Tabela II 
O Quadro 14 apresenta o detalhamento do Plano de Ações do Eixo "Resíduos de Equipamentos Eletroeletrônicos". Este detalhamento também contempla 6 Ações a partir do Objetivo Estratégico e das Metas definidas. Com essas ações espera-se como um dos resultados que os REEE sejam destinados adequadamente, atendendo o objetivo de gerenciamento apropriado dos REEE produzidos pela Instituição. O Plano de ação deste Eixo possui um caráter desafiador em sua execução na perspectiva da realidade de implantação da logística reversa na região.

Quadro I4. Plano de Ações de Resíduos de Equipamentos Eletroeletrônicos (REEE)

\begin{tabular}{|c|c|c|c|c|}
\hline \multicolumn{5}{|c|}{ Eixo: Resíduos de Equipamentos Eletroeletrônicos. } \\
\hline \multicolumn{5}{|c|}{ Objetivo Estratégico: Gerir adequadamente os REEE produzidos pela UEPA-Capital } \\
\hline \multicolumn{4}{|c|}{$\begin{array}{l}\text { Meta I: Implementar o sistema de logística reversa para os REEE em } 100 \% \text { das Unida- } \\
\text { des da UEPA-Capital. }\end{array}$} & $\begin{array}{l}\text { Período de Execução: } \\
2021-2030\end{array}$ \\
\hline \multicolumn{4}{|c|}{ Meta 2: Enviar $100 \%$ dos REEE da UEPA- Capital para a destinação adequada. } & $\begin{array}{l}\text { Período de Execução: } \\
202 \text { I-2030 }\end{array}$ \\
\hline Ação & Produto & Prazo & Responsável & Resultado Esperado \\
\hline $\begin{array}{l}\text { Implantar o Projeto "Sistema de lo- } \\
\text { gística reversa da UEPA-Capital". }\end{array}$ & $\begin{array}{l}\text { 0l Projeto } \\
\text { implantado }\end{array}$ & 2021 & $\begin{array}{l}\text { PROGESP/ } \\
\text { UEPA } \\
\text { Ambiental/ }\end{array}$ & $\begin{array}{l}\text { REEE destinados ade- } \\
\text { quadamente }\end{array}$ \\
\hline $\begin{array}{l}\text { Instalar em todas as Unidades da } \\
\text { UEPA lixeiras específicas para pilhas } \\
\text { e baterias. }\end{array}$ & $\begin{array}{l}12 \text { lixeiras } \\
\text { implantadas* }\end{array}$ & 2021 & $\begin{array}{l}\text { UEPA Am- } \\
\text { biental/CAD }\end{array}$ & $\begin{array}{l}\text { Segregação de pilhas e } \\
\text { baterias realizada. }\end{array}$ \\
\hline $\begin{array}{l}\text { Definir um espaço físico para acon- } \\
\text { dicionamento temporário dos resí- } \\
\text { duos de equipamentos de iluminação, } \\
\text { telecomunicações, etc. }\end{array}$ & $\begin{array}{l}\text { I I Espaços } \\
\text { adequados } \\
\text { definidos }\end{array}$ & 2021 & CAD & $\begin{array}{l}\text { Acondicionamento } \\
\text { interno adequado ga- } \\
\text { rantido }\end{array}$ \\
\hline Realizar coleta periódica dos REEE & Coletas realizadas & $2021-2030$ & & $\begin{array}{l}\text { REEE coletados adequa- } \\
\text { damente }\end{array}$ \\
\hline $\begin{array}{l}\text { Estabelecer parceria/contrato com } \\
\text { empresas especializadas na recepção } \\
\text { e tratamento dos REEE. }\end{array}$ & $\begin{array}{l}3 \text { Parcerias } \\
\text { estabelecidas }\end{array}$ & $2021-2030$ & $\begin{array}{l}\text { PROGESP/ } \\
\text { UEPA } \\
\text { Ambiental }\end{array}$ & $\begin{array}{l}\text { Destinação e tratamen- } \\
\text { to adequado dos REEE } \\
\text { garantida. }\end{array}$ \\
\hline $\begin{array}{l}\text { Destinar às cooperativas especiali- } \\
\text { zadas os REEE de acordo com sua } \\
\text { capacidade. }\end{array}$ & $\begin{array}{c}3 \text { cooperativas } \\
\text { para destinação }\end{array}$ & $202 I-2030$ & $\begin{array}{c}\text { UEPA } \\
\text { Ambiental }\end{array}$ & $\begin{array}{l}\text { Contribuição para a } \\
\text { preservação do meio } \\
\text { ambiente e saúde pú- } \\
\text { blica. } \\
\text { Apoio às cooperativas } \\
\text { especializadas garantida. }\end{array}$ \\
\hline
\end{tabular}

*Descrição da distribuição e quantidade das lixeiras para pilhas e baterias por Unidade são apresentados na Tabela II.

Para aprofundar o detalhamento dos Planos de ações dos Eixos RSU e REEE, a Tabela II descreve quantitativamente a distribuição de recursos materiais que serão utilizados. Este detalhamento foi definido a partir dos diagnósticos que demonstraram a real necessidade desses equipamentos para uma execução eficaz das Ações propostas. 
Tabela I I. Descrição da distribuição, quantidade das lixeiras e colaboradores de Limpeza por Unidade referente ao Plano de Ação dos Quadros 13 e 14.

$\begin{array}{lcccc}\text { Unidades } & \text { Lixeiras seletivas } & \text { Contêineres } & \begin{array}{c}\text { Colaboradores } \\ \text { de Limpeza }\end{array} & \begin{array}{c}\text { Lixeiras para } \\ \text { ilhas e baterias }\end{array} \\ \text { Reitoria } & 2 & 3 & 7 & 1 \\ \text { CCBS- Campus II } & 6 & 3 & 14 & 1 \\ \text { CCBS- Ed. Física } & 6 & 3 & 9 & 1 \\ \text { CCNT } & 5 & 3 & 9 & 1 \\ \text { Almoxarifado } & 1 & 1 & 1 & 1 \\ \begin{array}{l}\text { Arquivo/Patrimônio } \\ \text { EDUEPA/Confúcio }\end{array} & 1 & 1 & 1 & 12 \\ \quad \text { Total } & 1 & 1 & 64 & 1\end{array}$

O Quadro 15 apresenta o detalhamento do Plano de Ações do Eixo "Resíduos de Serviços de Saúde”. Este detalhamento contempla 4 (quatro) Ações a partir do Objetivo Estratégico e das Metas definidas para este tipo de resíduo. As Unidades CSE; UEAFTO; CCBS: Enfermagem e Campus II são o alvo destas Ações para que o gerenciamento dos RSS nestas Unidades ocorra adequadamente de acordo com a PNRS e ANVISA. A execução destas ações possuem um caráter de urgência devido seus efeitos na qualidade do ambiente e saúde da comunidade acadêmica.

Quadro I5. Plano de Ações dos Resíduos de Serviços de Saúde (RSS).

\begin{tabular}{|c|c|c|c|c|}
\hline \multicolumn{5}{|l|}{ Eixo: Resíduos de Serviços de Saúde } \\
\hline \multicolumn{5}{|c|}{$\begin{array}{l}\text { Objetivo Estratégico: Gerir adequadamente os RSS produzidos pelas Unidades CSE; UEAFTO; CCBS: Enferma- } \\
\text { gem e Campus II }\end{array}$} \\
\hline \multicolumn{4}{|c|}{$\begin{array}{l}\text { Meta I: Realizar a coleta e encaminhar } 100 \% \text { dos RSS das Unidades CSE; UEAFTO; } \\
\text { CCBS: Enfermagem e Campus II para a destinação adequada. }\end{array}$} & $\begin{array}{l}\text { Período de Execução: } \\
2021-2030\end{array}$ \\
\hline \multicolumn{4}{|c|}{$\begin{array}{l}\text { Meta 2:Aplicar medidas eficientes para o descarte correto dos Resíduos de Serviços } \\
\text { de Saúde no âmbito da UEPA Capital. }\end{array}$} & $\begin{array}{l}\text { Período de Execução: } \\
\text { 2021-2030 }\end{array}$ \\
\hline Ação & Produto & Prazo & Responsável & Resultado Esperado \\
\hline $\begin{array}{l}\text { Implantar o Projeto "Descarte cons- } \\
\text { ciente dos Resíduos de Serviços de } \\
\text { Saúde” }\end{array}$ & $\begin{array}{l}\text { Ol Projeto } \\
\text { Implantado }\end{array}$ & 2021 & $\begin{array}{l}\text { UEPA } \\
\text { Ambiental }\end{array}$ & $\begin{array}{l}\text { Contribuição para a } \\
\text { preservação do meio } \\
\text { ambiente e saúde pú- } \\
\text { blica. } \\
\text { RSS descartados ade- } \\
\text { quadamente }\end{array}$ \\
\hline $\begin{array}{l}\text { Instruir os servidores da saúde a } \\
\text { realizar o descarte adequado dos } \\
\text { RSS }\end{array}$ & $\begin{array}{l}65 \text { servidores } \\
\text { instruídos }\end{array}$ & $2021-2030$ & $\begin{array}{l}\text { UEPA } \\
\text { Ambiental/ } \\
\text { COODEPE } \\
\end{array}$ & Descarte adequado \\
\hline $\begin{array}{l}\text { Disponibilizar lixeiras e embalagens } \\
\text { para o descarte dos RSS de acordo } \\
\text { com a legislação específica. }\end{array}$ & $\begin{array}{l}\text { Quantidade de } \\
\text { lixeiras necessá- } \\
\text { rias implantadas }\end{array}$ & 2021 & $\begin{array}{l}\text { Empresa } \\
\text { Contratada/ } \\
\text { CAD } \\
\end{array}$ & $\begin{array}{l}\text { Segregação correta dos } \\
\text { RSS garantida }\end{array}$ \\
\hline $\begin{array}{l}\text { Possuir um contrato específico com } \\
\text { empresa especializada no tratamento } \\
\text { e disposição final dos RSS }\end{array}$ & $\begin{array}{l}\text { 0l contrato } \\
\text { estabelecido }\end{array}$ & $2021-2030$ & PROGESP & $\begin{array}{l}\text { Tratamento e destina- } \\
\text { ção final adequada dos } \\
\text { RSS. }\end{array}$ \\
\hline
\end{tabular}


Na finalização do detalhamento, o Quadro 16 apresenta o Plano de Ações do Eixo "Educação Ambiental". A partir do Objetivo Estratégico e das Metas definidas no âmbito da educação e conscientização, este detalhamento contempla 4 (quatro) Ações. A Ação de Implantação o Projeto "Descarte consciente" será fundamental para o alcance das Metas de todos os Eixos. Nesse sentido, este Projeto possui um caráter contínuo e sua frequência de execução das ações será definida na estrutura do Projeto.

Quadro 16. Plano de Ações de Educação Ambiental.

\begin{tabular}{|c|c|c|c|c|}
\hline \multicolumn{5}{|l|}{ Eixo: Educação Ambiental } \\
\hline \multicolumn{5}{|c|}{$\begin{array}{l}\text { Objetivo Estratégico: Conscientizar e sensibilizar a comunidade acadêmica em relação à gestão correta dos resí- } \\
\text { duos sólidos }\end{array}$} \\
\hline \multicolumn{4}{|c|}{$\begin{array}{l}\text { Meta I: Promover ações educativas que envolvam } 100 \% \text { dos servidores e alunos da } \\
\text { UEPA Capital }\end{array}$} & $\begin{array}{l}\text { Período de Execução: } \\
\text { 202I-2030 }\end{array}$ \\
\hline Ação & Produto & Prazo & Responsável & Resultado Esperado \\
\hline $\begin{array}{l}\text { Implantar o Projeto “Descarte cons- } \\
\text { ciente” }\end{array}$ & $\begin{array}{l}\text { Ol projeto } \\
\text { implantado }\end{array}$ & 2021 & $\begin{array}{l}\text { UEPA } \\
\text { Ambiental }\end{array}$ & $\begin{array}{l}\text { Maior conhecimento } \\
\text { a cerca da geração de } \\
\text { resíduos e do descarte } \\
\text { correto. }\end{array}$ \\
\hline $\begin{array}{l}\text { Orientar os servidores a não gerar e } \\
\text { descartar corretamente os resíduos } \\
\text { nas lixeiras seletivas }\end{array}$ & $\begin{array}{l}\text { I.II5 servidores } \\
\text { orientados }\end{array}$ & $2021-2030$ & $\begin{array}{l}\text { UEPA } \\
\text { Ambiental/ } \\
\text { COODEPE }\end{array}$ & $\begin{array}{l}\text { Maior conhecimento } \\
\text { a cerca da geração de } \\
\text { resíduos e do descarte } \\
\text { correto. }\end{array}$ \\
\hline $\begin{array}{l}\text { Orientar os alunos a não gerar e } \\
\text { descartar corretamente os resíduos } \\
\text { nas lixeiras seletivas }\end{array}$ & $\begin{array}{l}6.520 \text { alunos } \\
\text { orientados }\end{array}$ & $2021-2030$ & $\begin{array}{l}\text { UEPA } \\
\text { Ambiental/ } \\
\text { COODEPE }\end{array}$ & $\begin{array}{l}\text { Maior conhecimento } \\
\text { a cerca da geração de } \\
\text { resíduos e do descarte } \\
\text { correto. }\end{array}$ \\
\hline $\begin{array}{l}\text { Realizar eventos acadêmicos para } \\
\text { disseminar conhecimento sobre resí- } \\
\text { duos sólidos }\end{array}$ & $\begin{array}{l}\text { 0I evento anual } \\
\text { realizado }\end{array}$ & $2021-2030$ & $\begin{array}{l}\text { UEPA Am- } \\
\text { biental/PRO- } \\
\text { GESPI } \\
\text { PROPESPI } \\
\text { PROEX } \\
\end{array}$ & $\begin{array}{l}\text { Maior Conhecimento } \\
\text { sobre resíduos sólidos } \\
\text { e suas interconexões } \\
\text { gerado e disseminado. }\end{array}$ \\
\hline
\end{tabular}




\section{ASPECTOS DE GESTÃO}

Todo o conjunto de objetivos, metas, projetos e ações apresentado, para se configurarem e se implementarem efetivamente, demandarão, por parte da Gestão Superior da UEPA, a estrutura e operacionalização dos necessários instrumentos de caráter institucional, além do fortalecimento contínuo do Programa de Gestão UEPA Ambiental.

Será necessário que os gestores responsáveis por cada Centro e Unidades da UEPA adotem em suas agendas a aplicação e execução do PGIRS/UEPA - Capital como forma de alcançar as metas estabelecidas. Será necessário que as Coordenações administrativas (CAD) cumpram um papel de gerenciar e monitorar as ações que serão realizadas a fim de somar forças ao Programa de Gestão UEPA Ambiental.

A UEPA deverá incluir em seu planejamento orçamentário os investimentos com aquisição de bens permanentes/consumo que serão necessários na realização dos projetos. Todos os projetos serão unificados no sentido de atender todas as demandas específicas de cada Unidade. Caberá ao Programa de Gestão UEPA Ambiental estruturar os projetos e suas respectivas ações detaIhando todos os custos para sua execução.

Contudo, o envolvimento participativo de toda comunidade acadêmica será ferramenta-chave para o sucesso deste PGIRS/UEPA - Capital. Sendo assim, um modelo de gestão ambiental estratégica poderá ser adotado pela gestão superior da IES para promover a sustentabilidade na gestão de forma continuada.

\section{CONSIDERACOES FINAIS}

O PGIRS/UEPA - Capital é o primeiro instrumento de gestão construído pelo Programa de Gestão UEPA Ambiental que irá atender a PNRS e a A3P, além dos Objetivos do Desenvolvimento Sustentável da OMS. A disponibilização este documento para a sociedade irá incentivar outras instituições públicas e privadas a adotarem a gestão ambiental em sua estrutura de gestão.

Ambiciosamente, o próximo desafio será a elaboração do Volume II, que irá atender os Campi da UEPA no interior do Estado. O PGIRS/UEPA - Interiorização será a etapa conclusiva deste Plano e trará um panorama geral do gerenciamento de RS da UEPA em todo o Pará.

Por fim, o Programa de Gestão UEPA Ambiental agradece a todos que contribuíram direta e indiretamente com a construção deste Plano e espera ansiosamente sua revisão em 2030. 


\section{REFERÊNCIAS BIBLIOGRÁFICAS}

ABBONDANZA, M. N. M.; SOUZA, R. G. Estimating the generation of household e-waste in municipalities using primary data from surveys:A case study of Sao Jose dos Campos, Brazil. Waste Management, [s.I.], v. 85, p. 374-384, fev. 2019. http://dx.doi.org//0.1016/j.wasman.2018.12.040

ADENIRAN,A. E; NUBI,A.T.;ADELOPO,A. O. Solid waste generation and characterization in the University of Lagos for a sustainable waste management. Waste Management, v. 67, p. 3-10, 2017. https://doi.org/10.1016/j.wasman.2017.05.002

AGAMUTHU, P.; KASAPO, P.; NORDIN, N. A. M. E-waste flow among selected institutions of higher learning using material flow analysis model. Resources, Conservation And Recycling, [s.I.], v. I05, p. I77-185, dez. 20I5. http://dx.doi.org/I0.1016/j.resconrec.2015.09.018

AGÊNCIA NACIONAL DE VIGILÂNCIA SANITÁRIA. Resolução da Diretoria ColegiadaRDC n. 306, de 07 de dezembro de 2004. Dispõe sobre o Regulamento Técnico para o gerenciamento de resíduos de serviços de saúde. Brasília, DF, 2004.

ALLEN, A. S. Institutional environmental change at Tulane University. Tulane University, New Orleans, USA, 1999.

ARAÚJO, R. S.;VIANA, E. Diagnóstico dos resíduos sólidos gerados na escola de artes, ciências e humanidades $(E A C H)$ como instrumento para a elaboração de um plano de gestão na unidade. Revista Eletrônica em Gestão, Educação e Tecnologia Ambiental, v. 8, n. 8, p. I805-1817, 2012. http://dx.doi.org/|0.5902/2236|| 70723 |

ARCIOTTE, M. L.; SACCARO JUNIOR, N. L. Sensibilização e mobilização dentro da Política Nacional de Resíduos Sólidos: desafios e oportunidades da educação ambiental. Texto para discussão / Instituto de Pesquisa Econômica Aplicada - IPEA. ISSN I4I 5-4765. 20 I2.

ASSOCIACAO BRASILEIRA DE NORMASTÉCNICAS - ABNT. NBR n. $\mathbf{1 0 . 0 0 4 / 2 0 0 4}$, de 30 de novembro de 2004. Resíduos Sólidos - classificação. Recuperado em I4 de novembro de 2019 , disponível em www.abnt.org.br/

ASTM D523I-92(2016), Standard Test Method for Determination of the Composition of Unprocessed Municipal Solid Waste. ASTM International, West Conshohocken, PA, 20I6, http://www.astm.org/cgi-bin/resolver.cgi?D523I. https://doi.org/I0.I520/D523I-92R I6

BALDÉ, C. P.; FORTI,V.; GRAY,V.; KUERH, R.; STENGMANN, The Global E-waste Monitor 20 I7, United Nations University (UNU), International Telecommunication Union (ITU) \& International Solid Waste Association (ISWA), Bonn/Geneva/Vienna. Electronic Version, 978-92, 20 I 7.

BARROS, A. B. et al. Produção de resíduos sólidos urbanos na regional de Paraíso do Tocantins, BRASIL. In: Fórum Internacional de Resíduos Sólidos - Anais. 2017. 
BARROS, R.T.D.V.; SILVEIRA, Á.V. F. Uso de indicadores de sustentabilidade para avaliação da gestão de resíduos sólidos urbanos na Região Metropolitana de Belo Horizonte. Engenharia Sanitária e Ambiental, v. 24, n. 2, p. 4I I -423, 20 I9. https://doi.org/I0.1590/SI4I3-4I 522019|77499

BONNET, J. F.; DEVEL, C.; FAUCHER, P.; ROTURIER, J.Analysis of electricity and water end-uses in university campuses: case-study of the University of Bordeaux in the framework of the Ecocampus European Collaboration. Journal of Cleaner Production, v. I0, n. I, p. I 3-24, 2002. https:// doi.org/10.1016/S0959-6526(01)00018-X

BRASIL ( 198 I). Lei n. 6.938 de 3 I de agosto de I98I. Estabelece a Política Nacional de Meio Ambiente. Brasília: Diário Oficial da União. http://www.planalto.gov.br/ccivil_03/Leis/L6938.htm

BRASIL (2010). Lei n. 12.305, de 02 de agosto de 20I0. Estabelece a Política Nacional de Resíduos Sólidos; altera a Lei $\mathbf{n}^{\circ} \mathbf{9 . 6 0 5}$, de $\mathbf{I} 2$ de fevereiro de 1998 e dá outras providências. Brasília: Diário Oficial da União. http://www.planalto.gov.br/ccivil_03/_ato200720/0/20// ei/ $\underline{112305 . h t m}$

BRASIL. (2004) Agência Nacional de Vigilância Sanitária (ANVISA). Resolução da Diretoria Colegiada $n^{\circ}$ 306, de 7 de dezembro de 2004. Dispõe sobre o Regulamento Técnico para o gerenciamento de Resíduos de Serviços de Saúde. Diário Oficial da União, Brasília.

BRASIL. (2005) Conselho Nacional do Meio Ambiente (CONAMA). Resolução n 358, de 29 de abril de 2005. Dispõe sobre o tratamento e a disposição final dos resíduos dos serviços de saúde e dá outras providências. Diário Oficial da União, Brasília.

BRASIL. Decreto n. 7.404, de 23 de dezembro de 2010. Regulamenta a Lei no 12.305, de 2 de agosto de 20 I0, que institui a Política Nacional de Resíduos Sólidos, cria o Comitê Interministerial da Política Nacional de Resíduos Sólidos e o Comitê Orientador para a Implantação dos Sistemas de Logística Reversa, e dá outras providências. Brasília, DF, 2010.

BRASIL. Ministério da Saúde (MS). Saúde ambiental: guia básico para construção de indicadores. Brasília: MS; $201 \mathrm{I}$.

CASTRO, A. B. C; LIMA, U. R.; SANTOS, S. D. T.; BEZERRA, C. M. C. Gestão de resíduos de equipamentos eletroeletrônicos: Um estudo de caso sobre o descarte de toners de impressoras em uma empresa privada do nordeste do Brasil. Revista Gestão \& Sustentabilidade Ambiental, v. 6, n. 3, p.666-675, 2017. http://dx.doi.org/I0.19177/rgsa.v6e32017666-678.

CIROTTO, M. F. S.; LÍBANO, A. M. Abordagem do correto descarte de cartuchos de tinta e toners por meio de cartilha educativa. Artigo (Graduação em licenciatura em ciências biológicas) - Centro Universitário de Brasília, 2013. 
CONSELHO NACIONAL DO MEIO AMBIENTE - CONAMA. Resolução n. 358, de 29 de abril de 2005. Dispõe sobre o tratamento e a disposição final dos resíduos dos serviços de saúde e dá outras providencias. Brasília, DF, 2005.

CONTE, A. A. Ecoeficiência, logística reversa e a reciclagem de pilhas e baterias: revisão. Revista Brasileira de Ciências Ambientais (Online), n. 39, p. I 24- 139, 20 I6. http://dx.doi.org/ | 0.5327/ z2176-947820167||4

COSTA, K. B. M.; RODRIGUES, M.A.A educação ambiental e o lixo: um estudo de caso realizado em uma escola pública de Teresina (PI). Revista Brasileira de Educação Ambiental (Revbea), São Paulo, v. 9, n. 2, p. 344-363, 2014.

DE CONTO, S. M.; BRUSTOLIN, I.; PESSIN, N.; SCHNEIDER,V. E.; BEAL, L. L. Gestão de resíduos na Universidade Caxias do Sul: um processo de construção das atividades de ensino, pesquisa e extensão com responsabilidade socioambiental. In: DE CONTO, S. M. (ORG.) Gestão de resíduos em Universidades. Educs, Caxias do Sul, Brasil, p. 33-59, 2010.

DE NEZ, E. Os dilemas da gestão de universidades multicampi no Brasil. Revista Gestão Universitária na América Latina-GUAL, v. 9, n. 2, p. I3|-|53, 2016. https://doi.org/|0.5007/ $\underline{1983-4535.2016 v 9 n 2 p|3|}$

DE VEGA, C. A.; BENÍTEZ, S. O.; BARRETO, M. E. R. Solid waste characterization and recycling potential for a university campus. Waste management, v. 28, p. S2I-S26, 2008. https://doi.org/l0.1016/j.wasman.2008.03.022

DEMAJOROVIC, J.;AUGUSTO, E. E. F.; SOUZA, M.T. S. Reverse Logistics of e-waste in developing countries: challenges and prospects for the brazilian model. Ambiente \& Sociedade, v. 19, n. 2, p. I I7-I36, 20 I6. http://dx.doi.org/ I0.1590/|809-4422asoc|4I545v|922016

ESTADO DO PARÁ (1993). Lei n. 5.747 de 18 de maio de 1993. Cria a Universidade do Estado do Pará. Belém-PA: Diário Oficial do Estado. http://www.legispara.pa.gov.br/estado

SCHOELER, G. P.; SOUZA, P.; AGRA, M., SILVA, N.; ROMANI, R. F. Diagnóstico do gerenciamento e gestão integrada de lâmpadas em uma instituição de ensino superior. In: Anais do Congresso Sul-Americano de Resíduos Sólidos e Sustentabilidade, (Vol. 2). Foz do Iguaçu - PR, 2019.

FARIA,A.S.D.; FERREIRA, C. E. C.; MEIRELES, J. L. S.; SILVA, G. R.A.; BRAGA, R. M. Q. L. Um panorama do gerenciamento dos resíduos eletroeletrônicos na cidade universitária José Silveira Netto - UFPA/PA. In: Congresso Brasileiro de Engenharia Sanitária e Ambiental, 28. Anais. Rio de Janeiro: Riocentro, 2015.

FERREIRA, C. P.; GONZALEZ, M. H.; DA SILVA VIANA, L. Gestão e gerenciamento de resíduos 
químicos dos laboratórios didáticos do departamento de química e ciências ambientais e do entreposto de resíduos do IBILCE/UNESP. Periódico Eletrônico Fórum Ambiental da Alta Paulista, v. I2, n. I, 2016.

FINKLER, N. R.; T, PANNIZON.; SCHNEIDER, V. E. Avaliação da composição gravimétrica dos resíduos sólidos comuns gerados na Universidade de Caxias do Sul - RS e comparação com outras instituições de ensino superior. In:Anais do Congresso Internacional de Tecnologias para o Meio Ambiente, v. 5. Bento Gonçalves, 2014.

GATTI,T. H.; OLIVEIRA, D.; SUAREZ, P.A. Z.; ANDREOLI, J. C. A produção artesanal de papel na Universidade de Brasília e as patentes de reciclagem. In: CATALÃO, V. M. L; LAYRARGUES, P. P.; ZANETI, I. C. B. B. (ORGS.). Universidade para o século XXI: educação e gestão ambiental na Universidade de Brasília. Cidade Gráfica e Editora, Brasília, Brasil, p. 45-57, 201 I.

GHINEA, C.; DRĂGOI, E. N.; COMĂNIȚĂ, E. D.; GAVRILESCU, M.; CÂMPEAN, T.; CURTEANU, S. I. L.V.I.A.; GAVRILESCU, M. Forecasting municipal solid waste generation using prognostic tools and regression analysis. Journal of environmental management, v. I82, p. 80-93, 20 I6. https:// doi.org/I0.1016/j.jenvman.2016.07.026

GOLLAKOTA, A. R. K.; GAUTAM, S.; SHU, C. Inconsistencies of e-waste management in developing nations - Facts and plausible solutions. Journal Of Environmental Management, [s.I.], v. 26I, p. I I0-234, maio 2020. Elsevier BV. http://dx.doi.org/I0.10 I6/j.jenvman.2020.I I 0234

GOMES,A. S.T.; SOUZA, L.A.;YAMANE, L. H.; SIMAN, R. R. Quantification of E-Waste:A Case Study in Federal University of Espírito Santo, Brazil. International Journal of Environmental and Ecological Engineering, v. I I, n. 2, p. 195-203, jan. 20 I7. https://doi.org/ | 0.528 I/zenodo. I I 29099

HUANG, T.T; SARTORI,V.C. Estudo sobre remanufatura de cartuchos de toner de impressora de duas faculdades da UNICAMP. Revista Ciências do Ambiente On-Line, v. 8, n. 2, p. 2-6, 2012.

IBGE 20I3. Instituto Brasileiro de Geografia e Estatística. Métodos de Projeções e estimativas da população do Brasil e das Unidades da Federação. Disponível em https://www.ibge.gov.br/ apps/populacao/projecao/notatecnica.html

ILANKOON, I. M. S. K.; GHORBANI, Y.; CHONG, M. N.; HERATH, G.; MOYO, T.; PETERSEN, J. $E$-waste in the international context - A review of trade flows, regulations, hazards, waste management strategies and technologies for value recovery. Waste Management, v. 82, p. 258-275, 2018. http://dx.doi.org/10.1016/j.wasman.2018.10.018

IMBIRIBA, B. C. O.; RAMOS, J. R. D. S.; DE SOUSA SILVA, R.; CATTANIO, J. H.; DO COUTO, L. L.; MITSCHEIN,T.A. Estimates of methane emissions and comparison with gas mass burned in CDM action in a large landfill in Eastern Amazon. Waste Management, v. I0 I, p. 28-34, 2020. https:// doi.org/I0.1016/j.wasman.2019.09.029 
INSTITUTO BRASILEIRO DO MEIO AMBIENTE E DOS RECURSOS NATURAIS RENOVÁVEIS - IBAMA. Instrução normativa IBAMA N08, de 03/09/20I2. Institui para fabricantes nacionais e importadores, os procedimentos relativos ao controle do recebimento e da destinação final de pilhas e baterias ou produto que as incorporem. 2012.

WAHRLICH, J.; DA SILVA, F.A.; JUNIOR, M. R. F.; ZANETTI, D.; SIMIONI J. S. Logística reversa dos resíduos eletroeletrônicos: Um estudo de caso da empresa Eco Centro Sul. In: Anais do Fórum Internacional de Resíduos Sólidos, Vol. 8. Curitiba, 2017.

JACOBI, P. R.; BESEN, G. R. Gestão de resíduos sólidos em São Paulo: desafios da sustentabilidade. Estudos Avançados, v. 25, n. 7I, p. I35-I58, 201I. http://dx.doi.org/10.1590/S0103$\underline{40142011000100010}$

KER,A. B.; DE FREITAS, D. P.; NUNES, F. R. G.; GIANETTI,T.T.; CRUZ, S. L.; PINTO,T. G.; GIANETTI, T.T.;THEODORO, D. C; PELISSARI,V. B. Composição gravimétrica dos resíduos sólidos produzidos no campus I do Centro Universitário FAESA. Revista Científica FAESA, v. I3, n. I, 20 I7. https://doi.org//0.5008//809.7367.1/3

KIDDEE,P.;NAIDU,R.;WONG,M.H.Electronic waste management approaches:an overview. Waste Management, v. 33, n. 5, p. I237-1250, 2013. http://dx.doi.org/I0.1016/j.wasman.2013.01.006

KIPPER, L. M.; MÄHLMANN, C. M.; RODRÍGUEZ, A. L.; LOPEZ, D.A. R.;WEISS, F.; KIST, L.T.; MACHADO, E. L. Sistema de gestão ambiental com ênfase em processos circulares: o estudo de caso da Unisc. In: DE CONTO, S. M. (ORG.). Gestão de resíduos em universidades. Educs, Caxias do Sul, Brasil, I63-184, 2010.

LAVNITCKI, L.; BAUM, C.A.; BECEGATO,V.A. Política Nacional dos Resíduos Sólidos:Abordagem da problemática no Brasil e a situação na região Sul. Ambiente \& Educação - Revista de Educação Ambiental, v. 23, n. 3, p. 379-401, 2018.

LEOPOLDINO, C. C. L.; MENDONÇA, F. M.; SIQUEIRA, P. H. L.; BORBA, É. L The disposal of fluorescent lamps of industries of the metropolitan region of Belo Horizonte - MG. Journal Of Cleaner Production, v. 233, p. I486-1493, 2019. http://dx.doi.org/10.1016/j.jclepro.2019.06.192

LEVIS, J.W.; BARLAZ, M. A.; DE CAROLIS, J. F.; RANJITHAN, S. R. A generalized multistage optimization modeling framework for life cycle assessment-based integrated solid waste management. Environmental modelling \& software, v. 50, p. 5I-65, 2013. https://doi.org/10.1016/j. envsoft.2013.08.007

LOURENÇO, V. A.; ZANCHIN, M.; PAULA, L. S.; CORREA, A. G.; NADALETI, C.W. Resíduos perigosos gerados em uma gráfica: Estudo de caso de uma instituição de ensino superior de Pelotas/RS. In:Anais do Congresso Sul-Americano de Resíduos Sólidos, vol. 2. Foz do Iguaçu: Parque Tecnológico de Itaipu, 2019. 
MALDONADO, L. Reduction and recycling of urban waste at higher education institutions: a case study. Revista Ingeniería, v. I0, n. I, p. 59-68, 2006.

MARCHI, C. M. D. F. Novas perspectivas na gestão do saneamento: apresentação de um modelo de destinação final de resíduos sólidos urbanos. urbe. Revista Brasileira de Gestão Urbana, v. 7, n. I, p. 9 I-I05, 20I5. https://dx.doi.org/I0.1590/2I75-3369.007.00I.AO06

MARQUES, E.A. F.;VASCONCELOS, M. C. R. L.; GUIMARÃES, E. H. R.;BARBOSA, F. H. F. Gestão da Coleta Seletiva de Resíduos Sólidos no Campus Pampulha da UFMG: Desafios e Impactos Sociais. Revista de Gestão Ambiental e Sustentabilidade, v. 6, n. 3, p. I 3 I-I49, 20 I7. http://dx.doi. org/|0.5585/geas.v6i3.82I

MARTINS, A. F.; SILVEIRA, D. D. Gestão de resíduos em universidades: a experiência da Universidade Federal de Santa Maria. In: DE CONTO, S. M. (ORG.). Gestão de resíduos em universidades. Educs, Caxias do Sul, Brasil, I43-I62, 2010.

MATUS C. Política, planejamento \& governo. Brasília: IPEA; 1996.

MBULIGWE, S. E. Institutional solid waste management practices in developing countries: a case study of three academic institutions in Tanzania. Resources, Conservation and Recycling, v. 35, n. 3, p. I31-146, 2002. https://doi.org/10.1016/S092I-3449(01)001 I3-6

MELLEIRO, M. M.;TRONCHIN, D. M. R.; CIAMPONE, M. H.T. O planejamento estratégico situacional no ensino do gerenciamento em enfermagem. Acta Paulista de Enfermagem, v. I8, n. 2, p. I65-I7I, 2005.

MELLO,A. S. Desenvolvimento de Equação para previsão da Taxa de Geração Per Capita de Resíduos Sólidos Urbanos no Estado de São Paulo. Dissertação de Mestrado. Universidade de Ribeirão Preto UNAERP, Programa de Pós-Graduação em Tecnologia Ambiental, p. $120,2014$.

MINISTÉRIO DO MEIO AMBIENTE - MMA. Agenda Ambiental na Administração Pública - A3P. Brasília, DF: MMA. Recuperado em 04 de novembro de 2019, de http://a3p.mma.gov.br/

MINISTÉRIO DO MEIO AMBIENTE - MMA. Guia para elaboração dos Planos de Gestão de Resíduos Sólidos. Secretaria de Recursos Hídricos e Ambiente Urbano. Brasília - DF, 20 I I.

MINITTO, J. B. et al. Gestão de resíduos sólidos na Universidade Federal do Rio Grande do Sul - Brasil. In:Anais do Fórum Internacional de Resíduos Sólidos, 2018.

MONTEIRO, J. H. P. et al. Manual de Gerenciamento Integrado de resíduos sólidos. 200 I. Coordenação técnica Victor Zular Zveibil. Rio de Janeiro: IBAM. 
MONTEIRO, P. C. L. Logística reversa para lâmpadas fluorescentes no município de são gabriel (RS).. TCC, 37 f (Graduação) - Bacharelado em Gestão Ambiental, Universidade Federal do Pampa, São Gabriel, 2017.

MONTERREY,T. (2007). Sustainable Campus. Campus Operations. Wastes and Recycling. Waste Reduction, v. I4, n. 3, p. 94-107, 2007.

MOREIRA, P. G.; DI VITTA, P. B.; PIMENTA, A. C.; MEIRA, A. M.; SILVA, A. R.; CAVALHEIRO, C. H. T.; ZORIGIAN, C. M.; SUDAN, D. C.; LIMA, E.T.;TAVARES, G. A.; COOPER, M.; LEME, P. C. S.; SIMONELLI, S. B. J.;ALBUQUERQUE,V. G. C.; DELITTI,W. B. C. Construção de política para gestão de resíduos na Universidade de São Paulo como modelo para implementação da PNRS em IES. Revista Eletrônica em Gestão, Educação e Tecnologia Ambiental, Santa Maria, v. I8, n. I, p.38I-387, 20 I4. http://dx.doi.org//0.5902/2236 I I70I2435

NAGASHIMA, L. A.; DE BARROS JUNIOR, C.; FONTES, C. E. R. Análise da produção e taxa de geração de resíduos sólidos de serviços de saúde do Hospital Universitário Regional de Maringá. Acta Scientiarum Technology, v. 29, n. 2, p. I3 - |39, 2007.

NEZ, E. Os dilemas da gestão de universidades multicampi no Brasil. Revista Gestão Universitária na América Latina - Gual, v. 9, n. 2, p. |3|-|53, 20|6. http://dx.doi.org/|0.5007| $\underline{|983-4535.2016 v 9 n 2 p| 3 \mid}$

NUNES, L. P. M.; DOS SANTOS, J. S.; SILVA, S. C. S.; PIMENTEL, M.A.Variação da temperatura do solo no leste da Amazônia. Os Desafios da Geografia Física na Fronteira do Conhecimento, v. I, p. 4787-4797, 2017. https://doi.org/I0.20396/sbgfa.vli2017.2187

OKENIYI, J. O.;ANWAN, E. U. Solid wastes generation in Covenant University, Ota, Nigeria: Characterisation and implication for sustainable waste management. J. Mater. Environ. Sci, v. 3, n. 2, p. 4I9-424, 2012.

OLIVEIRA M. L. B. C.; FARIA S. C. Aplicação do modelo FPSEEA na construção de indicadores de saúde ambiental. In: PHILIPPI A. J.; MALHEIROS T.F. (editores). Indicadores de Sustentabilidade e Gestão Ambiental. Barueri, SP: Manole; p. 445-47I, 2012.

OLIVEIRA, J. D.; SELVA, V.; PIMENTEL, R.; SANTOS, S. M. Resíduos Eletroeletrônicos: Geração, impactos ambientais e gerenciamento. Revista Brasileira de Geografia Física, v. I0, n. 5, p. I655-1667, 2017. http://dx.doi.org/|0.26848/rbgf.v10.5.p|655-1667

OLIVEIRA, M. J. S. Comunidade acadêmica do campus Amazônia da UFOPA descarta resíduos de maneira inadequada.Trabalho de Conclusão de Curso de Especialização, PPG em Gestão Estratégica em Políticas Públicas, Universidade de Campinas, 2018.

PAIVA, L. N.; MULLER, S.; ARRUDA, J. B. F.; ALCANTARA, R. L. C.; DELIBERADOR, L. R. Prog- 
nóstico da gestão dos resíduos sólidos urbanos de uma cidade de médio porte: estimativa de impactos ambientais. Revista Produção Online, v. 19, n. 4, p. I42I-I440, 2019. https://doi. org/I0.14488/1676-190I.v19i4.3550

PANIZZON, T.; REICHERT, G. A.; SCHNEIDER, V. E. Avaliação da geração de resíduos de equipamentos eletroeletrônicos (REEEs) em uma universidade particular. Engenharia Sanitária e Ambiental, v. 22, n. 4, p. 625-635, 2017. http://dx.doi.org/I0.I590/s I4I3-4I5220I7|42636

PARLAMENTO EUROPEU. Diretiva 20 I 2/I 9/UE do Parlamento Europeu e do Conselho, de 4 de julho de 2012 . Relativa aos resíduos de equipamentos eléctricos e eletrônicos (REEE). Reformulação. Jornal Oficial da União Europeia.

PERUCHIN, B.; GUIDONI, L. L. C.; CORRÊA, L. B.; CORRÊA, É. K. Gestão de resíduos sólidos em restaurante escola. Tecnológica, v. I7, n. I, p. 13-23, 2013. http://dx.doi.org/10.17058/tecnolog. vl7il.3627

PINHEIRO, C. D. P. D. S.; DOS SANTOS, D. S.; TORRES, L. M.; RODRIGUES, P. R. S. Práticas de gestão ambiental em Instituições de Ensino Superior: $O$ caso da Universidade Federal Rural da Amazônia, Campus Belém. Revista Gestão \& Sustentabilidade Ambiental, v. 8, n. 2, p. 487 $512,2019$.

PINHEIRO, P.T.; FRANCISCHETTO, G. P. P.A política nacional de resíduos sólidos como mecanismo de fortalecimento das associações de catadores de materiais recicláveis. Derecho y Cambio Social, p. 24, 2016.

PORTO, W. S.; BRASNIESKI, A. C. F.; SOUZA, J. A.; FREITAS, M. A. L. Resíduos de equipamentos eletroeletrônicos: Um diagnóstico da destinação na percepção do consumidor final de Vilhena - RO. Amazônia, Organizações e Sustentabilidade, v. 8, n. 2, p. 07-26, 2020. http://dx.doi. org/10.17648/aos.v8i2.1008

PRODANOV, C. C.; FREITAS, E. C. Metodologia do trabalho científico: métodos e técnicas da pesquisa e do trabalho acadêmico. 2a ed. Novo Hamburgo, RS: Feevale, 2013.

RODRIGUES,A. C.; BOSCOV, M. E. G.; GÜNTHER,W. M. R. Domestic flow of e-waste in São Paulo, Brazil: Characterization to support public policies. Waste Management, v. I02, p. 474-485, 2020. http://dx.doi.org/10.1016/j.wasman.2019.10.052

RODRIGUES, N.A. et al. Gerenciamento de resíduos de serviços de saúde na Universidade Federal de Minas Gerais: percepção de risco no ICB e no Campus Saúde. Rev Med Minas Gerais, v. 26, n. 8, p. SI95-SI99, 2016.

RODRIGUES,W.; MAGALHÃES FILHO, L.N.; PEREIRA, R.S.Análise dos Determinantes dos Cus- 
tos de Resíduos Sólidos Urbanos nas Capitais Estaduais Brasileiras. Urbe. Revista Brasileira de Gestão Urbana, v. 8, n. I, p. I30-I4I, 20 I6. http://dx.doi.org/I0.I590/2 I75- 3369.008.00I.AO02

ROOS, A. A. et al. Concepções e práticas de servidores públicos acerca do tema resíduos sólidos. In:Anais do Fórum Internacional de Resíduos Sólidos, 2017.

SANTOS, J.W. Caracterização e separação dos materiais presentes em cartuchos de toner pós consumo - avaliando o potencial econômico para reciclagem. Dissertação (Mestrado em Engenharia de Minas, Metalúrgica e de Materiais) - Universidade Federal do Rio Grande do Sul, Porto Alegre, 2019.

SANTOS, L. B.; SILVA, E. R.; LOUREIRO, J. O. Gestão de resíduos sólidos e a logística reversa de resíduos eletrônicos. Revista UNIABEU, v. 8, n. 20, p. I44-I60, 2015.

SANTOS, M. M. Proposta de ação para o descarte de resíduos eletroeletrônicos: Um estudo na Universidade Federal de Sergipe. 2018. 70 f. Monografia (Graduação) - Curso de administração, Universidade Federal de Sergipe, São Cristóvão, 2018.

SCHNEIDER,V. E.; STEDILE, N. L. R. Resíduos de serviços de saúde: um olhar interdisciplinar sobre o fenômeno. Caxias do Sul: Educs, v. 3, 2015.

SECRETARIA DE ESTADO DE MEIO AMBIENTE E SUSTENTABILIDADE. Plano de Gestão Integrada de Resíduos Sólidos do Estado do Pará (PEGIRS). Relatório de síntese, vol. I. Belém-PA: Brencorp. 2014.

SILVA,A. F; MATTOS, U.A. O. Logística reversa - Portugal, Espanha e Brasil: Uma revisão bibliográfica. Revista Internacional de Ciências, v. 9, n. I, p. 35-52, 2019. Universidade de Estado do Rio de Janeiro. http://dx.doi.org//0.12957/ric.2019.36108

SILVA, E. M. DA.; DE ALBUQUERQUE,W. G.; SOBRINHO, L. G. A.; MEDEIROS, A. N. Estimativa da geração e composição gravimétrica dos resíduos sólidos da Universidade Federal de Campina Grande, Pombal, Paraíba. Revista Verde de Agroecologia e Desenvolvimento Sustentável, v. I3, n. I, p. 66-73, 2018.

SILVA, E. N. C. Gerenciamento de Resíduos de Serviços de Saúde: adaptação transcultural e validação do instrumento Health-care Waste Manegement - Rapid Assessment Tool. 278 f. Tese (Doutorado) - Escola Nacional de Saúde Pública, Rio de Janeiro. 201 I.

SODRÉ, M. S.; LEMOS, C. F. O cenário do gerenciamento de resíduos dos serviços de saúde no Brasil. In:Anais do Fórum Internacional de Resíduos Sólidos, 2017.

SOUZA, H. E. N.; BISPO, C. J. C.; SARDINHA,A. S.; NOGUEIRA, C.J. L. G.; COSTA, D. C. T.; SILVA, E. M.;THIJM, F. S.A.; SANTANA,T. M.; ROSA,V. L. G. Gestão de resíduos sólidos em uma Uni- 
versidade na Amazônia. In:Anais do $10^{\circ}$ Fórum Internacional de Resíduos Sólidos do Instituto Venturi Para Estudos Ambientais (p. I-9). João Pessoa: Instituto Venturi Para Estudos Ambientais. 2019

STEDILE, N. L. R.; SCHNEIDER,V. E.; NUNES, M.W.; KAPPES,A. C.A aplicação do modelo FPSEEA no gerenciamento de resíduos de serviço de saúde. Ciência \& Saúde Coletiva, v. 23, p. 36833694, 2018. https://doi.org/I0.1590/1413-81232018231I.19352016

TAUCHEN, J.; BRANDLI, L. L.A gestão ambiental em instituições de ensino superior: modelo para implantação em campus universitário. Gestão \& Produção, v. I 3, n. 3, p. 503-5 I 5, 2006.

UEHARA, S. C. S.A.;VEIGA,T. B.;TAKAYANAGUI,A. M. M. Gerenciamento de resíduos de serviços de saúde em hospitais de Ribeirão Preto (SP), Brasil. Engenharia Sanitária e Ambiental, v. 24, n. I, p. I I I-I30, 2019. http://dx.doi.org/|0.1590/s |4|3-4|5220|9|75893

VENTURA, H. F. R. Gestão sustentável dos resíduos sólidos: Práticas na Universidade da Paraíba quanto à destinação adequada dos cartuchos e toners. 2018. I I 2 f. Dissertação (Mestrado) - Curso de Desenvolvimento e Meio Ambiente, Universidade Federal da Paraíba, João Pessoa, 2018.

VERCEZI, G. D.; DIAS, R. F.;ANTUNES, M. B.; DE ALMEIDA, C. R.; BOLSONI, L. L. M.; DONINI, J. D.; CHARLO, P. B. Condição de Saúde e utilização da árvore dos problemas em pacientes hipertensos na atenção primária. Saúde Coletiva (Barueri), v. 49, p. 1627-163I, 2019. http://revistas. mpmcomunicacao.com.br/index.php/saudecoletiva/article/view/I35

WATANABE, F. P.; CANDIANI, G. Gestão de resíduos de equipamentos eletroeletrônicos em instituições de ensino superior. Revista Ibero-Americana de Ciências Ambientais, v. I0, n. 5, p. 169-186, 2019. http://doi.org//0.6008/CBPC2179-6858.2019.005.0016

XAVIER, L. H.; LINS, F.A. F.; NASCIMENTO, H. F. F.; OTTONI, M. S. O.; SUEMITSU,W. I.; CALDAS, M. B.; SILVA, L. O. S.;ARAUJO, R.A.; SANTOS, R. M.; MANÇANO, M. R.; CARDOSO, E. R.; REINOL, P. C.; GUSMÃO,A. C. F. Manual para a destinação de resíduos eletroeletrônicos no estado Rio de Janeiro - Orientação ao cidadão sobre como dispor adequadamente os resíduos eletroeletrônicos. $2^{\mathrm{a}}$ Edição. Rio de Janeiro: Cetem, 2018.

YOUNES, M. K. et al. Landfill area estimation based on integrated waste disposal options and solid waste forecasting using modified ANFIS model. Waste Management, v. 55, p. 3-I I, 20 I6. https:// doi.org/10.1016/j.wasman.2015.10.020

ZAVARIZ, C. Documento de recomendações a serem implementadas pelos órgãos competentes em todo território nacional relativas as lâmpadas com mercúrio, $20 \mathrm{I}$ I. 


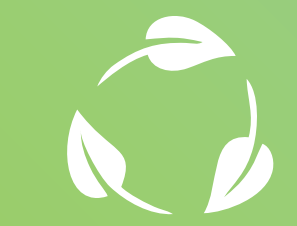

UEPAMBIIENTAL
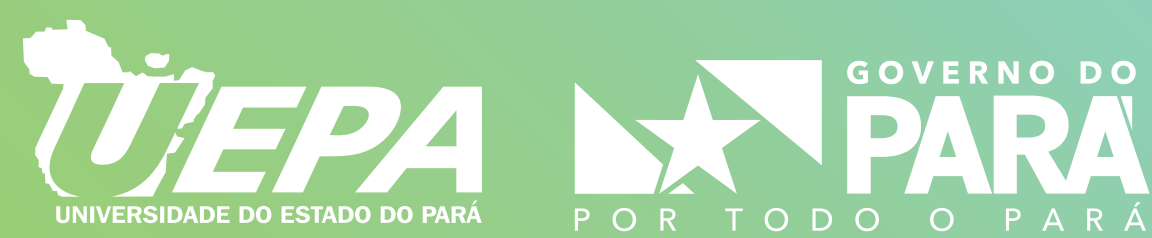
f UepaOficial
You ascomuepa
(0) ascom.uepa
(e)@uepa_pa
(๑) biuepa
(여) @uepaoficial

UNIVERSIDADE DO ESTADO DO PARÁ

Reitoria - Rua do Una, 156

Telégrafo - Belém - PA

Tel: (91) 3299-2200 | Site: www.uepa.br 